Portland State University

PDXScholar

\title{
The Role of Culturally Responsive Pedagogy in the Preparation of Secondary Teacher Candidates for Successful Teaching of Diverse Learners: a Multiphase Mixed Methods Case Study
}

Rosalyn Taylor

Portland State University

Follow this and additional works at: https://pdxscholar.library.pdx.edu/open_access_etds

Part of the Curriculum and Instruction Commons, Educational Leadership Commons, and the Secondary Education Commons

Let us know how access to this document benefits you.

\section{Recommended Citation}

Taylor, Rosalyn, "The Role of Culturally Responsive Pedagogy in the Preparation of Secondary Teacher Candidates for Successful Teaching of Diverse Learners: a Multiphase Mixed Methods Case Study" (2018). Dissertations and Theses. Paper 4255.

https://doi.org/10.15760/etd.6139

This Dissertation is brought to you for free and open access. It has been accepted for inclusion in Dissertations and Theses by an authorized administrator of PDXScholar. Please contact us if we can make this document more accessible: pdxscholar@pdx.edu. 
The Role of Culturally Responsive Pedagogy in the Preparation of Secondary Teacher Candidates for Successful Teaching of Diverse Learners:

A Multiphase Mixed Methods Case Study

by

Rosalyn Taylor

A dissertation submitted in partial fulfillment of the requirements for the degree of

Doctor of Education

in

Educational Leadership: Curriculum and Instruction

Dissertation Committee:

Esperanza De Vega, Chair

Samuel Henry

Anita Bright

Yves Labissiere

Portland State University

2018 
C 2018 Rosalyn Taylor 


\begin{abstract}
The dramatic demographic shift occurring in this country makes it essential that our nation examines its policies, practices, and values as they relate to culturally diverse learners (Taylor \& Cohn, 2012; National Center for Educational Statistics, 2012). That this student population remains underserved needs immediate attention (Marbley, Bonner, McKisk, Henfield \& Watts, 2007; NCLB, 2002). One arena that can become a part of the solution to the underachievement of diverse learners is teacher education and preparation programming.

The purpose of this research study was to give attention to this issue and to understand what an urban teacher education program (UTEP) with an educational equity and social justice mission does to prepare its secondary teacher candidates (STCs) to work successfully with diverse learners. An additional purpose was to determine what role culturally responsive pedagogy (CRP) played in STCs' perceptions of their readiness to work with our nation's ever-growing culturally diverse school-age learners.

Using a multi-phase mixed methods case study research design, I collected data from secondary teacher educators using interviews and artifacts as well as from secondary teacher candidates' pre-and-post Likert scale and open-ended responses to the Learning to Teach for Social Justice-Beliefs scale. This survey was adapted from the work of Ludlow, Enterline, and Cochran-Smith (2008).

I coded and analyzed the data to shed light on the following research questions: 1. What does an urban teacher education program do to operationalize it educational equity and social justice missions?
\end{abstract}


2. How do secondary teacher candidates' perceptions of their readiness to work with culturally diverse learners change from the beginning of their teacher education program to the end?

3. To what extent if any, is culturally responsive pedagogy associated with secondary candidates' perceptions of readiness?

The findings indicate that several factors influence teacher candidates' perceptions; reflection, critical consciousness of the educational landscape and a willingness to embrace diversity as it presents itself in the classroom were common among participants. 


\section{Dedication}

To my Mother who encouraged me to follow my dreams

To my Sister, Angela, who instilled in me of the importance of loving relationships To my Life Partner, Susan, whose generous spirit, laughter and love sustained me and

To teachers everywhere 


\section{Acknowledgements}

I have been surrounded by wonderful people who have supported me over the course of this project. Dr. Jacqueline Temple served as my advisor and shepherded me through my Core Paper before her retirement. Dr. De La Cruz worked closely with me, meeting with me regularly, offering feedback and supporting me until her passing.

My committee members Dr. De La Vega, Dr. Samuel Henry, Dr. Anita Bright, and Dr. Yves Labissiere believed in the value of this work and embraced it and me, making its completion possible.

My TRIO SSS and PSU colleagues kept me on my game by inquiring regularly on the status of my work. My director, Linda Liu, gave me the enormous gift of time which allowed me to write - the main ingredient needed to complete such an undertaking.

My writing group, consisting of Cindy Stadel and Elizabeth Dubois, was a wonderful oasis of support, laughter and friendship. Their contributions are reflected in this work. Marjorie McGee tutored me on SPSS and answered all my questions when I was lost and confused. fun.

My friends Kristen, Marcia, Beth, Ruth, Kimie and Annette kept me sane and life And finally to my family, my sisters Jean and Brenda and my brothers Albert and Anthony who were my first teachers. You taught me to work hard, stay focused, and to believe that I can achieve my goals.

My love and gratitude to you all. 
Table of Contents

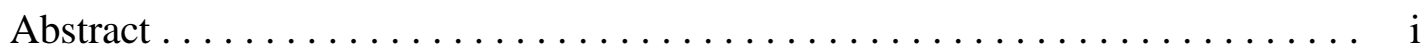

Dedication ........................................ ii

Acknowledgements $\ldots \ldots \ldots \ldots \ldots \ldots \ldots \ldots \ldots \ldots \ldots \ldots \ldots \ldots \ldots \ldots \ldots \ldots \ldots$, iv

List of Tables $\ldots \ldots \ldots \ldots \ldots \ldots \ldots \ldots \ldots \ldots \ldots \ldots \ldots \ldots \ldots \ldots \ldots \ldots \ldots$, vii

List of Figures $\ldots \ldots \ldots \ldots \ldots \ldots \ldots \ldots \ldots \ldots \ldots \ldots \ldots \ldots \ldots \ldots \ldots \ldots \ldots \ldots$, viii

Chapter 1-Introduction ............................. 1

Statement of the Research Problem ........................... 5

Purpose of the Research Study. .......................... 7

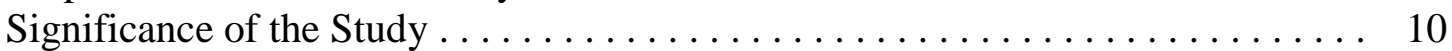

Research Methodology and Research Questions .................. 12

Definition of Terms .................................. 14

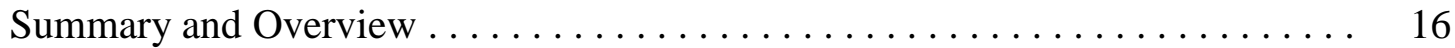

Chapter 2-Literature Review ................................. 19

$\begin{array}{ll}\text { Introduction } & 19\end{array}$

Significance of the Achievement Gap in the Context of this Research Study . . . 21

Introduction of the Culturally Responsive Theoretical Framework .......... 30

Interplay of Critical Race Theory Tenets and Culturally Responsive Pedagogy . . 46

Relevant Themes .................................. 48

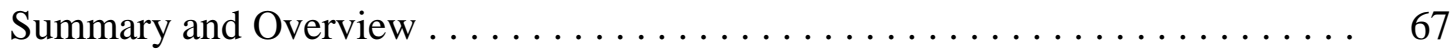

Chapter 3-Research Methodology $\ldots \ldots \ldots \ldots \ldots \ldots \ldots \ldots \ldots \ldots \ldots, 68$

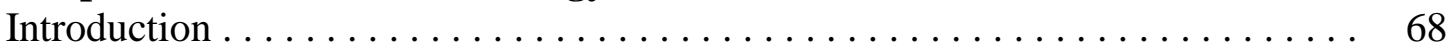

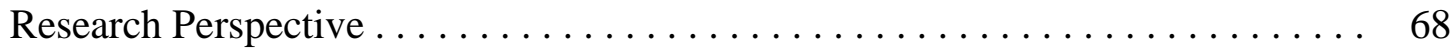

Research Questions .................................. 71

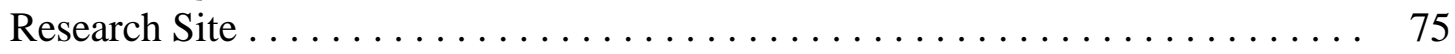

Sampling and Recruitment Procedures $\ldots \ldots \ldots \ldots \ldots \ldots \ldots \ldots \ldots \ldots \ldots \ldots$

Research Participants ............................... 78

Informed Consent, Privacy, and Data Storage $\ldots \ldots \ldots \ldots \ldots \ldots \ldots \ldots \ldots . \quad 80$

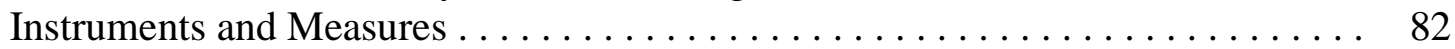

Data Collection Procedures . . . . . . . . . . . . . . . . . . . . . . 90

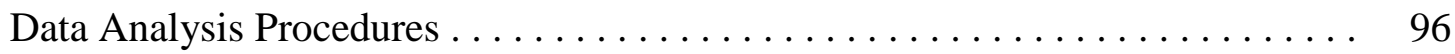

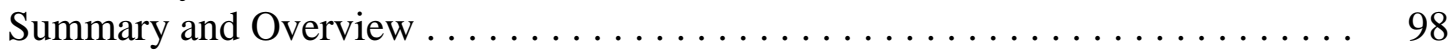

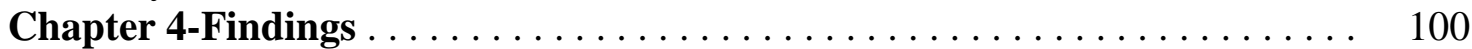

Introduction ......................................... 100

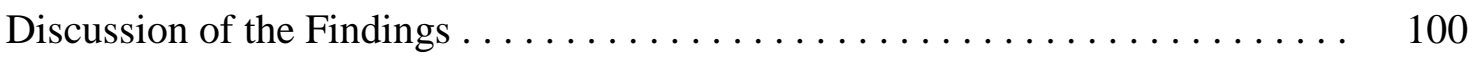

Research Question One ............................... 101

Research Question Two ................................. 115

Research Question Three................................. 125

Final Comments .................................... 162

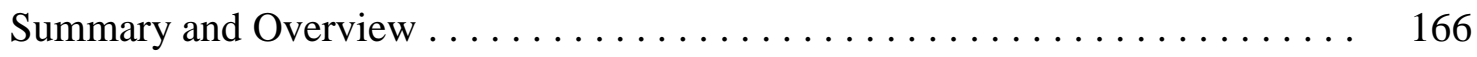

Chapter 5-Discussion ................................. 168

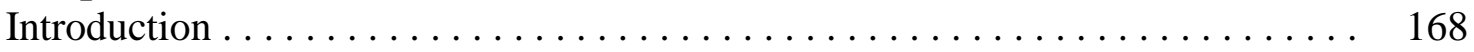

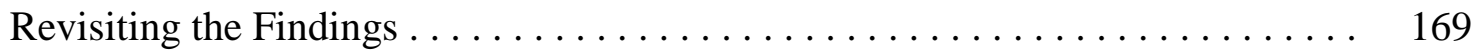


Research Question One . . . . . . . . . . . . . . . . . . . . . . . . 170

Research Question Two . . . . . . . . . . . . . . . . . . . . . . . 175

Research Question Three . . . . . . . . . . . . . . . . . . . . . . . 175

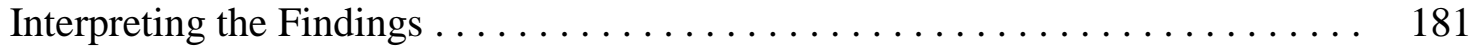

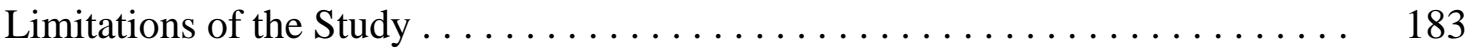

Implications for Future Research . . . . . . . . . . . . . . . . . . 183

Conclusion . . . . . . . . . . . . . . . . . . . . . . . . . . . . . . . . . 184

References . . . . . . . . . . . . . . . . . . . . . . . . . . . . . . 192

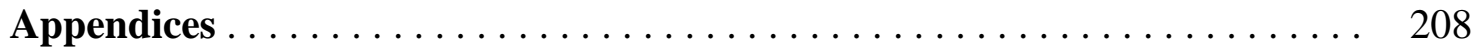

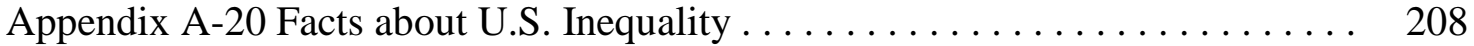

Appendix B-2015 Oregon Census Data . . . . . . . . . . . . . . . . . . . 210

Appendix C-Learning to Teach for Social Justice-Beliefs Scales and Secondary

Teacher Candidates' Final Comments . . . . . . . . . . . . . . 213

Appendix D-Letter to Portland Metro-Area Deans of Education . . . . . . . . . . . 220

Appendix E-Email to Recruit Secondary Teacher Educators . . . . . . . . . . . . . . 222

Appendix F-Script for Classroom Visits . . . . . . . . . . . . . . . . . . 223

Appendix G-Informed Consent Forms for Secondary Teacher Candidates and

Secondary Teacher Educators . . . . . . . . . . . . . . . . . . . . 224

Appendix H-Demographic Information from Secondary Teacher Educators . . . . . 228

Appendix I-Demographic Information from Secondary Teacher Candidates

Collected Electronically . . . . . . . . . . . . . . . . . . . . . 229

Appendix J-Semi-structured Questions for Interview $1 \ldots \ldots \ldots \ldots \ldots \ldots \ldots$

Appendix K-Semi-structured Questions for Interview $2 \ldots \ldots \ldots \ldots \ldots \ldots \ldots$

Appendix L-Thank you Note to Participants . . . . . . . . . . . . . . . . . . . . 232 
List of Tables

Table 3.1-Sample Descriptive of Secondary Teacher Candidates . . . . . . . . . 80

Table 3.2-Sources of Data . . . . . . . . . . . . . . . . . . . . . . 89

Table 3.3-Timeline for Research Study Activities . . . . . . . . . . . . . . . . . 91

Table 3.4-Units of Analysis . . . . . . . . . . . . . . . . . . . . . . 95

Table 4.1-Research Questions and their Data Sources. . . . . . . . . . . . . . . 101

Table 4.2-Sample Statistics . . . . . . . . . . . . . . . . . . . . . 120

Table 4.3-Belief 1 Paired Samples Statistics . . . . . . . . . . . . . . . . . . . . 141

Table 4.4-Belief 1 Paired Samples Statistics . . . . . . . . . . . . . . . . . . . . 142

Table 4.5-Belief 2 Paired Samples Statistics . . . . . . . . . . . . . . . . . . . 145

Table 4.6-Belief 3 Paired Samples Statistics . . . . . . . . . . . . . . . . . . 151

Table 4.7-Belief 4 Paired Samples Statistics . . . . . . . . . . . . . . . . . 154

Table 4.8-Belief 10 Paired Samples Statistics . . . . . . . . . . . . . . . . . 158

Table 5.1-Research Questions and a Summary of Findings . . . . . . . . . . . . 170

Table 5.2-Belief 1 Paired Samples Statistics . . . . . . . . . . . . . . . . . 175

Table 5.3-Belief 1 Paired Samples Statistics . . . . . . . . . . . . . . . . . . 177

Table 5.4-Belief 2 Paired Samples Statistics . . . . . . . . . . . . . . . . 178

Table 5.5-Belief 3 Paired Samples Statistics . . . . . . . . . . . . . . . . . . . 178

Table 5.6-Belief 4 Paired Samples Statistics . . . . . . . . . . . . . . . . . . . . . . 179

Table 5.7-Belief 10 Paired Samples Statistics . . . . . . . . . . . . . . . 180 


\section{List of Figures}

Figure 2.1-Gay's Conception of Culturally Responsive Pedagogy . . . . . . . . . . . 34 Figure 2.2-Interplay of Culturally Responsive Pedagogy and Critical Race Theory. ................................ 50

Figure 3.1 -Study's Research Design. . . . . . . . . . . . . . . . . . . . . . 69 Figure 3.2 Interplay of Culturally Responsive Pedagogy and Critical Race Theory. . . . . . . . . . . . . . . . . . . . . . 


\section{Chapter 1-Introduction}

Education in America for our nation's diverse learners continues to be a controversial issue. From denied the right to an education to winning Supreme Court decisions (Brown vs. Board of Education, 1954; Lau vs. Nichols, 1974), the experiences of our nation's culturally diverse learners in our public education system are

confounding. Creating legislation (such as Americans with Disabilities Act of 1990 and Individuals with Disabilities Education Act of 1975) that attempts to rectify past practices has also had mixed results. Though legislation is a tool for improving the lives of our nation's citizens, it often has unintended consequences (Marshall \& Gerstl-Pepin, 2005). Subsequently, it is not surprising that their educational experiences and histories have reflected these mixed results.

The intent of judicial and legislative action is as important as the consequences. When the Supreme Court determined in Brown v Board of Education (1954) that "separate but equal" was inherently unequal, its decision paved the way for African American children to have equal access and opportunity to receive a free and appropriate public education. Similarly, in Lau v Nichols (1974), the court decided that students who speak a language other than English had the right to receive instruction to support their acquisition of English. Legislative efforts like the Americans with Disabilities Act (1990) and the Individuals with Disabilities Education Act (1975) intended to rectify past practices that limited the full participation of student populations with disabilities and access to a free and appropriate public education. These legislative and judicial efforts were potential turning points; however, in many statistical measures of achievement (see 
Appendix A), culturally diverse learners continue to lag behind their able-bodied, middleclass peers of European descent (from this point forward, "White" refers to people of European descent). For diverse student populations, inequity and exclusion remain their experience when we assess current-day achievement levels for diverse student populations (Delpit, 2006, 2012; Howard, 2010; Villegas \& Lucas, 2002a, 2002b; Rothstein, 2004).

Since the publication of $A$ Nation at Risk (1983), administrators, civil rights advocates, educators, parents, policymakers, researchers and other concerned citizens have focused much attention on the achievement gap. A plethora of reasons attempt to explain diverse learners' continued underperformance. However, whatever the cause, it is safe to say that the reasons are complex.

Freeman (2006) contends that people of African descent have encountered numerous barriers to education in America. Lewis (2003) contends: "Schools are arguably one of the central institutions involved in the drawing and redrawing of racial lines" (p. 4). And Lewis goes on to state:

Race is about who we are, what we do, and how we interact. It shapes where we live, with whom we interact, how we understand ourselves and others. But it does so in specific ways based on our social and historical location. (p. 7)

These experiences of exclusion, discrimination, and racism affect every aspect of one's life. This is evident in the educational access and opportunities that diverse learners receive and do not receive.

In the early history of this country, indentured servants in the U.S. had greater access to education because of the perceived need by their masters to attend to the moral 
values of its workforce (Ladson-Billings, 2005); however, the same was not true for diverse learners, particularly students of African-American descent (Cross, 1998; Douglass, 2007; DuBois, 1994; Equiano, 1999; Ladson-Billings, 1994). For these learners, their experiences over time, dating back from the first White settlers to contemporary times, reflect a systematic denial of access to the necessities of life: quality education, gainful employment, inclusion into mainstream American society and safety (Alexander, 2010; Cross, 1998; DuBois, 1994; Howard, 2010; Marable, 2000, 2002; Myrdal, 1944; Tyack, 2004). Those who did become literate did so at great human risk (Coates, 2017; Cross, 1998; Douglass, 2007; Marable 2009).

Race and education in this country have been inextricably linked (Cross, 1998; DuBois, 1994; Howard, 2010; Ladson-Billings, 2006; Marable, 2000, 2002). Scholars have documented exclusionary practices and denial of human rights throughout the history of this country. From these and other scholars' work, it is clear that "race matters" in this country and can be an important determinant of the trajectory of a person of color's social mobility (Cross, 1998; Delpit, 2006; Marable, 2000; West, 1993; Wise, 2007, 2013). Autobiographical and historical accounts of oppression and marginalization of diverse people and the conditions under which they lived are plentiful (Douglass, 2007; DuBois, 1994; Equiano, 1999; Takaki, 1993; Wise, 2007, 2013; Zinn, 2003). As a social construct, race in the U.S. influences access to mainstream institutions and services; it affects opportunities in mainstream society; and it influences one's ability to maneuver within society economically, politically and socially (Alexander, 2010; Kozol, 
2005; Marable, 2002, 2000; Takaki, 1993; Tatum, 2000; West, 1994; Wise, 2007, 2013; Zinn, 2003).

As Tatum (2000) states, the powerful have always "set the parameters within which the subordinates operate" (p.11). In setting parameters, Tatum asserts the powerful determine which group is valued and which is not because of the perception of the “"subordinate group' being incapable of performing at the level the 'dominant group' perceives acceptable" (p.12). American history is replete with examples of the systematic exclusion of diverse people. Years of systematic denial of adequate housing, education and employment opportunities for culturally diverse people have served to reinforce the privilege of the dominant group (Bell, 1973; Bowles \& Gintis, 1976; Marable, 2002; Wise, 2013).

American schools are a microcosm of our society, reflecting the inequities of access and opportunity (Delpit, 2006; McDiarmid \& Clevenger-Bright, 2008; QuintanarSarellana, 1997; Reiter \& Davis, 2011). Delpit (2006) writes pointedly of the relationship between schooling and power (p. 25). The school experience that diverse learners encounter determines their life chances in terms of their readiness for post-secondary education or employment opportunities. That not all students have access to the resources and services they need speaks to the power of a few to determine the plight of many. Given the complex interaction between racism and power, it is unlikely that the achievement gap will improve if the dominant group fails to acknowledge its role in perpetuating the attitudes, practices, and the economic, social and political conditions that foster inequality (Alexander, 2010; Bell, 2010; Delpit, 2006; Howard, 2010; Ladson- 
Billings, 2006b; Marable, 2002, 2000; Tatum, 2000; Wise, 2013). As the school-age children of our nation become more and more diverse, educators and our government must ensure their future (Ladson-Billings, 2006a, 2006b). Our governing principles require that we afford them every opportunity to assume their roles as educated adults and global citizens (Wise, 2013).

Research on improving educational outcomes for diverse learners draws attention to the teacher as having an indispensable role in student learning (Cochran-Smith, 2002, 2009; Correa, 1991; Darling-Hammond, 2010a; Delpit, 2006, 2012; Futrell, 1999; Howard, 2010; Ladson-Billings, 1994; Ravitch, 2010). The No Child Left Behind Act (NCLB) of 2001 clearly articulated that every classroom must have a highly qualified teacher. One cannot deny the varying educational experiences in this country for diverse learners (Bell, 2010; Kozol, 1991, 2005; Howard, 2010; Marable, 2000, 2002; Tatum, 2000; Wise, 2013). Just as school districts have tried to comply, teacher education programs across the nation have endeavored to prepare teachers to meet this designation as prescribed by $N C L B$. However, how we handle this problem is well within the power of teacher preparation programs to solve (Cochran-Smith, 2002; Gay, 2010b; Howard, 2010; Milner, 2009).

\section{Statement of the Research Problem}

$N C L B$ (2001) placed emphasis on the teacher and mandated that every classroom must have a qualified teacher, defined as one who must: 1) "[hold] a bachelor's degree; 2) [have] full state certification or licensure; and 3) prove that they know each subject they teach" (U.S. Department of Education, 2002). Darling-Hammond (2010a) asserts that 
diverse learners are more likely to have a teacher who is uncertified than their White, middle-class peers. Moreover, Darling-Hammond states: "In the United States, teachers are the most inequitably distributed resource" (p. 40). This scenario establishes an inequitable system that contributes significantly to the growing achievement gap that exists among our nation's diverse learners and their White peers.

The National Council for Accreditation of Teacher Education (NCATE) and the Council for Accreditation of Educators Programs (CAEP) attest to the fact that teachers play a critically important role in the education of our children. As the accrediting agencies for public teacher education programs (TEPs), they have as one of their standards the preparation of teachers who have the capacity to work successfully with diverse learners. Given this fact, the continued underperformance of diverse learners is inexplicable and unacceptable and raises questions about our nation's teacher preparation programs.

Many scholars draw attention to the fact that as our school-aged population grows more and more diverse, our teaching corps lacks the diversity of our classrooms and our nation (Ball \& Tyson, 2013; Bell, 2010; Correa, 1991; Gay, 2002, 2010a; LadsonBillings, 2006b; Latham, Gitomer \& Ziomek, 1999; Villegas, \& Lucas 2002a, 2002b; Milner, 2009; Nieto, 2000, 2003; Sleeter, 2001). Given the demographic shift in our school-age population and the static nature of the population of teaching professionals, a research study that explores how teacher education programs prepare teachers to work successfully with diverse learners is necessary. A body of research states that all learners - not just diverse learners — do better in school when their teachers engage in 
culturally responsive pedagogical practices (Delpit, 2006, 2012; Gay, 2010a; Griner \& Stewart, 2012; Howard, 2010; Ladson-Billings, 1994, 1995a; Nieto, 2003). Thus, it makes sense for urban teacher education programs (UTEPs) to adopt a culturally responsive pedagogical lens by which to prepare teacher candidates so that improved educational outcomes for our diverse learners is a viable possibility.

Finally, a research study that investigates the preparation of secondary teacher candidates for entry into diverse classrooms is equally important. Research shows that the achievement gap widens as diverse learners continue throughout their K-12 educational experience. Barton (2003) states that diverse learners and poor learners "will, on average, be behind White children in their cognitive development" (p. 36). Barton continues by stating that these gaps "have deep roots-deep in out of school experiences and deep in the structures of school" (p. 36). Pointing out some of the variables that contribute to these gaps, Barton's work identifies teacher preparation as being one area that "make[s] a difference in student achievement" (p. 10). Thus, how teacher candidates are prepared has much to do with their readiness to improve student achievement. This has particular relevance as it relates to teacher education programs and their curricula and pedagogical stances. Therefore, a research study that explores the preparation of secondary teacher candidates to work successfully with culturally diverse learners could add knowledge to this growing body of investigation.

\section{Purpose of the Research Study}

Darling-Hammond (2010a) claims that how America educates its most vulnerable populations "will determine our future". In The Flat World and Education: How 
America's Commitment to Equity Will Determine our Future, Darling-Hammond examines the teachers, resources and other components of education to make a case for needed changes to improve educational outcomes for our diverse learners. The purpose of this research study is:

1. to learn how an urban teacher education program (UTEP) operationalizes its educational equity and social justice missions;

2. to understand how secondary teacher candidates' perceptions of their readiness to work successfully with diverse learners change over time from the beginning of their teacher education program to its conclusion; and

3. to determine to what extent, if any, culturally responsive pedagogy (CRP) influences secondary teacher candidates' perception of their readiness to work with diverse learners.

For nearly thirty years, much information has become available about the kind and quality of education that diverse learners receive in this country as measured on standardized tests of achievement. From a Nation at Risk (1983) to the most recent reauthorization of the Elementary and Secondary Education Act, known as No Child Left Behind, to the Every Student Succeeds Act, reforms of curriculum, instruction, teacher qualifications, and testing have changed the landscape of teaching and learning in our public schools. While the achievement gap has received much attention, little improvement in either standardized test scores or the school experience has materialized. With budget cuts quickly becoming the rule rather than the exception, class size increases are commonplace; moreover, teachers are teaching out of their grade level areas because 
of layoffs, and fewer resources for curriculum and experiential learning opportunities have become normal practice (Anonymous, April 2013).

Howard (2010) includes 2008 statistical data for the Scholastic Aptitude Test (SAT) which indicate that Blacks and Latinos continue to underperform when compared with their White peers in the areas of critical reading, math, and writing (p. 27). Recent National Assessment of Educational Progress (2011) data denote a similar trend. According to Taylor and Cohn (2012), by the year 2050, our country will be a "majority minority nation" (para. 1). With continued underachievement and a growing schism between the racial makeup of students and teachers, it is essential that further research is conducted to determine how a UTEP prepares new teachers for the demographic realities that exist in the American classroom. Delpit (2006), Futrell (2010), Gay (2002), Howard (2010), and Ladson-Billings (1994) speak powerfully in their work of the need to have culturally responsive and culturally competent teachers in our nation's classrooms and of the impact they have on improving educational outcomes for our most vulnerable schoolage population - the culturally, ethnically, linguistically, mentally, physically, racially, religiously, sexually oriented and socio-economically different.

Given the gravity of our nation's educational challenge, more research is necessary to determine how to best prepare teachers to work successfully with learners with whom they have very little in common (Liston \& Zeichner, 1996; Nieto, 2003). At the center of students' learning stands the teacher. Her or his knowledge of content, pedagogy, student cultures, languages, lives and experiences and their concern about making their teaching relevant to their students make her or him more effective in helping 
students learn (Achinstein \& Anthanases, 2005; Darling-Hammond, 1997; Freirè, 2000; Gay, 2002, 2010a, 2010b; Ladson-Billings, 1994; Noguera \& Wing, 2006; Villegas \& Lucas, 2002b).

My hope is this study will add to our understanding of how one UTEP's practices impact educational outcomes (e.g., achievement scores, persistence and graduation rates, college and employment readiness) for culturally diverse learners. By investigating a UTEP, this study explores the attitudes, practices and pedagogical knowledge and skills teacher educators espouse to prepare their secondary teacher candidates to meet NCATE/CAEP standards for teachers to work successfully with diverse learners (www.ncate.org).

To realize this goal of how a UTEP operationalizes its educational equity and social justice mission, the researcher gathered information from secondary teacher educators and teacher candidates to understand what pedagogical knowledge, skills and practices the UTEP espouses and how these might inform and shape the kind of preparation current and future teacher candidates could receive. This study also attempts to gain insights into how secondary teacher candidates' readiness changed over the course of their teacher education program. In addition, the study explores the relationship between the teacher candidates' readiness and the use of culturally responsive pedagogy within the UTEP to meet its educational equity and social justice mission.

\section{Significance of the Research Study}

Our nation can ill-afford the underdevelopment of human potential (Marable, 2000, 2002; Wise, 2013). Economically, politically, and socially it is untenable and 
unsustainable. Statistics show that students who underachieve are more likely to drop out of school, have fewer life opportunities, be incarcerated, and experience greater health problems (Alexander, 2010; Barton, 2003; McKinsey \& Company Report, 2009; McKown \& Weinstein, 2008; Wise, 2013). That this is the reality of many diverse learners begs the question: Why do our diverse learners continue to lag behind their middle-class White peers? Cochran-Smith (2002) asserts that teacher education has much to do with diverse learners' educational outcomes.

This research study examines the beliefs and practices of secondary teacher educators and teacher candidates. Teacher candidates' attitudes, curriculum decisions, knowledge, and instructional practices directly affect diverse learners' educational experiences in their future classrooms. Since a growing number of our school-aged population is diverse, the focus on teacher education programming and the teachers they prepare is germane and significant as an entry point to understanding and making sense of an extremely complex issue.

Thus, the ultimate goal of this study is to explore how we might better educate and prepare secondary teacher candidates for their roles in creating a more socially just and equitable society. The classroom is the platform upon which the intersection of teaching and learning occurs. For secondary teacher educators and secondary teacher candidates involved in this process, it becomes clear that each has important information to impart that could greatly affect the nature of teaching and learning now and into the future. Their voices in this study are our most promising hope for a future that offers 
improvements in teaching and learning outcomes for all learners and in particular, our nation's diverse learners.

\section{Research Methodology and Research Questions}

Given that research has made a strong case for the efficacy of culturally responsive pedagogy (Delpit, 2006, 2012; Gay, 2010a; Griner \& Stewart, 2012; Howard, 2010; Ladson-Billings, 1994; Villegas \& Lucas, 2002a), why have teacher education programs not adopted it as a lens by which to prepare teacher candidates to work successfully with diverse learners? In attempting to have this research play a significant role in understanding how to improve educational outcomes for our diverse school-aged learners, this multiphase mixed methods case study aims to answer the following questions:

1. How does a UTEP operationalize its educational equity and social justice missions in its efforts to prepare secondary candidates?

2. Upon completing their teacher preparation program, how do secondary teacher candidates' perceptions of their readiness to work successfully with diverse learners change over time, from the beginning to the conclusion of their teacher education program?

RQ2 Hypothesis: Upon completion of their teacher preparation program, secondary teacher candidates will perceive themselves as more prepared to work successfully with diverse learners.

3. To what extent if any, is culturally responsive pedagogy (CRP) associated with secondary teacher candidate perceptions of readiness? 
RQ3 Hypothesis: The researcher expects that high levels of perceived readiness are associated with high levels of culturally responsive pedagogical practices. In order to answer these questions, this research study examines the practices used to prepare secondary teacher candidates to work effectively with diverse learners which I posit could improve their educational outcomes.

The inquiry considers how stakeholder attitudes, beliefs, pedagogical content knowledge, experiences and teaching strategies and reflections on instruction shape the conversation and adds diverse voices to the discussion. I study these concepts through artifacts, interviews, and open and closed ended survey responses to the Learning to Teach for Social Justice-Beliefs scale (see Appendix C) devised by Ludlow, Enterline and Cochran-Smith (2008).

While there is no definitive perspective on what teacher candidates need to become effective educators (Cruishank, 1986, n. p.), teacher education programs (TEPs) needs to consider pedagogical stances that bring them closer to educational equity and social justice. It is for this reason that I chose to conduct this research study-to answer the call for ways to bring schooling closer to realizing greater educational equity and social justice for our nation's growing population of diverse learners.

Research findings on culturally responsive pedagogy have purported that where it has been used, improved educational outcomes for diverse students has resulted (Delpit, 2006, 2012; Gay, 2010a; Griner \& Stewart, 2012; Howard, 2010; Ladson-Billings, 1994, 1999; Villegas \& Lucas, 2002b). Research that explores how culturally responsive pedagogy works and how it is incorporated into urban teacher education program (UTEP) 
practices can potentially contribute much to understanding how to better prepare current and future teachers for the realities of the $21^{\text {st }}$ century American classroom. Gaining knowledge from stakeholder participants is essential in order to provide a coherent picture of what their experiences are (Maxwell, 2005); bringing the complex voices of all those involved in the educative process of secondary teachers offers an opportunity to examine the intersections between knowledge, understanding, application and practice. My hope is that this research study provides information that teacher education programs can use to more intentionally and culturally responsively prepare secondary teacher candidates for the realities of the contemporary U.S. classroom.

\section{Definition of Terms}

For the purpose of this paper, I define the following key terms as follows:

Achievement gap refers to the disparities that exist between low-income students of color and their middle-class peers of European descent on standardized measures of achievement, particularly in math and reading (advocacy.collegboard.org; Howard, 2010).

Cultural competence refers to "a commitment and engagement in activities that encourage and build capacity for the use of practices and strategies that address diverse learners' needs successfully”' (Tervalon \& Murray-Garcia, 1998, p. 117).

Culturally responsive pedagogy refers to curriculum inclusion and instructional practices that value diverse students' cultural, ethnic, linguistic and socio-economic backgrounds and use these to promote academic achievement (Gay, 2002). 
Diverse learner(s) is used to signify student(s) who have a history of marginalization and oppression in this country due in large part to their [ability (both learning and physical)], ethnicity, socioeconomic class, linguistic background, racial identity, [and in their gender expression] (Gay, 2002).

Educational equity refers to "the principles of fairness and justice in allocating resources, opportunities, treatment, and success for every student. Educational equity programs promote the real possibility of equality of educational results for each student and between diverse groups of students. Equity strategies are planned, systemic, and focused on the core of the teaching and learning process" (www.educationnorthwest.org).

Highly qualified teacher is one who, according to the No Child Left Behind Act of 2001, holds a bachelor's degree and is certified in the content area in which they teach.

No Child Left Behind (NCLB) Act of 2001 is the education legislation passed under the Bush Administration in 2001 with the objective to close the achievement gap between low-income students of color and their White, affluent peers on standardized measures of achievement in math and reading by the year 2014 (U.S Department of Education, 2002). Readiness relates to one's capacity to be fully prepared to act. (American Heritage Dictionary of the English Language, 1978, p. 1085). In the context of this study, it refers to a teacher's ability to display positive beliefs and attitudes towards diverse learners, possess pedagogical content and cultural knowledge as well as exhibit an understanding of the processes involved in learning and their ability to use these skills successfully with an array of learners. 
Social justice is an educational philosophy that attempts to "challenge oppressive systems" so that "full and equal participation of all groups in a society" is realized (Teaching for social justice: A source book, 1997, p. 3).

Teacher education program is an educational entity situated within an institution of higher education whose purpose is the successful education and preparation of teacher candidates to enter local educational agencies.

Urban teacher education program is an educational entity situated within an institution of higher education located in an urban metropolitan area whose purpose is the successful education and preparation of teacher candidates to enter diverse local educational agencies.

\section{Summary and Overview}

Education in America continues to be a discriminatory practice (Delpit, 2006; hooks, 1994; Howard, 2010; Tatum, 2000; Wise, 2013). Nowhere is this more pervasive than in America's classrooms where curriculum is laden with White middle-class values (Green, 2009; hooks, 1994; Howard, 2010). Even today, teaching continues to be a predominantly White, middle-class, monolingual, female profession (Achinstein \& Anthanases, 2005; Ball \& Tyson, 2013; Bell, 2010; Cochran-Smith, 2002; Correa, 1991; Gay, 2002; Latham et al., 1999; Liston \& Zeichner, 1996; Milner, 2009; Nieto, 2003; Sleeter, 2001, 2008, 2013; Taylor et al., 2001). What this means to and for diverse students is a historical legacy of being viewed as a national problem (Delpit, 2012; DuBois, 1994; Ladson-Billings, 1994), when in fact, the system has failed to meet its legislative and moral commitments (Ladson-Billings, 2006b). 
Given the fact that the focus on improving test scores and other educational outcomes for historically underperforming learners rests squarely in the hands of teachers and teacher educators (Gale, Mills \& Cross, 2017; Lopes-Murphy, 2012), how is it that we have been so unsuccessful in educating our diverse learners?

Landsman and Lewis (2006) state:

Some believe it is White people's unwillingness to talk about racism, much less work on changing the methods and curriculum. Others say it is already being addressed - we just have to give it more time. Still others refuse to admit that there is a problem at all, unless it resides solely in the Black or Latino or Native community. (p. 1)

Regardless of the rationale for diverse learners' underachievement, all involved in the education of secondary teachers must inculcate in them the skills and knowledge of the various intersections between what secondary teacher candidates believe, know, and are able to do. These capacities directly influence what happens in the classroom as well as outside the classroom (Duncan, 2011; Taylor, 2010). Research shows that when teacher candidates lack a strong teacher education program, they fall back on their own experiences of learning and of how to teach their curriculum to "other people's children" (Achinstein \& Anthanases, 2005; Delpit, 2006; Villegas \& Lucas, 2002b).

What follows is a review of relevant literature appropriate for inclusion in this research study. The chapter provides an historical context on the concerns impacting the educational outcomes for culturally diverse learners and continues with an introduction and discussion of the theoretical frameworks. Included in this discussion are the relevant themes that exert influence on this research study. Central to the discussion are the 
students and teachers and how teacher education programs prepare teacher candidates to work with the diversity of students who inhabit public classrooms around the country. 


\section{Chapter 2-Literature Review}

\section{Introduction}

For the purpose of this research inquiry, race and class are central issues addressed as they relate to teacher education and preparation. Thus, this study is influenced by the theoretical framework of culturally responsive pedagogy (CRP) which emerges out of the tenets of critical race theory (CRT). The tenets of CRT make a case for the use of CRP in teacher preparation by highlighting educational equity and social justice as potential outcomes.

The literature review that follows first explores the broad educational reality of diverse learners in secondary schools today; it also examines the achievement gap, and finally it provides suggestions for how urban teacher education programs can meet the challenge for improving educational outcomes of our nation's diverse learners.

Scholars acknowledge the teacher as playing an invaluable role in student learning (Cochran-Smith, 2002; Darling-Hammond, 1997, 2010a; Delpit, 2006; Gay, 2002; hooks, 1994; Howard, 2010; Ladson-Billings, 1994; Milner, 2009; Sleeter, 2013). So much significance was afforded the role of teacher that the education legislation known as No Child Left Behind (NCLB) (2001) mandated that every low-income student receive instruction from a "highly qualified teacher." Though what qualifies as being a "highly qualified teacher" varies from state to state, what continues to be true for our nation's diverse learners is a widening gap in achievement made clear by factors such as access to and opportunities to learn from truly "highly qualified teachers" (DarlingHammond, 2010a). 
In order for our nation to engage successfully in the question of equal access and opportunities for our culturally diverse K-12 learners, we need to understand our nation's history of discrimination and its link to educational outcomes. From the Native Americans who experienced assimilationist practices of boarding schools to indentured servants to the slaves to the immigrants who speak a language other than English to people with disabilities and to youth questioning their gender identity, education was supposed to be the great equalizer, but has failed at being so. Discriminatory practices influence the educational experience of many who are considered other and are othered.

This is an inevitable outcome when teacher accountability and test scores become the focus of attention and instruction focuses on how well our nation's school-aged children perform on state, national and international measures of academic achievement rather than on preparing teachers to create successful learning opportunities for all learners. Consequently, in some cases teaching and teacher education has become a practice of teacher socialization into the profession (Achinstein \& Anthanases, 2005; Brouwer \& Korthagen, 2005; Villegas \& Lucas, 2002b).

When one considers the importance past and recent education legislation has played on specific populations receiving a high-quality education, it is difficult to understand why our nation continues to wrestle with this issue. Legislation attempts to make inclusion a reality (e.g., Americans with Disabilities Act; Civil Rights Act of 1964; Individuals with Disabilities Education Act, 1975; the Oregon Equality Act, 2007) (www.lambdalegal.org), which protects the rights of lesbian, gay, bisexual and transgender people. However, practices (i.e., standardized testing, narrowed curriculum, 
and alternative pathway teachers) and realities at the classroom level (i.e., low teacher retention, budget cuts, and large class sizes) serve as barriers, while policies serve to maintain practices that fail to make educational equity and social justice a reality (Darling-Hammond, 2000, 2010a; Delpit, 2006, 2012; Johnson, 2007; Ladson-Billings, 2006a; Ladson-Billings \& Tate 1995; Milner, 2010; Sleeter, 2001, 2008, 2013).

If legislation fails at its intended purpose, then it is time for those who have a direct impact on what occurs in the classroom to reestablish themselves as change agents (Futrell, 1999, 2010; Gay, 2002; Hackman, 2005; Milner, 2006, 2010). Secondary teacher candidates and the teacher educators who educate and prepare them for this role must create the environment for intentional work on educational equity and social justice to begin (Cochran-Smith, 2002; Delpit, 2006, 2012; Gay, 1993; Howard, 2010; LadsonBillings, 2006a, 1999; Nieto, 2003; Sleeter, 2013).

\section{The Significance of the Achievement Gap in the Context of this Research Study}

The gap in standardized measures of achievement between our nation's diverse learners and their White middle-class peers is a topic which has received much research and discussion. Characterized as the achievement gap, legislation known as the No Child Left Behind (NCLB) Act of 2001 was passed with the specific task of closing it by the year 2014. This legislation had been the most ambitious effort to improve education in our country since the Elementary and Secondary Education Act of 1965. However, with the election of President Barack Obama in 2008, NCLB turned in a new direction. Every Student Succeeds Act (2015), President Obama's signature education legislation, allowed 
states to opt out of the unfunded NCLB mandate and to determine their own measures of academic achievement and teacher accountability.

The Trump administration is taking an entirely different direction that could change the future of public education in this country. Their focus on vouchers to provide options to parents to educate their child or children could mean pulling critical funding from public schools, while increasing the likelihood that a focus on charter schools could leave our culturally diverse learners further behind by sequestering them in poor performing public schools. In thinking about what contributes to these historic disparities, it is important to understand what educational improvements need to take place.

Over the years, several explanations frame why academic disparities exist between our nation's White middle-class students and their culturally diverse peers. Delpit (2012) titles the opening chapter of her book, Multiplication is for White People: Raising Expectations for Other People's Children, "There Is No Achievement Gap At Birth" (p. 4). Documenting the findings of several researchers such as Frankenburg, and Dodds (mid-1960s) and Rippeyoung (2006) whose work confirms no achievement gap at birth, Delpit makes a compelling case for possible factors that contribute significantly to the gap in standardized test scores between students of African descent.

Specifically, Delpit identifies curriculum, instruction, psychological stressors such as stereotype threat and others as reasons for explaining the current achievement gap. Statistical data on achievement clearly illustrate these differences and point to the teacher and living conditions such as housing and economic status as contributing factors to the 
achievement gap (Barton 2003; Barton and Coley, 2010; Sleeter 2013). The important question is: Why do they exist?

The next section examines a few justifications that continue to covertly and overtly influence the educational backdrop of our nation and affect the educational experience of our diverse learners.

\section{Longstanding Explanations for the Achievement Gap}

Coleman report. Commissioned by the U.S. Department of Education (1966), the Coleman Report claimed that poverty was a non-factor in the poor academic performance of African American students. The report asserts that the family plays a central role in whether or not diverse learners excel academically. However, much research discounts this assertion (Noguera, 2008). Although value is attributed to the importance of the family as being a child's first teacher, public education-our nation's system of compulsory education - is the site where all learners expect to gain the access and opportunities they need to have the lives they desire in mainstream society (Kozol, 2005; Ladson-Billings, 2006b; Sleeter, 2013). Whether one accepts this view of the Coleman Report or not, this thinking continues to impact the educational experience of African American learners and other diverse learners and to give credibility to other explanations for the poor achievement of culturally diverse learners.

Unfortunately, diverse learners remain sequestered in low performing schools (Howard, 2006; Kozol, 2005; Lenski, Crumpler, Stallworth, \& Crawford, 2005; Mills, n.d.). According to Ladson-Billings (2006a), “[w]hen schools fail to provide for those [access and opportunity] needs, these students are locked out of social and cultural 
benefits" (p. 32). They can but do not acquire the requisite knowledge and skills of engaged citizenry — one of the many "values of equity, justice and democracy" espoused by public education (Dewey, 1916 as cited in Allen, 2006, p. 10).

Parenting. Another rationale that has acceptance is that parents of diverse learners do not care about their child's education (Howard, 2010; Moultrie, Magee \& Paredes Scribner, 2017; Nieto, 2003; Taylor, 2010; Taylor \& Sobel, 2001; Villegas \& Lucas 2002a, 2002b). However, a Pew Research Center poll conducted in 2016 shows that this is completely unfounded. Parents of diverse learners' place education as a high priority for their child(ren) (Lewis, 2003; Stepler, 2016).

Intelligence. A third explanation for the continued poor achievement of diverse learners is the perspective that African American learners in particular, are intellectually inferior (Delpit, 2012; Howard, 2010; Milner 2005). This particular perspective has a long history in this country as promulgated by literature or as the basic belief held by individuals as well as practiced by those within education and other institutions. Noguera (2008) explains that "[t]he history of beliefs about the relationship between race and intelligence in the United States is not irrelevant to current efforts aimed at closing the achievement gap" (p. 91). The Bell Curve by Herrnstein and Murray (1994) offered credibility to the notion of White superiority and an explanation as to why our nation's diverse learners fail. However, their work - though widely acclaimed - possessed no scientific facts and perpetuated deficit thinking associated with people who are not White (Noguera, 2008). 
Culture. Noguera (2008) points out that "culture has been embraced as a less distasteful explanation [for the achievement gap] because it is assumed that cultures are not immutable but can change over time" (p. 92). Noguera reports that the reasoning ranges from diverse learners having a resistance to learning (Flaxman, 2003) to parenting (Tough, 2006) to music listening preferences as contributors to diverse learners' poor academic achievement. What these explanations fail to do is to "account for those who deviate from established patterns . . , but who share a culture with others who conform to these patterns ..." (p. 92). Though cultural theories are as equally disturbing as the above-mentioned theories, they too continue to exert great influence on the educational experience of our nation's diverse learners.

And though this kind of deficit thinking is politically incorrect, it still exists, so much so that a former superintendent of Philadelphia schools stated that some people believed funding Philadelphia's public schools was likened to "putting money down a rat hole" (Morning Edition, November 22, 2013). Noguera (2008) notes that "[d]ifferences related to socioeconomic status and income, the educational background of parents, the kind of neighborhood a student lives in, and most importantly the quality of school a student attends [emphasis added], significantly affect student achievement” (p. 94). Howard (2006) echoes this sentiment:

It is no mere coincidence that the children of certain racial, cultural, linguistic, and economic groups - those who have for centuries been marginalized by the force of Western White domination - are the same students who are failing or underachieving at disproportionate rates in our nation's public schools. (p.188)

While perspectives that view poverty as a non-factor, families as dysfunctional and uncaring, learners as incapable, and culture as a major factor still impact educational 
outcomes, legislation and research point to the teacher as being instrumental in helping all learners. According to Ladson-Billings (2006a), diverse learners need teachers who understand that they are "school dependent," acknowledging that some learners have access to resources that can ameliorate the impact of adverse educational experiences ( $\mathrm{p}$. 31).

Therefore, accepting any of the above-mentioned explanations for the continued poor achievement of diverse learners places these learners at a distinct educational disadvantage. Holding diverse families and learners responsible for their educational predicament unfairly penalizes them and ignores the inherent inequity of support for public education (Darling-Hammond, 2010a; Kohn, 1998; Kozol, 1991, 2005; Tom Segrue, Morning Edition, December 2013), while teaching diverse learners in ways that do not align with their learning styles (Càrdenas, 1976 as cited in Quintanar-Sarellana, 1997, p. 43; Freirè, 2000).

As previously mentioned, the issues surrounding education in our nation are complex. Consequently, the issues related to the achievement gap are equally complex. The next section provides a few key perspectives that attempt to contribute more breadth and depth of understanding to an extremely important and complex issue than does 'blaming the victim thinking'.

\section{Alternative Explanations for the Achievement Gap}

Many scholars have written about the changing makeup of our nation's public classrooms and the fact that the teaching profession remains "White, middle-class, female and monolingual" (Darling-Hammond, 2006; Milner, 2006; Nieto, 2000; Sleeter, 2001; 
Villegas \& Lucas, 2002a, 2002b). This lack of teacher diversity plays a major role in students' dropout rates, academic success, self-esteem and college going and graduation rates (Darling-Hammond, 2006; Wlodkowski \& Ginsberg, 1995). If we as a nation are to prepare all learners to assume their roles as productive citizen, our teachers are instrumental in changing the current reality for our diverse learners.

One thing is clear; in terms of educating its citizens, our nation can no longer allow our diverse learners to linger in educational mediocrity. Too much is at stake. We, as a nation, can ill-afford the continued underdevelopment of our citizens (Marable, 2000; Wise, 2013). Furthermore, because of the achievement gap's potential impact on our nation's democratic values and economic competitiveness, we need teachers who possess the attitudes, beliefs, knowledge, and skills to work effectively within our nation's diverse classrooms.

Stereotype threat. Uncovered through the work of Steele (2009), stereotype threat refers to a phenomenon that attributes poor academic performance among African American students as emanating from a sense that their performance will perpetuate negative stereotypes about the group to which they belong.

In several mathematics experiments conducted with groups of Stanford students, Steele (2009) found that when one group of students was instructed that men and women score about the same on the math test and the other group was not, the group with no instruction displayed a gap which was gender based. Steele and his colleague extended this research to investigate language skills among Black and White Stanford students in testing situations. Using a similar protocol, Steele discovered a similar pattern among 
those informed that the test was not a diagnostic tool, but a tool to determine problemsolving strategies. Participants who received no instructions performed poorly.

These results led the researchers to conclude that stereotype threat occurs when students perceive some negative association connected to their performance in a domain in which they identify. Thus the use of standardized tests serve as a barrier to diverse learners who experience stereotype threat.

Teacher certification. Darling-Hammond (2010a), sharing her teaching experiences in various settings around the country, points out in The Flat World and Education that schools serving a majority of diverse learners are more likely to have teachers who are uncertified in the subject area they teach or teachers who have pursued alternative routes to teaching. Moreover, due to teacher shortages in some content areas, like math and science, long-term substitute teachers tend to have no stake in their students' education because they are not teachers of record (Morning Edition, December 2013). Furthermore, these schools employ teachers who have little in common with the learners in their charge (Gay, 1993; Leavell, Cowart \& Wilheim, 1999; Villegas \& Lucas, 2002a, 2002b; Marbley et al., 2007; Nieto, 2000, 2003; Taylor \& Sobel, 2001). Finally, many teachers are unprepared for the diversity in their classrooms (Duncan, 2011; Sleeter, 2013).

Preparation. Former Secretary of Education, Arne Duncan (2011) in his annual gathering of educators, stated "a staggering 62 percent of all new teachers - almost twothirds - report they felt unprepared for the realities of their classroom" (para.13). There exists a huge divide between what teachers receive in their preparation programs and 
what they need (Duncan, 2011). Thus, it becomes clear that access to highly qualified teachers is an extremely important condition for academic improvement for diverse learners (Barton, 2003; Darling-Hammond, 2010a)

Teacher education programming. This is the sphere where teacher education programs (TEPs) with educational equity and social justice missions can exert great influence. Making sure that all teachers meet the highly qualified designation is insufficient. TEPs must ensure that teacher candidates possess the knowledge, skills and dispositions to work successfully with an ever-growing diverse student population (Darling-Hammond, 1997; Gay, 1993; Ladson-Billings, 2006a).

Student resources. Another area that needs addressing is the fact that schools with a majority of diverse learners are sorely underequipped in terms of funding and human and curriculum resources (Darling-Hammond, 2010a). At a minimum, our diverse learners must have access to curriculum, pedagogy, and technology afforded their White, middle-class peers to ensure that they have an "equal opportunity to learn in school" (Banks, 2004 as cited in Gorski, 2006, p. 65). To do otherwise is to deny diverse learners their rights to a free and appropriate education — further disadvantaging them.

In order for there to be the needed paradigmatic shift in education toward a more educationally equitable and socially just society, Mills (n. d.) states there is a need for teachers who can "act as agents of transformation rather than reproduction" (p. 1). Additionally, there is a need for teachers who see learners as holding possibility, not being a liability (Delpit, 2012; Ladson-Billings, 1994, 1995b). 
Curriculum and pedagogy. Many factors influence the quality of education students receive, but the content learned also affects the quality (Darling-Hammond, 2010a; Delpit, 2012). Curriculum constitutes that content, and necessarily influences the level of rigor students receive. Historically, tracking has been an important tool for perpetuating discrimination in our nation's schools (Noguera \& Wing, 2006; Oakes, 2005). Tracking determines what is learned and by whom. When diverse learners learn curriculum that is irrelevant to their lives and fails to challenge their intellect, they lose interest (Oakes, 2005; Orfield, 2004; Rubal-Lopez, 2004; Steele, 2009). The result is a great loss of human potential and economic productivity (Marable 2000; McKinsey Report, 2009).

Curriculum and pedagogy are powerful influences for improving the educational experiences of our diverse learners. In order for education to live out its hope, it must regain its transformative mission. Landsman and Lewis (2006) assert, "We believe that much of the work must be done within the community and in the racial group who does most of the educating: White teachers, administrators, counselors, and social workers of our students" (pp. 1-2). The tool at their disposal is culturally responsive pedagogy (Howard, 2006). "[P]edagogy is the most strategic place to begin this work because of its location as a central message system in education" (Gale et al., 2017, p. 345).

\section{Introduction of the Culturally Responsive Pedagogy Theoretical Framework Explanation of the role of culturally responsive pedagogy. For this research} study, culturally responsive pedagogy (CRP) pulls from critical race theory (CRT) to highlight the need for educational equity and social justice to be enacted in teacher 
preparation. CRP reveals how the concerns of educational equity and social justice are opportunities for urban teacher education programs (UTEP) to re-establish their value as institutions that matter (Bales and Saffold, 2008; Cochran-Smith, 2002; Howard, 2010; Ladson-Billings, 1995, 1998).

CRP places race and class at the center of our education conundrum. In an online article in the Washington Post, Layton (2013) reports that 50\% of our school aged population lives in poverty. In Oregon, recent U.S. Census (2015) data show that White families are estimated at living below the poverty level at $13.1 \%$ compared to Black families who the data state live below the poverty level at 38.1\% (see Appendix B). When one considers the intersection between race and class and the kinds of educational experience afforded certain learners, it becomes clear that CRP is indeed an appropriate perspective from which to conduct this inquiry and that CRT can serve as an explanatory tool that justifies its use.

The reality of race and how it impacts material wealth and how this plays out in the lives of diverse learners makes CRP an even more powerful tool of educational critique. "Education is often perceived to be the great equaliser in an otherwise unjust society" (Mills, n.d., p. 1). Hence, the purpose of education is to assist all learners in gaining access and opportunities within mainstream U.S. society (Kozol, 2005; Lenski, et al., 2005; Ladson-Billings, 1994, 2006a; Ludlow et al., 2008; McKown \& Weinstein, 2008; Sleeter, 2013). However, if one is a diverse learner and fails, the perception is that the learner is the problem and not the school in which she or he is educated (Landsman \& Lewis, 2006; Milner, 2005; Nieto, 2000, 2003; Noguera, 2008; Noguera \& Wing, 2006). 
One of the values of framing this research study from a CRP perspective is that it highlights many of the assertions that Milner (2009) claims teacher educators and students of teaching must address if the achievement gap is to close. He asserts that the incorporation of diversity studies in the preparation of teacher candidates could greatly improve the academic achievement of our nation's culturally diverse learners. CRP has much in common with CRT in that race is central to the discussion about how to improve educational outcomes for our diverse learners. What follows is a discussion of the major tenets of CRP and a rationale for its use in this research study.

\section{Discussion of Culturally Responsive Pedagogy}

Culturally responsive pedagogy (CRP) emerged from the work of numerous practitioner-scholars who were concerned about the continued educational underperformance of our diverse learners (Gay, 1993, 2002; Ladson-Billings 1994, 1995b; Villegas \& Lucas, 2002a, 2002b). According to Ladson-Billings (1995a), the primary instructional goal of this framework is to use diverse learners' cultural backgrounds to improve their academic success. Ladson-Billings points out that this approach to instruction goes by several names ranging from "culturally appropriate" to “culturally congruent" to "culturally responsive" to "cultural synchronization", and her own term, "culturally relevant pedagogy". The combined scholarship of practitioners along with the work of Ladson-Billings (1995a) and Gay (1993) would help culturally relevant pedagogy evolve into what is culturally responsive pedagogy or culturally responsive teaching (for my purposes culturally responsive pedagogy will be used). 
In placing CRP as a compelling framework for improving teacher education, Gay (1993) highlights why CRP has value. She states, "There is a growing cultural and social distance between students and teachers that is creating an alarming schism in the instructional process" (p. 287). Gay continues her assertion by highlighting the important role teachers have by pointing out the major challenges that confront teacher education programs. Gay states that preparing teacher candidates to incorporate pedagogical practices that improve learning outcomes for our diverse learners should be a primary objective for pre-service teacher education. "Preparing teachers to connect meaningfully [with culturally diverse learners] is the ultimate challenge of teacher education in an ethnically and culturally, pluralistic and technological complex world” (p. 288). By speaking to the diversity in our public schools and the challenge that this diversity presents to teacher education programs, Gay offers five propositions for CRP as a theoretical framework for preparing teacher candidates to work successfully with diverse learners. Concomitantly, Ladson-Billings (1995b) offers three criteria that frame outcomes for learners instructed by teachers who espouse a CRP stance and three conceptions that frame CRP.

What follows is an elaboration of each scholar's notions of CRP with greater emphasis placed on teacher education programs and CRT's role in for this study.

Gay's conception of CRP. Gay's (1993) theoretical propositions situate themselves within a teacher education framework whereby teacher educators intentionally inculcate the following principles in teacher candidates: (a) situational competence, (b) cultural context teaching, (c) teacher as cultural broker, (d) acquiring 
cultural knowledge, and (e) teacher as social change agent. A brief explanation of each proposition follows. In Ladson-Billings' (1995b) conception of CRP the three criteria addressed are: teacher as cultural broker, acquiring cultural knowledge, and teacher as social change agent. From her perspective these three criteria are the foundational components of culturally responsive pedagogical instruction.

The visual below illustrates Gay's conception of how CRP functions to create the educational outcomes possible through its tenets and implementation.

Figure 2.1 Gay's Conception of CRP

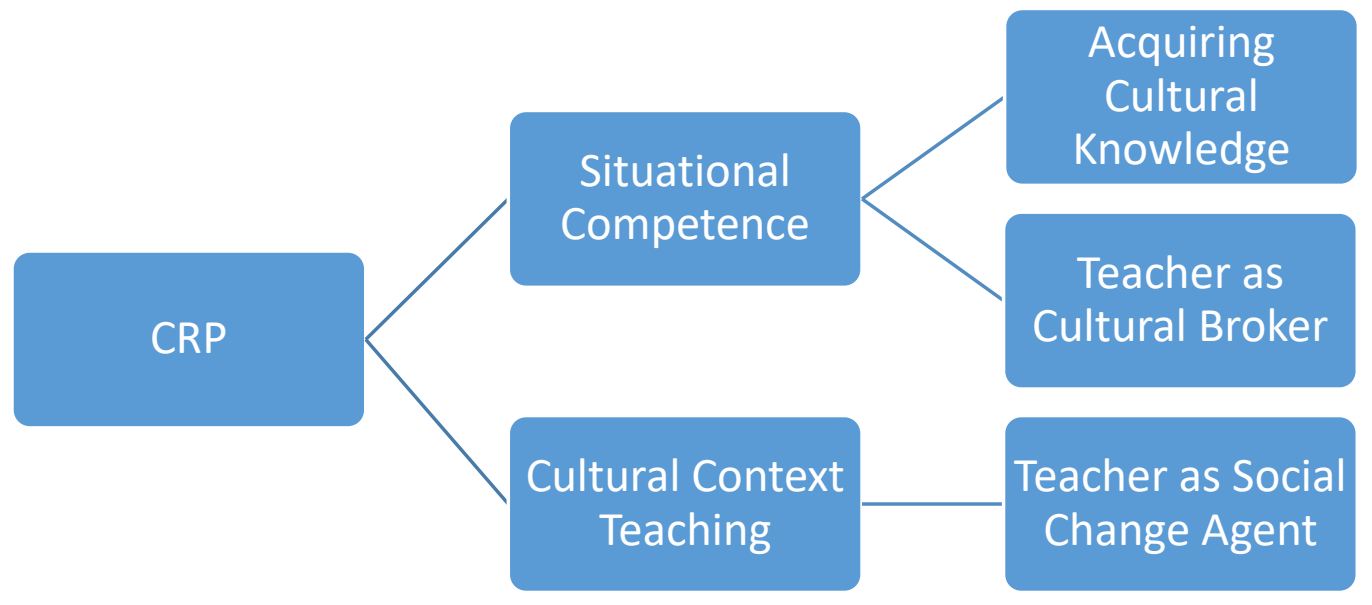

Situational competence. Given the demographic gap in our nation's public schools, teachers are aware that diverse learners do not share the same knowledge base as their White middle-class peers (Delpit, 2012; Ladson-Billings, 1999; Noguera \& Wing, 2006). Oftentimes, teachers perceive these learners as possessing fewer skills to support the scaffolding of new learning than their White peers (Gale et al., 2017; Howard, 2010; Ladson-Billings, 1994, 1995b, 2013; Rothstein, 2004). Consequently, teachers need to 
draw out what students do know to assist them in learning what they need to know. Freirè (2000) refers to this process as "mining".

According to Gay (1993), situational competence suggests that all learners possess competence in something given the environment, and a teacher's pedagogical practices must maximize these learning opportunities. Consequently, drawing on diverse learners' lived experiences aids in the acquisition of abstract ideas so that they may become relatable (Garcia, Arias, Murri \& Serna 2010).

However, it is simply not enough for teacher candidates to use this strategy to collect information about diverse learners' lives from them, but teacher education programs (TEPs) must provide curricular and extracurricular opportunities for their teacher candidates to engage in meaningful interactions with diverse learners. This is important because meeting the needs of these learners and positively influencing learning outcomes most likely occurs best when teacher candidates know their learners and the circumstances of their lives (Cochran-Smith, 1997; Correa, 1991; Garcia et al., 2010; Steele, 2009). The combination of these ideas that learners possess expertise and that this expertise can scaffold new learning lends itself to Gay's second proposition, cultural context teaching.

Cultural context teaching. Constructivist educators will find much in common with the principles of CRP (Villegas and Lucas, 2002a, 2002b; Wlodkowski \& Ginsberg, 1995). Gay's (1993) second proposition speaks to building competence through contextualizing learning. Cultural context teaching involves knowing who learners are and by doing so, gaining trust and an understanding of their values so that the teacher can 
better serve/educate them. Cultural context teaching also involves teachers viewing themselves as cultural brokers as well as understanding "how the dynamics of cultural conditioning operates in teaching and learning" (p. 292).

If our society continues to perpetuate points of view that race no longer matters, then our society ignores the human qualities that make individuals unique. Ignoring human differences encourages holding everyone to the same expectations, to the same life experiences, and the same cultural norms and values. However, doing so denies learners their most salient qualities of race, religion, language, and culture and exposing them to a system that sees their values, ways of being, and ability in deficient terms (Delpit, 2012, 2006; Gay 2013; Howard, 2010; Ladson-Billings, 1994, 1995b; Marable, 2000; Milner, 2005; Young, 2010; Ullucci \& Battey, 2011).

CRP views diverse learners as infinitely capable of learning, provided the appropriate circumstances and conditions are in place (Delpit, 2012). However, when these are not in place, Villegas and Lucas (2002b) and Achinstein and Anthanases (2005) assert that teachers resort to the ways they were taught without regard to whether or not it is appropriate. This lack of pedagogical expertise unduly penalizes the diverse learner, who, from a CRP perspective, is more than capable of academic success.

To illustrate, Ladson-Billings (1994) conducted research that looked at eight elementary teachers of African American students and the pedagogical practices they used to improve academic success. Using a variety of pedagogical strategies that drew on the cultures of their students and the relationships they developed with each one allowed these educators to affirm and strengthen these students' self-concepts and academic 
achievement. Ladson-Billings chronicled the pedagogical journeys of these teachers, which spoke encouragingly of the potential of culturally responsive pedagogy to improve academic success for all learners.

Exploring how diverse learners construct understanding and create knowledge from their experiences in conjunction with the instructional practices of a teacher is a departure from a traditional approach so often espoused in our nation's classrooms. This "one size fits all" traditional approach is the rule rather than the exception in schools (Bartolemè, 1994; Garcia, 2010). As a pedagogical position, CRP sees a solution to this mismatch in how diverse learners learn and how they are taught. Gay’s (1993) third proposition attempts to remedy this issue by calling on teacher education programs to prepare teacher candidates for their role as cultural brokers.

Teacher as cultural broker. According to Gay (1993), a cultural broker is someone who possesses full knowledge of different cultural systems and can incorporate this knowledge in their teaching. These teachers have the ability to understand different systems and integrate elements of these systems into classroom processes, programs and practices.

When teachers enter the profession, they must be conscious of the fact that our nation's public schools serve diverse learners, and they must be capable of meeting their educational needs (Correa, 1991; Darling-Hammond, 2010a). In our nation's schools, it is no longer as Ladson-Billings (1999) states, "Public School Way Back When" (p. 220), when the school-aged population was predominantly White. The diversity of our nation's school-aged learners requires the advancement of social justice and educational equity. 
Acquiring cultural knowledge of our diverse learners is a means of accomplishing these goals.

Leavell, et al, (1999) conducted a study which implemented culturally responsive pedagogy in the preparation of teacher candidates. The authors acknowledge the demographic gap that exists between the next generation of teachers and the school-aged children they will encounter and posit the need for more awareness of cultural differences in order to better prepare them. In a joint collaboration between a school district and teacher education program, a professional development institute (PDI) emerged. The goal of this collaboration was to align the teacher education experience with the tenets of culturally responsive teaching. This occurred through having teacher candidates engage in various interactions with the students and community to dispel some of the negative thinking about the community and its residents. While engaging in these activities, teacher candidates learned, observed and applied that learning within the school district so that meaningful interactions and learning about teaching diverse learners were the learning objectives.

Leavell et al. (1999) highlight the need for teacher candidates to develop cultural understanding of themselves and others and to build pedagogical practices that consider the cultural makeup of their learners. This study addressed the need for improved pedagogical practices and greater understanding of the cultural diversity that currently exists in our public education system. Leavell et al.'s study shows how intentionality in preparing teacher candidates for diverse classrooms stands at the intersections of learning and pedagogy. Thus, the PDI provided the teacher candidates with learning opportunities 
that encouraged them to examine their own culture and the privilege it affords them in order to determine how it might affect curriculum choices and interactions with diverse learners in their communities. This intentionality has pedagogical implications that can help future teachers align practices more closely with the cultural experiences of their learners.

A conclusion of the study, according to Leavell et al. (1999), is that teacher candidates "need a chance to see and try the strategies that they are being asked to use in a real classroom before they will adopt them as practice" (p. 79). Ultimately, the authors, citing Cochran-Smith's work, assert that "[t]he goals of teacher education programs should emphasize that [teacher candidates] develop their own theories of practice, which should include ways to support learners who are less like themselves in terms of culture, race, class, and ethnicity" (p. 65).

It is these types of intentional practices that can lead to personal and social change — qualities inherent in CRP_-because they assist learners. While these types of activities are not a panacea, they do aid in bringing awareness to teacher candidates that public schools have changed and in order to be successful in them, a different set of pedagogical skills and knowledge is required (Correa, 1991; Ladson-Billings, 1995b).

Acquiring cultural knowledge. Teacher education programs must provide teacher candidates opportunities to interact with members of diverse communities; to engage in learning situations that provide growth and understanding of cultural factors that influence learning; and to get to know their students individually, collectively and personally (Correa, 1991; Leavell et al., 1999; Steele, 2009; Ullucci \& Battey, 2011; 
Villegas and Lucas, 2002a; Wlodkowski \& Ginsberg, 1995). According to the scholars previously cited, building relationships and opportunities matter in significant ways to diverse learners. They matter in terms of staying motivated, remaining in school, improving self-concepts, and other factors of educational success beyond standardized measures.

Thus, Gay's (1993) fourth proposition suggests that acquiring cultural knowledge necessitates learning facts, understanding pedagogical implications of cultural characteristics and constructing a philosophy of cultural context teaching. Developing these qualities is tantamount to improving teacher candidates' educational experiences. As previously mentioned, relationships and relevance are crucial to maintaining diverse learners' engagement and a motivation to learn. Without grounding the preparation of teacher candidates in these realities, abstract terms will be the only means by which teacher candidates come to know what working successfully with diverse learners entails.

While these actions are a beginning to creating the conditions for improved outcomes for diverse learners, they must be maintained through a constant willingness by teachers to question their beliefs and practices. If teachers' efforts are committed to closing the achievement gap between our growing diverse learners and their White peers, then they need to embrace the transformative vision of education to be the "great equalizer".

Teacher as social change agent. Gay's (1993) final proposition builds on the four previous propositions. In this nation, there is a strong belief that education is the great equalizer. The notion presumes individuals transform due to the educative process; her or 
his transformation allows society to transform through their participation as educated citizens. As such, Gay's final proposition requires teachers to become social change agents. This involves teacher education programs and the teacher educators working to prepare teacher candidates to improve the social conditions that will allow citizens equal access to the benefits of mainstream society. In many ways, this teacher as social change agent concept embodies what Leavell et al. (1999) state involves a "life-long process of personal, social and self-critique" (p. 66). This is more likely, according to the authors, when "teacher candidates have the opportunity to discuss openly the topics that have the power to transform a classroom community wherein culturally diverse learners feel safe to share their beliefs and values" (p. 66).

Ladson-Billings (1995b) also speaks to the role that teacher candidates have in promoting social justice and educational equity. If indeed the responsibility of education is to create greater opportunity, then teachers are indispensable. While the burden is not entirely the teacher educators or the institutions, TEPs are, however, instrumental in preparing teacher candidates. Similarly, teachers are responsible for preparing the next generation of citizens for the challenges and opportunities that await learners beyond the K-12 experience.

Educating for social justice and educational equity is a complex, multi-faceted undertaking (Hackman 2005). In Gay’s (1993) five propositions, the reader gains a vision of teacher education and the education of teacher candidates that focuses on preparing teacher candidates more intentionally for the demographic changes of our nation's public schools. Moreover, Gay provides a set of required qualities and capacities that urban 
teacher education programs (UTEPs) must inculcate in their candidates if the teaching profession is to meet its obligation to all its learners.

The discussion now turns to the work of Ladson-Billings and her conception of the role of CRP in its use by UTEPs in the preparation of teacher candidates.

Ladson-Billings’ conception of CRP. Ladson-Billings' (1995b) work complements Gay’s (1993) propositions well. Ladson-Billings' focus is on the outcomes that the use of CRP provides all learners. This does not imply that Ladson-Billings is unconcerned with the preparation of teachers, quite the contrary. She maintains that in order for these outcomes to exist, teachers must have the knowledge, skill, and attitudes needed to work well with diverse learners.

These are not innate qualities, but qualities honed through the rigors of a teacher education program. Drawing on the work of Bartolomè (1994), Ladson-Billings (1995b) believes CRP is a tool to "re-educate the candidates we currently attract [to teaching] towards a more expansive view of pedagogy" (p. 483). Accordingly, Ladson-Billings proposes the following possible learner outcomes through the incorporation of CRP in the preparation of teacher candidate. If CRP is incorporated, the goals are:

1. To have diverse learners succeed academically;

2. To nurture and support their cultural competence; and

3. To develop in learners a critical consciousness that allows for informed critique of their experiences.

Consequently, Ladson-Billings believes that within these three criteria, three theoretical underpinnings emerge. The underpinnings that Ladson-Billings identifies are: 
1. Conceptions of self and others;

2. Social relations; and

3. Conceptions of knowledge.

A brief discussion of these concepts follows.

Conceptions of self and others. In Ladson-Billings' (1995b) view, the conceptions of self and others refers to two concepts: a) the sense that teachers have of themselves as members of a learning community whereby they view their teaching as a craft and as a means to give back and b) teachers' abilities to develop academic success in the learners in their community. Ladson-Billings' first idea of conceptions of self and others, complements Gay's (1993) propositions of situational competence, and acquiring cultural knowledge.

In terms of situational competence, Gay contends that given the environment, all learners possess competence in something, and that it is the teacher's responsibility to exploit that knowledge in support of a learner's academic success. Ladson-Billings' conceptions of self and others view the success of students synonymously with the ability of the teacher to create a community ethos that values and welcomes who the learners are and the diversity of experience each brings. By doing so, the teacher and students learn and teach each other, creating a safer and more cooperative learning environment. Furthermore, Ladson-Billings asserts that all learners are capable of academic success. Ensuring that success requires pedagogical skill and knowledge of the learners' world in and outside the classroom. 
By making learning meaningful and relevant, greater and greater depth of knowledge and understanding can occur. Teachers who create these conditions and possess these qualities create bridges to academic success.

Social relations. Continuing her discussion, Ladson-Billings' (1995b) explanation of social relations addresses the ways that teachers interact with learners. These relationships, according to Ladson-Billings, determine to what degree a teacher engages in CRP. Teachers, who do, practice the following:

1. Maintain equitable and mutual relationships with all learners;

2. Exhibit a connectedness with all learners;

3. Create a sense of community among learners; and

4. Encourage collaboration among learners.

In many ways, these constructs align themselves with Gay’s (1993) propositions of viewing the teacher as cultural broker and as acquiring cultural knowledge. For both, the result is improved achievement without the risk of a learner losing her or his cultural identity, but in having their cultural identity shared, embraced, and valued. These connections help strengthen our shared understanding and our mutual capacity to work toward societal transformation.

Conceptions of knowledge. Ladson-Billings' (1995b) final conception explores teachers' ideas about knowledge. According to Ladson-Billings, teachers who are successful with diverse learners hold the following beliefs:

1. Knowledge is dynamic;

2. Knowledge must be critiqued; 
3. Teachers must possess a passion for knowledge and learning;

4. Teachers must draw on what learners know to assist learning; and

5. Assessment must take multiple forms in order for learners to show their mastery.

These ideas inform and embody Gay's five propositions and make clear the role teachers have in teaching and learning as well as informing how education can and must serve our diverse learners.

It is important to acknowledge that there are those who feel that education is not about transformation, but about teaching the basics of reading, writing and arithmetic, and more about American economic supremacy, than about teaching for democratic values inherent to our national identity and its future (Giroux, 2009; McLaren \& Farahmandpur, 2006; Sleeter, 2008, 2013). Moreover, those who hold these beliefs believe that the civil rights movement remedied many of the ills that continue to plague our society. Thus, education becomes more of a commodity and a means to an end to gainful employment than a human right (Giroux, 2009).

However, without the constant creation and critique of knowledge, we as a nation will be doomed to lose the qualities and values that embody our nation and are foundational to nation's character. When teaching professionals fail at their most rudimentary task of ensuring that all learners learn, so does our nation.

As previously mentioned, culturally responsive pedagogy is situated within critical race theory (CRT) in such a manner as to serve as the vehicle for operationalizing educational equity and social justice. In this section I discuss the tenets of critical race 
theory and conclude the chapter with a discussion of the Relevant Themes that inform this research study.

\section{Interplay of Critical Race Theory Tenets and Culturally Responsive Pedagogy}

Racism is ubiquitous in American society. From a critical race theory (CRT)

perspective, racism is viewed as being ubiquitous in American society to such an extent

that it permeates all aspects of diverse people's lives and experiences (Bell, 1973). As a

result, it is not surprising that our culturally diverse learners underachieve; live in

neighborhoods steeped in poverty and attend some of our nation's poorest K-12 schools.

Bell (2010) sees CRT “as a social justice paradigm that looks at diversity through

the structural dynamics of power and privilege" (p. 11). Because the status quo is a race-

based ideology, CRT recognizes that race is a social construct and argues for the

eradication of racial suppression. Again, Bell confirms the power of race.

[It has] significant material consequences in the real world . . . It shapes our government, schools churches, businesses, media, and other social institutions in multiple and complex ways that serve to reinforce, sustain, and continually reproduce an unequal status quo. (p.13)

However from a CRP perspective, race is viewed as a solution to the underachievement of culturally diverse learners (Gay, 1993; Ladson-Billings, 1995a). By having these learners' cultural values, norms, and lived experiences play a central role in teaching and learning, culturally diverse learners gain a sense of belonging as well as build new knowledge on their existing schema (Gay, 1993, 2002; Ladson-Billings 1994, 1995b; Villegas \& Lucas, 2002a, 2002b). Thus, CRP has the potential to make teaching and learning more interesting, relevant and meaningful, while improving educational outcomes for our nation's historically under-achieving learners. 
Interest convergence. Another way that CRT exerts support for the use of CRP is in its awareness that the interests of the parties involved in any endeavor must converge if positive change is to occur. Bell (2009) coined this idea interest convergence. How this plays out in terms of CRP is that CRP can serve as the means by which goals of education legislation can meet the goals of educational policies and practices to insure that our nation's most vulnerable school-age populations succeed. CRP provides this opportunity for real improvement for our nation's culturally diverse learners by valuing the importance of knowing one's content, understanding the intricacies of learning and the role culture plays in learning (Darling-Hammond, 2002).

If CRP were the lens by which teacher education program prepared their teacher candidates, these institutions would be meeting their goals of preparing teachers to fulfill their roles of service to students and the communities in which their work serves (UTEP, syllabi).

Marginalized voices. In continuing the discussion of the ways CRT supports the use of CRP, it is important to speak to the role that secondary teacher candidates play in giving voice to their school experiences. Though one might not consider teacher candidates as marginalized, their voices contribute to and foster an understanding of the learner's experience as well as their own.

Being central to the teaching and learning experience, secondary teacher candidates have a unique vantage point from which to critique their experience and those of their students. Their insights offer ways to change and respond to the kind and quality of teaching and learning that is needed to improve outcomes for our culturally diverse 
learners. By sharing their experience, there is the potential to gain powerful knowledge and understanding about our nation's culturally diverse learners' experiences.

Paradigm shift. Critical race theory contends that our systems of laws must remove barriers that sequester culturally diverse learners in conditions that limit their access to the social, political, economic, and educational advantages. As school-age children in a nation where K-12 education is compulsory, our nation's culturally diverse learners have the same liberties and rights as their White middle-class peers. However, our educational system fails to reflect these inherent rights to a free appropriate education. Thus, CRP offers an alternative to the traditional educational practices that have failed to meet the needs of our culturally diverse learners. Embedded in CRP is an appreciation of students' cultures, not a desire to require students to assimilate to the dominate culture, hence, perpetuating the status quo. CRP offers a real possibility for educational improvement for these learners by promoting educational equity and social justice to improve their schooling experience.

With the school-aged learners in our nation's public schools becoming more and more diverse, it becomes incumbent upon UTEPs to assert their roles in dismantling oppression so that all learners acquire the knowledge and skills to become fully contributing citizens. Unless dramatic changes occur, our nation will have a majority of its population undereducated, underprepared, and underdeveloped (Marable, 2000).

\section{Relevant Themes}

The major constructs this study attempts to unpack are social justice and educational equity. They are relevant because they determine the kind of education and 
preparation teachers receive to work successfully with our nation's diverse secondary learners. In reviewing the literature relevant of these two constructs, I attempt to bring together the disparate voices that inform my belief in the need to adopt a new instructional paradigm for preparing our nation's teachers. Culturally responsive pedagogy (CRP) fills that need.

However, it is important to note that CRP draws its salience from a legal belief known as critical race theory (CRT) that emerged from critical legal studies (LadsonBillings, 1998; Taylor, 2009; Tate, 1997). It is also important to acknowledge the themes covered in this section indeed draw their relevance from the work of critical race theorists as they comment on the experiences of people of color in the U.S.

The image below provides a visual as well as a perspective of how I view the relationships between the two frameworks. CRT, with it its focus on race, drives the theoretical underpinnings of CRP and makes possible the potential realization of educational equity (Ed Eq) and social justice (SJ) the potential positive outcomes of their interplay. The application of this knowledge can inform the preparation of teacher candidates and improve outcomes of our nation's diverse learners.

Relevant themes. What follows is a larger and more focused discussion of the relevant themes as they situate themselves within the CRP theoretical framework. 
Figure 2.2 Interplay of CRP and CRT

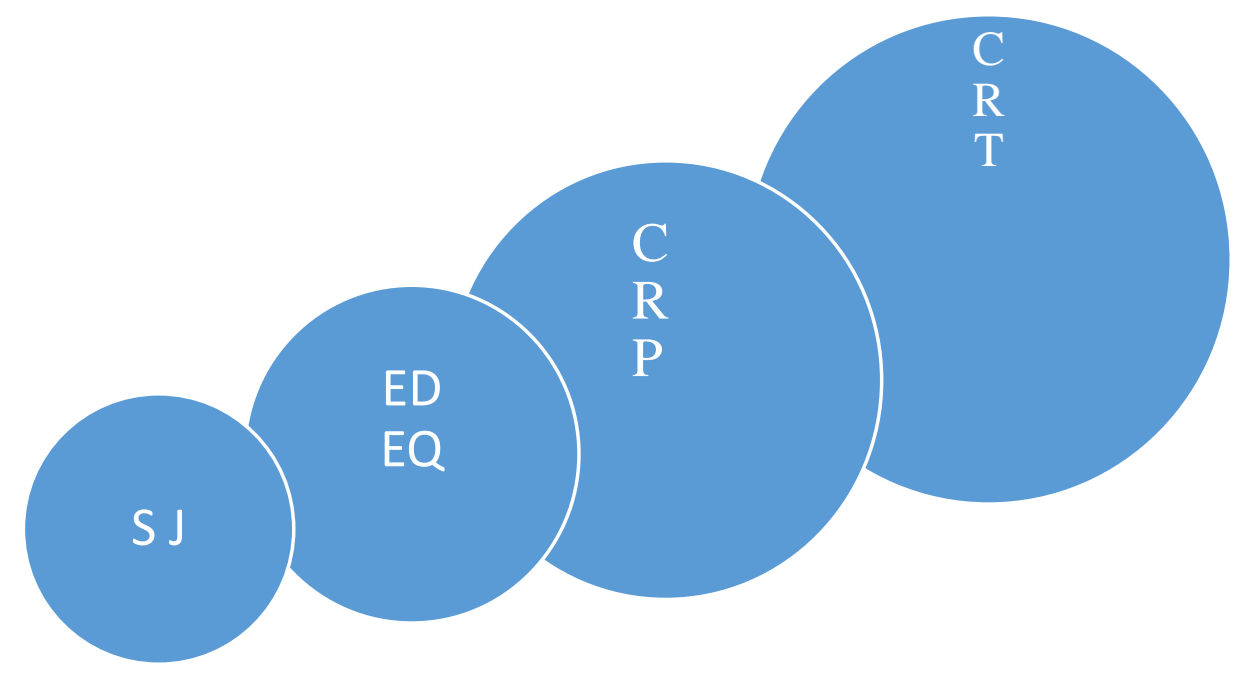

According to Gay (2002, 2010a), CRP offers a comprehensive approach to educating all learners. It does so by honoring and valuing the gifts that each learner brings to the educational experience. CRP accomplishes the central goals of educating for educational equity and social justice espouses by insuring that all learners have the access and opportunity to learn that allows full participation in mainstream society. This is possible by securing the financial and human resources and accessing high quality curriculum and instruction that create opportunities for historically marginalized populations to gain an equal chance at success. These two constructs-educational equity and social justice — are possible outcomes of CRP. Thus, CRP serves as a viable mechanism by which educational equity and social justice can become societal realities for our nation's diverse learners and all learners, empowering public education to fulfill its legal and moral responsibilities (Ladson-Billings, 2006b). 
Theme: Educational equity. As mentioned, educational equity is:

The principles of fairness and justice in allocating resources, opportunities, treatment, and success for every student. Educational equity programs promote the real possibility of equality of educational results for each student and among diverse groups of students. Equity strategies are planned, systemic, and focused on the core of the teaching and learning process. (www.educationnorthwest.org)

In reading this definition, it is clear that CRP has implication for operationalizing this concept. At its core, CRP provides a focused, systematic approach that traditional and behaviorist approaches fail to provide (Darling-Hammond, 1997; Fraser, 1997). CRP engages learners from a cultural lens and draws on what students know to build greater and more complex understanding. The traditional "banking system" of education that is most common in public schools does not serve the needs of diverse learners (Bartolemè, 1994; Freirè, 2000; Garcia, et al., 2010). Moreover, Rubal-Lopez (2004) states: “The most tragic result of the banking method is that it leads to student disinterest in learning and, ultimately, a lack of vision regarding the importance of learning" (p. 105).

In creating the public-school system in the United States, the aim was to create an educational system that offered opportunity for everyone to transform their lives by becoming literate and informed citizens who will contribute to the maintenance of our nation's common, democratic values. The objective of our nation's public education system is and remains to provide citizens with the basic skills to be able to go out into the world and fulfill their potential whether that is post-secondary education or employment. The goal of public schooling historically and socially has been to ready the individual for the pursuits of her or his choosing. 
These notions are the reason that education remains the great equalizerproviding opportunities to all who participate in the American public education system. As educational needs change, society makes greater and greater demands of teachers. As a result, teachers instruct on skills and knowledge emphasizing math, science, and technology to the next generation of Americans who will need them in order to fulfill their roles as educated and informed citizens (Giroux 2009, Villegas \& Lucas, 2002b). Public education is truly a great and noble undertaking for which not all of America's citizens have reaped the benefits (Howard, 2010; Sleeter 2013).

Grant (2008) contends: "[I] ssues of diversity have for the most part been marginalized or omitted from the discourse" (p. 129). In order to shift the discourse, issues of importance to diverse learners need examination because of their inherent importance to the greater society. Here is an instance where the interests of culturally diverse learners hopefully align with those of our nation. Even as the demographic shift in the school-aged population is underway, little concrete action has addressed the needs of this new generation of American citizens who inhabit our classrooms. Our nation is changing and becoming more and more diverse; the implications of this change have a major impact on what occurs in our nation's classrooms and on the teacher education programs that prepare the next generation of teachers. This diversity speaks naturally to the changing role of the teacher and "[w] hat teachers should be able to do, know, and care about" (Grant, 2008, p. 133). CRP has the potential to play pivotal in how teachers are prepared. 
To respond to Grant's statement would require more time than I am able to devote presently, but suffice it to say, teaching itself is a complex undertaking. My experience as an educator permits me to say that diversity adds to that complexity. It is especially so in settings where diversity is viewed by the teacher as a "problem rather than as a resource" (Melnick \& Zeichner, 1997, p. 26) and also where practitioners hold deficit beliefs about the learners in their classrooms (Correa, 1991; Howard, 2006; Marbley et al., 2007; Milner, 2005; Taylor, 2010). I identify these not to imply that improving the educational outcomes of diverse learners is an impossible task, but if we continue along this path of deficit thinking, we will continue having the same results. Teacher education holds the key to transforming how teachers succeed in the profession.

The National Council of Accreditation of Teacher Education (NCATE) and the Council for the Accreditation of Educator Program (CAEP) standards to improve teachers' readiness to work successfully with diverse learners caused many colleges and schools of education to add courses that dealt with the needs of these special student populations. At their worse, colleges and school of education held fast to past practices that ignored the NCATE/CAEP requirement and conducted business as usual (Melnick \& Zeichner, 1997). What we do not yet know is what would happen if colleges and schools of education prioritize the use of culturally responsive pedagogy to prepare teacher candidates to meet the needs of our diverse learners. Melnick and Zeichner (1997) highlight some teacher education programs that attempt to actualize the NCATE/CAEP standards for working with diverse learners; however, they note all have shortcomings 
that relate to recruitment and retention of faculty of color and approaches used to prepare teachers to work with diverse learners.

Melnick and Zeichner (1997) citing the work of Zeichner and Gore (1990) and Haberman (1991) assert that "teacher education is a weak intervention . . . to change the attitudes and dispositions developed over a lifetime" (pp. 26-27). We know that most traditional teacher education programs have not produced the needed results in preparing teachers to work successfully with diverse learners. Standalone courses related to diversity have proven ineffective (Milner, 2009). However, an approach I believe holds promise is the infusion approach, which incorporates culturally responsive pedagogy throughout the curriculum in addition to culturally relevant co-curricular activities. Intentional work that places emphasis on improving how teachers work with diverse learners is crucial to achieving success. An infusion program that is coupled with strong curriculum and instruction holds the key to improving outcomes for our diverse learners. Ideally, a teacher education program committed to social justice and educational equity will have the following components focused on beginning teacher development.

Theme: Self-reflection and critical consciousness. One area in which teacher education can have an impact is by embedding into the curriculum and instruction a component that intentionally involves teachers in exploring themselves as educators and individuals. Gay and Kirkland (2003) state that "[s]elf-reflection and cultural critical consciousness [on the part of teachers] are imperative to improving the educational opportunities and outcomes for students of color" (p.182). They subscribe to this thinking because they believe that "teacher accountability involves being more self- 
conscious, critical and analytical of one's own beliefs and behaviors" (p.181). To elaborate, the premise here is that by providing teachers with opportunities to explore their own cultural heritage they will come to understand themselves better as individuals who possess a culture as well as become aware of how their culture influences their teaching.

According to Gay and Kirkland (2003), this understanding of themselves as 'cultured' sheds light on how teachers themselves engage in the classroom. Accordingly, this knowledge can aid awareness regarding decisions about practice, curriculum and disciplinary choices as well as interpersonal relationships with students and peers. These are not the only factors; this exploration adds a layer of self-knowledge and complexity to their teaching that may or may not have been previously present. This kind of critical self-critique is consistent with culturally responsive pedagogical practices.

Considering the fact that most White teachers intend and prefer to teach students much like themselves (Villegas \& Lucas, 2002a. 2002b; Melnick \& Zeichner, 1997; Nieto, 2000, 2003), self-reflection and cultural critical consciousness are essential prerequisites for working with diverse learners. As the demographics of the American classroom change, a homogenous classroom is an unrealistic expectation. Consequently, unless White teachers receive the kinds of preparation they need and deserve, they will unintentionally and/or knowingly do harm. Therefore, it becomes imperative that teacher candidates develop a cultural critical consciousness and the concomitant self-reflection. Teacher educators must be at the forefront of turning around the "extraordinarily poor job 
of educating low-income and minority students" (Darling-Hammond, 2002, p. 149).

Darling-Hammond continues by stating:

Perhaps the most important difference in what happens to children at school depends on who their teachers are, what they understand about children and about learning, what they are able to do to respond to the very different approaches and experiences children bring with them to the learning setting, what they are about and are committed to as teachers. (p. 150)

This quote reveals the interconnected relationship between the teacher and her/his practices and how these practices influence educational outcomes for learners. While the quote does not explicitly address educational equity, it makes clear that a teacher education program needs to inculcate in its secondary teacher candidates certain skill sets to assist all learners. This practice has at its core a commitment to educational equity. All must be mindful that teaching is as much a profession as a craft. The knowledge and skills teacher candidates learn in their preparation programs are refined in the classroom. The development of these take time, practice, and introspection.

Theme: Develop teacher capacity. In considering the complex roles and responsibilities teachers have in the educative process, the question of teacher capacity naturally arises. A teacher's knowledge, skills and their attitudes have much to do with what occurs in the learning context at any given moment (Grant, 2008; Villegas \& Lucas, 2002b; Quintanar-Sarellana, 1997; Taylor \& Sobel, 2001). Grant (2008) points out that historical events play an important part in determining what gets valued, acknowledging that "debates. . change and evolve in response to changing social, economic, and political agendas" (p. 129). It is for this reason that educational equity must enter into the educational landscape if teachers are to meet the complex and ever- 
increasing expectations society places on them (McDiarmid \& Clevenger-Bright, 2008). The development of teacher capacity has become the province of colleges and schools of education whose responsibility it is to prepare the next generation of teachers to insure all learners have the opportunity to realize their promise.

With the increasing diversity of our nation's K-12 classroom, a shift away from a skills based view of teacher capacity gave rise to understanding how well a teacher knows the content enough to teach it (McDiarmid \& Clevenger-Bright, 2008). Having teachers who understand the intricacies of their content allows them to find more places to intersect with their students' schema thereby creating greater access to learning opportunities (Darling-Hammond, 1997; McDiarmid \& Clevenger-Bright, 2008). However, unless teacher education programs prepare teachers to work with learners from diverse backgrounds - an NCATE/CAEP standard - educational equity will remain elusive.

In order for a paradigm shift in teaching to happen, we need to move away from viewing teachers as unskilled technicians who deliver "prepackaged curriculum [that] is teacher-proof and designed is to be applied to any classroom context regardless of the historical, cultural, and socioeconomic differences that characterizes various schools and students" (Giroux, 2009, p. 442). However, this necessary shift is extremely difficult given our present educational predicament with testing and accountability playing greater and greater roles in what gets taught and how. We need teachers to assume their status of professionals able to create the transformative mission teaching originally held in our culture (Dewey, 2008; Howard, 2006). The qualities UTEPs need to inculcate in 
their teacher candidates are being reflective and transformational practitioners who use self-knowledge and experience to improve their craft.

Theme: Develop teachers as reflective practitioners. In placing education as the cornerstone of our democracy and teachers as the medium by which this foundational goal is achieved makes teacher education an integral component of the process (DarlingHammond, 2006). She asserts:

Thus, schools of education must design programs that help prospective teachers to understand deeply the wide array of things about learning, social, cultural contexts and teaching and be able to enact these understandings in complex classrooms serving increasingly diverse students; in addition, if prospective teachers are to succeed at this task, schools of education must design programs that transform the kinds of settings in which novices learn to teach and later become teachers. (p. 302)

Therefore, reducing a teacher's role to that of a technician removes an essential element of the teaching/learning partnership — the human relationship. That teaching involves not only an understanding of content but of how learners learn and how teachers might construct supportive learning opportunities is at the core of reflective practice. Understanding how to connect learning to existing knowledge, how to make learning relevant, how to build on schema in a way that encourages teachers to connect practice with outcomes, and how to gain learners' trust are common practices that reflective practitioners engage in (Darling-Hammond, 1997). Moreover, these practices are central to better serving diverse learners and serve as markers for how teacher education programs can approach the preparation of their teacher candidates. Grant (1997) states the time has come to uproot the current paradigm so that teacher education is more inclusive of diverse learners. 
This kind of attention to diverse learners in schooling is not something American education is good at (Darling-Hammond, 2006). However, if we are to meet the needs of future generations of American citizens, then we must change how teachers are prepared to ensure that all learners have equal opportunity to be contributing citizens. DarlingHammond (1997) states:

The work of educating teachers is, at root, the work that will enable us to sustain a productive and pluralistic democracy for it is the capacities of teachers that make a democratic education possible - that is, an education that enables all people to find and act on who they are; what their passions, gifts, and talents may be; and how they want to make a contribution to each other and the world. (p. viii) The complexity involved in teaching and learning requires teachers to attend to many moving parts in the classrooms and to diagnose the best delivery of curriculum in ways that aid learners in the acquisition of knowledge. This kind of deep teaching necessitates having teachers who are collaborative, deep thinkers and reflective practitioners who are devoted to a life of professional learning and service (Gay \& Kirkland, 2003; Howard, 2006). Teacher preparation reform has been unable to create the kinds of powerful conditions that are necessary for improving the outcomes of schools that serve all learners.

Unless teacher preparation in our country begins to address in its curriculum and co-curriculum activities the reality of the contemporary U.S. classroom, then our diverse learners will continue to lag behind their White middle-class peers. Again, DarlingHammond (2006) makes clear that successful teacher education programs have distinct features that separate them for the crowd, asserting that if given the opportunity, more teacher preparation programs have the capacity to do likewise. However, what it involves requires a real commitment to changing how teachers are currently prepared. 
Theme: Provide context and experience. Howard (2006) makes clear the fact that a teacher cannot teach what they do not know. Melnick and Zeichner (1997) state: "There is an old adage - teachers teach what they know—and so do teacher educators" (p. 33). This is important because how can we expect teacher candidates to acquire the knowledge and skills needed when teacher educators have limited exposure to diverse community members and experiences from which to draw and inculcate in their students. How can teacher educators impress upon their teacher candidates the importance of such activities and experiences in their professional education, practice, and life when they have few or none themselves?

Having schools where teachers lack knowledge of the students who attend or the community in which they work does a disservice to the community, students and the teachers (Giroux, 2009; Howard, 2006; Leavell et al., 1999; Lewis, 2003; QuintanarSarellana, 1997). It is extremely important that urban teacher education programs provide chances for urban secondary teacher candidates to engage in activities and have experiences that provide them a rich learning environment. This allows for the development of the prerequisite skills and knowledge these candidates need to work successfully with diverse learners, while providing these opportunities in contexts that support these goals (Darling-Hammond, 1997; Leavell et al., 1999; Lenski, et al., 2005; Melnick \& Zeichner, 1997, Quintanar-Sarellana, 1997; Taylor, 2010).

In this regard, "[t] eaching to and through diversity" (Gay, 2013, title) naturally requires teacher candidates to view themselves as members of a community of learners whose work is to bridge the gap between school and home/community. This revived 
approach to teaching "requires that schools structure themselves to support more productive forms of student and teacher learning than they currently permit-learning that is more intensive and collaborative and better supported by extended human relationships" (Darling-Hammond, 1997, p. x).

Melnick and Zeichner (1997) discuss the use of a yearlong immersion program that focuses on cultural knowledge. The actual teacher education program utilizes this knowledge to build on experiences from which to develop their practice. While this proved to have the most immediate and lasting impact, it does not seem appropriate for the urban setting where teachers encounter and interact with diverse learners who are ethnically, linguistically, racially unique. However, learning how to interact with the multiple cultures that inhabit a school is possible if schools and colleges of education prepare teacher candidates for this educational reality.

As mentioned, the economic, political, and social context dictates the terms that students learn and teachers are prepared. Our nation's emphasis on educational accountability and testing are out of touch with what supports our learners (Ravitch, 2010). Even if one ascribes to the notion that every teacher can teach, not every teacher can reach a child and gain her/his trust (Anonymous educator, public communication, June 12, 2014; Howard, 2006). Culturally responsive pedagogy has the potential to bridge the cultural and experiential divide.

Theme: Develop an understanding of teaching as a political act. The fact that “education must serve the purposes of democracy" (Darling-Hammond, 2006, p. 303) makes the role of teacher education even more important. For it is in the preserving of 
our national values of opportunity, fairness and equality that education offers its most potent contribution. Historically, transformation has been a foundational goal of education from its early use as a moral caliber of humans (Ladson-Billings, 2006a) to its status of potential change agent (Lenski et al., 2005; Ludlow et al., 2008). Mass, public education desires to shift the social order, by preparing a new generation of citizens ready and willing to assume their roles (Lenski et al., 2005). However, there are powerful forces that believe that legislation has provided the necessary changes to improve educational outcomes for diverse learners (Grant \& Agosto, 2008). Those who hold such views project them onto teachers who are charged with teaching and as a result, see the educator's role as less political and more practical (Villegas \& Lucas, 2002b). Thus, teachers must recognize that their work is political (Cochran-Smith, 1997; Freirè, 2000; Giroux, 2009).

\section{Theme: Shift paradigm from teachers as technicians. Though No Child Left} Behind (NCLB) had good intentions, the legislation failed at its purpose. It failed for several reasons, but perhaps the most important reason was its effort to remove from the teacher the power to decide how to teach the children in her/his charge, thus reducing their role. This situation arose in part from a failure to acknowledge and understand that all learners are not the same and neither are their experiences. The "one size fits all" rhetoric that ushered in the era of standardized testing has proven — in my opinion — to be our nation's greatest educational misstep in that we have not accomplished its primary goal. In fact, since NCLB's enactment, the achievement gap has widened for greater numbers of diverse learners in the K-12 system (Marbley et al., 2007). This flaw in the 
legislation rightly brings us to consider this question: If we teach and treat all students the same, then why are the majority of our diverse learners continuing to perform poorly on these tests of academic knowledge?

The answer to this question lies in what kind of knowledge gets valued in the $\mathrm{K}$ 12 school system. According to Kincheloe (2004), "[t]he positivistic effort to devise precise, universally applicable rules for what a teacher is supposed to do in a [teaching] setting is futile- the situation is far too mercurial and complex" (p. 16). Kincheloe's comment speaks to the heart of what NCLB failed to understand as an inherent quality of the teaching and learning dynamic. Students and teachers bring unique experiences, cultural knowledge, backgrounds and personalities into the classroom. This conflicts with the "one size fits all" approach propagated by a positivistic legislative agenda which would have teachers ignore the most salient qualities diverse learners and they themselves bring with them into the classroom - their cultural markings (LadsonBillings, 1994).

In this "one size fits all" view, instruction means filling students with knowledge for reproduction on the test and then forgotten. That fails to serve the child, the community, the school, or our nation. Quality teaching and learning is about more than test scores; it involves knowing the learners in your charge and their unique circumstances; it necessitates drawing on the background knowledge that the learners possess to support greater learning; and it requires teachers joining in the process of knowledge creation. This kind of teaching requires a different kind of teacher-one culturally responsive pedagogy can produce. 
Today, education is a means of securing employment, keeping the economy growing, and acquiring wealth and less about how to "[contribute] to each other and the world" (Darling-Hammond, 1997, p. viii). Nor is it about transforming the social order for those who continue to be educated in schools that are underfunded, understaffed and poorly equipped to serve its essential public role or about the growing education, health and wealth disparities that affect the majority of our diverse learners and their families (McKown \& Weinstein, 2008). This is why having teacher education programs tackle these issues through an educational equity and social justice lens is essential.

Theme: Developing a social justice lens. In espousing a social justice lens from which to prepare teachers, one commits to an educational philosophy which ensures "full and equal participation of all groups in a society" (Bell, 1997, p. 3). In order for this to occur, we need teachers who understand ". . . how schooling has been shaped by forces of social dominance .... [b]y acknowledging that racial and socioeconomic inequities and the resulting achievement gap are logical consequences of our system of education ...." (Howard, 2006, p. 121). Thus, change in the educational experience of our nation's diverse learners, according to Howard, requires that teachers know themselves, know their content, and know their learners (p. 126); while this is a beginning, it is not sufficient. Change requires a "complete unraveling [of] social dominance" (p. 121).

Theme: Dismantling social dominance. In covert and overt ways, the educational system reflects the logic of social dominance. Howard (2006) claims, "that the achievement gap cannot be understood without honestly confronting the issue of social dominance" (p. 118). Howard goes on to say that "[t]he raced-based achievement gap in 
public education is the demographic embodiment of our history of White social, political, and economic dominance" [emphasis in the original] (p. 118). Grant and Agosto (2008) admit that the civil rights movements did much to counter-act the social dominance of previous decades. White teachers were accountable for teaching diverse learners in ways that "respected and promoted each group's culture and each student's self-identity" (p. 183). However, with neoliberal ideology infiltrating the educational system, teachers and teacher education programs and the teacher educators who inhabit them must reestablish their roles as social change agents if our nation's educational system is to meet its responsibility because education is supposed to "pay off equally for everyone" (Sleeter, 2013, p. 168).

In order to unravel social dominance, we must inculcate in secondary teacher candidates the value of democracy beyond the notion of a concept, but as an integral component of living; moreover, we must reestablish the role education plays in maintaining our nation's democracy and concomitantly, the teachers' role in actualizing it in the service of learning. Furthermore, we must value pluralism and teach to it and to the importance of national cohesion in light of diversity. Our nation must live its creed, E Pluribus Unum: “Out of many one.”-instead of out of many, some. Finally, teacher preparation needs re-envisioning so that it means societal transformation.

Theme: Valuing democracy and education. Sleeter (2013) asserts our nation's diversity is its strongest attribute. Thus, a quality education is central to realizing and actualizing this attribute. One might inquire, what are the fine qualities that diversity offers? Inclusion is one of the fine qualities that diversity offers, but is one which public 
education has failed to realize for our nation's diverse learners. Our history of isolating people who are different is common knowledge. Whether isolating them in ghettos with no opportunities or in tracked classrooms with diminished opportunities, we can longer afford to continue to sequester learners based on race and class. To continue these practices is to perpetuate the social conditions that maintain an unequal playing field for our nation's diverse learners. Inclusion allows our nation to build on the diverse skills and knowledge of its citizens and in doing so, shift the current paradigm (Lenski et al., 2005).

Theme: Disruption of social reproduction. Teacher education programs, the educators and the teacher candidates who are prepared in them are the frontline for combating the educational conditions that preserve unequal access and opportunity. How teacher education professionals prepare teachers determines their readiness for their roles as change agents and collaborators in teaching and learning. Who programs recruit as teacher educators and candidates has been a long and ongoing debate in education (Gay, 1993; Howard, 2006; Ladson-Billings, 1999), but even more important is what happens once they are there. The disruption of social reproduction of inequity requires a pedagogy of possibility, not of poverty. Given the fact that many of the hopes of the civil rights movement have gone unrealized by the people for whom the movement championed and that integration has resulted in de jure segregation, our nation's best hope is culturally responsive pedagogy. 


\section{Summary and Overview}

In discussing the literature relevant to the research study, I discussed the themes central to quality teaching within the framework of culturally responsive pedagogy (CRP). In addition, CRT is discussed to provide an historical context that supports the use of CRP as an educational imperative to improve educational outcomes for our culturally diverse learners. The CRP framework attempts to provide a way forward that is a departure from our nation's current fascination with traditional ways of teaching and a focus on testing and accountability. CRP sees the relationship between the student and teacher as being the focal point of any conversation that relates to improving educational outcomes for diverse learners. This means that race and its impact on education must be addressed in a positive and productive manner. CRP can serve as this tool.

Many scholars have written about the need for a change in direction. Under our current educational policies, the traditional practices of "one size fits all" and standardized testing have not proven fruitful for our nation's diverse learners. Given the emphasis placed on interpersonal relationships, rigor, and reflective practices, it is possible that CRP is the paradigm shift our nation needs to realize all learners' full potential. CRP and CRT with their tenets and characteristics have the potential to change the way we prepare teachers and how they function in the classroom. 


\section{Chapter 3- Research Methodology}

\section{Introduction}

The aim of this inquiry is to explore how an urban teacher education program (UTEP) that self-identifies as having an educational equity and social justice mission prepares its teacher candidates to work successfully with diverse learners. As previously

mentioned, culturally responsive pedagogy is situated such that critical race theory (CRT) serves as the vehicle for operationalizing educational equity and social justice. Using a multiphase mixed methods case study research design, the research study attempts to discover what practices this UTEP incorporates that assists it in achieving its dual mission and in preparing secondary teacher candidates to work successfully with diverse learners.

This chapter includes a discussion of the research perspective, the data collection and analysis procedures used. In addition, a rationale for the research perspective is provided as well as the details concerning consent, recruitment and privacy as well as collection and analysis of data.

\section{Research Perspective}

This multiphase mixed methods study was conducted to examine how the UTEP operationalized its dual missions of educational equity and social justice as well as the extent to which culturally responsive pedagogy (CRP) is evident in how the UTEP prepares its secondary teacher candidates. Starting with the perspectives of secondary teacher educators is key to understanding their lived experience and perspectives; having 
these educators share their perspectives helps the researcher understand their points of view on issues of educational import for culturally diverse learners.

Drawing on the work of Maxwell (2005), and Tashakkori and Teddlie (2003), the choice for using a multi-phase mixed method research design rests on an assumption that the intellectual, practical and personal motivations for conducting research are interrelated. Because they are, they influence the choices a researcher makes in organizing the research and collecting and analyzing data. The multiphase mixed methods case study is a research design bounded by place and time — one site, over the duration of the teacher education program.

Within this research design, two types of data are collected. These data were qualitative and quantitative in character. Below, in Figure 3.1, is a visual of the kinds of data that I collected and analyzed.

Figure 3.1 Study's Research Design

\begin{tabular}{c} 
Multiphase Mixed Methods Research Design \\
Qual+ Quan $\rightarrow$ Qual \\
\hline
\end{tabular}

Source: Morgan 2014

Drawing on Morgan's (2014) work, this research design draws on both qualitative and quantitative data in order to provide a richer, more complex understanding of the phenomena under investigation. In order to obtain this understanding, qualitative data sources such as artifacts, interviews and pre- and post-open-ended statements are collected to explore the relationship between secondary teacher candidate experience and the preparation they receive. I use these data to address the three research questions being 
investigated in this study. In addition, I use quantitative data created by secondary teacher candidate Likert responses The Learning to Teach for Social Justice-Beliefs scale (see Appendix C) to ascertain information about their UTEP experience as it relates to instructional practices and change over time.

I chose this scale due to its alignment with many of the tenets of CRP and its ability to capture a snapshot of the skills and mindsets prospective teachers expect to develop during their teacher education program. Collection of these data added depth and breadth of understanding to the phenomena under investigation. From these multiple sources of data gathered, I drew conclusions and made interpretations about the kind of education secondary teacher candidates received as a result of their UTEP experience.

Morgan (2014) asserts that using a multiphase mixed methods research design allows the research study to "pursue a wider range of research goals than would be possible with any single method" (p.73). Thus, this design builds on the strengths of both qualitative and quantitative methods (Creswell \& Plano Clark, 2011; Fetters, Curry \& Creswell, 2013; Morgan, 2014). The multiphase mixed methods case study research design also allowed for a more in-depth and extensive interpretation of the phenomena under investigation (Creswell, 2008; Morgan, 2014; Tashakkori \& Teddlie 2003, 2010; Yin 2009). Yin (2009) and Creswell and Plano Clark (2011) aver that a multiphase mixed methods research design works well with contemporary issues, especially, according to Yin, when the researcher has no control over human behavior. Furthermore, Yin explains that this research design accommodates a plethora of evidence (i.e., documents, artifacts, interviews, and observations). But perhaps the most compelling reason for choosing the 
multiphase mixed methods research design is its ability to address research questions of a "how, why" and to a certain degree "what" nature.

This research study investigated:

a) how an urban teacher education program (UTEP) operationalizes its educational equity and social justice missions it in its efforts to prepare its secondary teacher candidates;

b) how teacher candidates' readiness to work effectively with diverse learners is impacted by instruction and changes over time from the beginning to the conclusion of their field experience; and

c) to what extent if any, CRP is associated with secondary teacher candidates' perceptions of their readiness to work successfully with diverse learners.

By enlisting the voices of secondary teacher educators and teacher candidates, whose work directly affects the K-12 classroom, insights were gained about their experiences, intentions, objectives and practices.

\section{Research Questions}

Before addressing the research questions, I think it is important to revisit a figure introduced earlier which conceptualized my view of the roles critical race theory (CRT) and culturally responsive pedagogy (CRP) play in creating the conditions for educational equity and social justice to be realized. I re-introduce it here to assist the reader in understanding how the research questions fit within my conceptual framework. 
Figure 3.2 Interplay of CRP and CRT

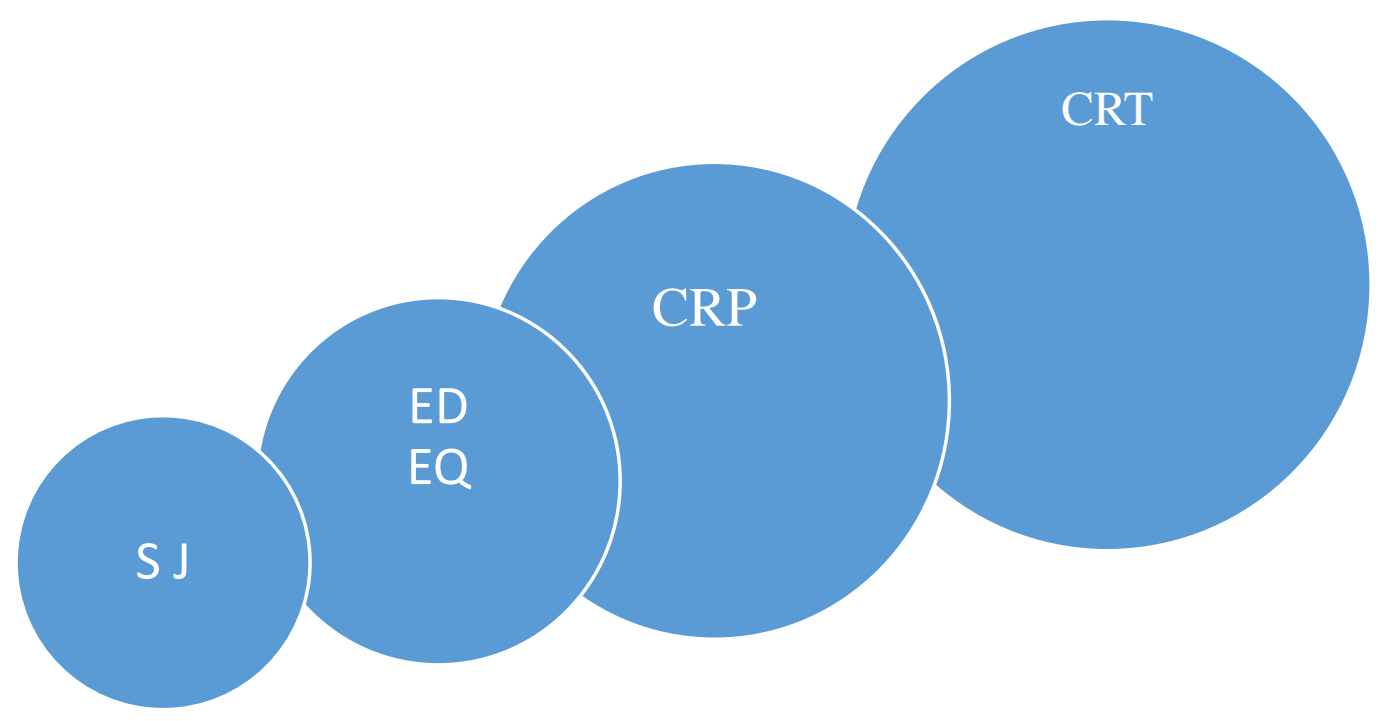

Richness of data is important; however, research questions are the central ingredient of any research study (Plano Clark \& Badiee, 2010). The research questions listed below are explored in an effort to shed light on just how a teacher education program with a social justice and educational equity dual mission prepares its teacher candidates to work successfully with diverse learners. In presenting the questions, some pretext and context is required.

1. How does a UTEP operationalize its educational equity and social justice missions in its efforts to prepare secondary candidates?

In posing Question 1, my objective was to understand how the UTEP interprets the dual mission of its teacher education program and to determine how instructional practices on the part of secondary teacher educators and the UTEP's philosophical stance support the attainment of its stated missions. 
Data to answer this question were derived from artifacts and interviews with secondary teacher educators and were combined with secondary teacher candidates' preand-post open-ended responses to the Learning to Teach for Social Justice-Beliefs scale to provide "a more "holistic" understanding" (Morgan, 2014, p. 74).

2. How does the secondary teacher candidates' readiness to work successfully with diverse learners change over time from the beginning to the conclusion of their field experience?

RQ2 Hypothesis: Because of their teacher preparation program, secondary teacher candidates will perceive themselves to be more prepared to work with diverse learners.

In posing Question 2, the aim was to determine how secondary candidates perceived their assignments, curriculum and co-curricular activities as preparation to be effective educators of diverse learners. This question is central to understanding what attributes the UTEP instilled in its secondary teacher candidates as well as to what degree its teacher candidates embraced the dual mission as well as practices.

Given the importance of having teacher candidates who are capable of stepping into their roles, one expects the UTEP to provide candidates with a breadth and depth of experiences that assist them for successful transition into their roles as in-service educators. Thus, opportunities to develop a practice that will incorporate the UTEP's educational equity and social justice missions will be an expected part of its preparation programming. 
Data used to answer this question were derived from secondary teacher candidates' pre-and-post Likert scale responses as well as their pre-and-post open-ended responses to Belief 1 of The Learning to Teach for Social Justice-Beliefs scale (see Appendix C).

3. To what extent if any, is culturally responsive pedagogy (CRP) associated with secondary teacher candidates' readiness?

RQ3 Hypothesis: I would expect that high levels of perceived readiness are associated with high levels of culturally responsive pedagogical practices. The goal of Question 3 was to discover what pedagogical orientation the UTEP utilized to accomplish its educational equity and social justice missions.

Data to answer this research question were derived from secondary teacher educator artifacts and interviews and secondary teacher candidate pre-and-post openended responses to Beliefs 1, 2, 4, 5, and 10 of the Learning to Teach for Social JusticeBeliefs (LTSJBs) scale.

Years of engaging in a traditional teacher preparation approach has not shown much promise when looking at educational outcomes for diverse learners (Barton, 2003; Delpit, 2012; Gay, 1993; G. Howard, 2006; T.C. Howard, 2010; Ladson-Billings, 1994). Quoting Howard (2006), “The realities of group membership in terms of race, culture, language, economics, and social positionality are inextricably tied to educational outcomes" (p. 51). Thus, this study places race at the center of examining one urban teacher education program. 
As greater and greater diversity exists in the classroom, our nation can no longer afford to have teachers who are incapable of working with all learners. As Howard (2006) states: "Too often we expect White teachers to be what they have not learned to be, namely, culturally competent professionals" (p. 6). Understanding what this UTEP does to prepare its secondary teacher candidates has implications for how teachers are prepared currently and in the future.

Preparing secondary teacher candidates for successful teaching and learning with our nation's learners is the quintessential goal of any teacher education program. This study explored these questions in an attempt to gain knowledge and understanding about what the UTEP does to operationalize and realize its social justice and educational equity missions in preparing its candidates for diverse classrooms.

\section{Research Site}

The research site for this multiphase mixed method case study consisted of an urban teacher education program (UTEP) located in the Pacific Northwest. This research site espouses a social justice and educational equity mission as articulated in its marketing materials and on its website. As an institution of higher learning, the UTEP has a reputation for its community engagement and research scholarship. In addition to the research site's focus on social justice and educational equity, the UTEP has a longstanding relationship with the communities its graduates serve and has close ties with a number of local area school districts. Moreover, the research site houses several educational programs that serve the unique needs of the surrounding communities. In addition to its teacher education program, there are programs that prepare counselors, $\mathrm{K}$ - 
12 administrators, special educators, educators who focus on adult learners and educators who serve the needs of K-12 students from various linguistic backgrounds.

In terms of the secondary level curriculum, teacher candidates complete a program that consists of a series of courses designed to provide teacher candidates with a breadth of knowledge necessary for successful work in the K-12 classroom. Courses that make up the curriculum are common amongst teacher education programs and include classroom management, teaching and learning, multicultural and urban education, and a student teaching component.

Many of the program's secondary teacher candidates complete their student teaching in schools and districts that serve diverse learners. Upon completion of the program, graduates earn licenses to teach in the state where the UTEP is located. Moreover, many of the graduates from this program become teachers in the schools and districts where they complete their student teaching experiences.

\section{Sampling and Recruitment Procedures}

To secure participants for this research study, I sent a letter to the Dean of the College of Education, and a short time later, a meeting occurred where I discussed the purpose and intent of the research study (see Appendix D). Later, I met with the Associate Dean to discuss specifics of the research study. A final meeting took place with the Secondary Coordinator before I received approval to conduct my study.

Secondary teacher educator recruitment. I corresponded via email with the Department Chair for Curriculum and Instruction who served as my liaison for prospective participants. In this email, I identified myself and summarized the nature of 
my study. After sending this information, four secondary teacher educators (STEs) expressed an interest in participating in the study (see Appendix E).

Secondary teacher candidate recruitment. Procedures for securing the participation of secondary teacher candidates (STCs) differed from the processes for recruiting secondary teacher educators (STEs). Recruitment for secondary teacher candidates occurred through visits to STE classrooms. During these visits, I informed STCs of the voluntary nature and intent of the study (see Appendix G) and secured contact information so that I could send informed consent forms electronically (see Appendix G).

In selecting STCs for this research study, I used a stratified purposive sampling of STCs from the UTEP. A stratified purposeful sampling includes participants who represent a variety of ages, backgrounds, genders, and ethnicities as well as allows for comparisons between subgroups (Miles and Huberman, 1994).

The number of participants who participated depended in part on the number of STCs willing to participate in the research study. As generalizability was not one of the goals of the research study (Salkind, 2008), I feel the sample sizes for both stakeholder groups (STEs and STCs) for the research study were adequate.

Each of these stakeholder categories played a significant role in giving voice to the content and experience of their teacher education program. How the program realizes its dual mission through curriculum, assignments and co-curricular opportunities was extremely important to discover, and how secondary teacher candidates felt the education 
and preparation they received contributed to their readiness to work with diverse learners was what this study investigated.

\section{Research Participants}

The urban teacher education program offered a variety of programs that certifies secondary teacher candidates (STCs) and secondary teacher educators (STEs) who prepare candidates for successful completion of teacher education program. The STC participants in my study were engaged in a full-time, one-year program that would certify candidates to teach in their content/subject area as well as earn an advanced degree. STEs who participated in my study were full-time faculty over the course of the STCs receiving their certification and degrees from the UTEP.

Study participants. The study consisted of two groups of participants. Via email, the Chair for the Curriculum and Instruction Department sent my email message to all STEs asking for their participation in the study. At the end of the recruitment period, four secondary teacher educators agreed to meet with me to discuss the purpose of my study. Of the four with whom I met, three signed informed consent forms that enabled me to share their voices in pages of this dissertation (see Appendix G).

For the STC group, 48 STC initially signed informed consent forms. Of those 48 STCs, 24 completed the pre-survey or first administration of the Learning to Teach for Social Justice-Beliefs (LTSJBs) scale and responded to the open-ended questions attached to each of the 12 Beliefs that make up the scale For the second administration of the scale, only 19 of the original 24 participants completed the survey. A more detailed 
discussion of each stakeholder group follows along with their demographic characteristics.

Secondary teacher educators (STEs). Once I identified STEs, I conducted informal face-to-face meetings. In these meetings, STEs learned about the rationale for the research study and the time commitment required. Before conducting the first interview, I informed potential participant of the voluntary nature of their participation, and the option to withdraw at any time. If the STEs agreed, I emailed them a copy of the informed consent form for their review that included information about procedures to protect their privacy before the interviews began. These were signed and collected from each participating STE.

There were 2 male participants, and one female participant. Participants were all $40+$ years of age or older. With the exception of one faculty member, all had terminal degrees that were either EdD or PhD degrees. Demographic Information asked and collected from secondary educators varied (see Appendix H).

Secondary teacher candidates (STCs). I hoped all STCs participating in the fulltime one-year program would participate in the research study. Unfortunately, that would not be the case. However, 24 STCs participated in the first administration of the scale. The majority of the candidates were female. Of the 24 candidates, 16 were females, and eight were males. This reality tended to align with current beliefs about the present-day teaching corps in our classrooms. Seventeen (17) of the 24 were in their twenties. Four of the candidates were in their thirties, and three were in their forties. Sixteen (16) of the 
candidates were of European descent while five identified as Latino and three identified as "Other".

Table 3.1

Sample Descriptive of Secondary Teacher Candidates $(N=$ 24)

\begin{tabular}{lcc}
\hline Characteristic & $n$ & $\%$ \\
\hline Gender & & \\
Female & 16 & 66.7 \\
Male & 8 & 33.3 \\
Race & & \\
$\quad$ European & 16 & 66.7 \\
Latino & 5 & 20.8 \\
Other & 3 & 12.5 \\
Age Group & & \\
20-29 & 17 & 70.8 \\
30-39 & 4 & 16.7 \\
40-49 & 3 & 12.5 \\
Undergraduate Major & & \\
English & 3 & 12.5 \\
Science & 2 & 8.3 \\
Math & 2 & 8.3 \\
Music & 6 & 25 \\
Other & 11 & 45.8 \\
Degree(s) Earned & & \\
Associates & 8 & 33.3 \\
Bachelors & 24 & 100 \\
Post-bac & 1 & 4.2 \\
Masters Before & 2 & 8.3 \\
Masters After & 19 & 79 \\
\hline
\end{tabular}

\section{Informed Consent, Protection of Privacy, and Data Storage}

Upon agreeing to participate in the research study, all stakeholders signed a letter of informed consent (see Appendix G). This letter spoke to the conditions, expectations, nature of the research study, terms, and possible benefits of their participation. It also 
included the guidelines, policies and practices used to protect participants' privacy. I used no real names to identify participants in this study. In all email communication with participants for the purpose of disseminating information such as opening and closing dates for completing surveys, I blind copied my correspondence to protect participant privacy.

Only I had access to the collected data. In an effort to maintain confidentiality, transcripts of interviews along with surveys and written responses were under my supervision at all times. I securely locked the data when I was not engaged in analysis. I made every effort to secure and protect participant information and their data.

To insure participants remained anonymous, I gave each stakeholder a code to protect their identity. For example, the first teacher educator became TE 1. All research data collected adhered to identifying secondary teacher educator stakeholders by this coding and numbering procedure. In follow up interviews, I used the same procedures to insure participant anonymity. For the second interview conducted with the same teacher educator, I labeled it TE 1_2. Member checks with interviewees were designated TE 1_MC, TE 2_MC, etc.

I collected the secondary teacher candidate data electronically, and had very little contact with them after soliciting their participation. After STC participants were recruited and signed the Letter of Informed Consent and returned the signed copy to me electronically, I gave each participant access to the LTSJBs scale. After a six (6) week period, respondents were sorted alphabetically by last names and given a number. Thus, based on the alphabet, the first teacher candidate with a last name starting with the letter 
A became STC 1, the next participant became STC 2, etc., and subsequent teacher candidates followed that ordinal pattern until all participants received an identifier. These procedures ensured that I took precaution to protect and maintain participants' privacy.

\section{Instruments and Measures}

How a research study unfolds depends a great deal on the kinds of data a researcher collects. In the case of this research study, the design required two qualitative phases and quantitative phases. The initial qualitative phase created the data by which I was able to interpret and understand Research 1: How do the secondary teacher educators conduct their work to instill in its secondary teacher candidates the UTEP's dual missions of educational equity and social justice?

The data collected in this initial qualitative phase consisted of STE artifacts and interviews along with the open-ended written responses from STCs generated from the Learning to Teach for Social Justice-Beliefs scale (LTSJBs) instrument (see Appendix C). The quantitative phase served as the means by which the two qualitative phases were integrated.

In the second phase the quantitative instrument, the LTSJBs scale, served to determine the change over time component of the research study addressed by Research Question 2 as well as to shed light on the kind and content of experience STEs provided their STCs as well as the STCs' perceptions of their experience. Their perceptions were obtained from STC open-ended responses to the LTSJBs scale before and after STCs embarked on their student teaching experience (see Appendix C). In addition to those data, STC final comments on their UTEP experience were collected (see Appendix C). 
In collecting quantitative data for this phase, demographic information were solicited from both secondary teacher educators (STEs) and secondary teacher candidates (STCs), along with the STC Likert survey responses to the LTSJBs- scale comprised the quantitative phase.

In the final phase, quantitative and qualitative from LTSJBs scale data and openend responses were combined, allowing for integration (Morgan 2014) and a richer understanding of the educational experience the UTEP offered and STCs experienced. The goals of this integration were to address Research Question 3-to determine the extent to which CRP plays a role in how the UTEP prepares its STCs and how STCs' perceptions of their readiness to work with diverse learners changed over time. A discussion of the purpose of each phase follows.

Purpose of the qualitative phases. The qualitative phase consisted of data generated from STE interviews and artifacts as well as STC open-ended response. From these qualitative data sources, ideas about the intentions of the STEs emerged as well as themes and codes that aided my understanding of the UTEP's philosophy and practices supporting its dual mission of educational equity and social justice education. In generating these data, the purpose was to determine what attributes the UTEP possesses and to discover how secondary teacher educators went about operationalizing these attributes in their students by studying the syllabi, assignments and STEs' instructional content.

Secondary teacher candidate qualitative data served to integrate the data from open-ended responses generated from the pre-and-post surveys administered of the 
LTSJ-Bs scale that occurred in the two quantitative data collection phases (see Appendix C). Having multiple sources of data was crucial to addressing the different research questions this research study endeavored to answer and integrate them into a holistic understanding of the UTEP educational experience.

Purpose of the quantitative phase. Having STCs respond to survey questions initiated the quantitative phase. They responded to 12 items directed at their UTEP experience before and after student teaching. I used, as in the qualitative phase, the Learning to Teach for Social Justice_Beliefs scale (see Appendix C). The Likert scale belief items remained unchanged with each administration of the survey in order to insure integrity of the data collected as well as to understand the STCs' UTEP experience.

Once STCs completed their student teaching experiences and responded to the LTSJBs scale items and the open-ended questions, differences between before and after student teaching Likert scale responses in addition to open-ended responses to the LTSJBs served as indicators of change/growth over time.

In order to gain a clear picture of the STCs' UTEP experience, it was essential that I collect data of various kinds and from a variety of stakeholders. Eliciting and collecting these data allowed the UTEP participants to share their experiences, practices, and perceptions and educational experience within the UTEP. The pre-and postadministrations of the LTSJBs scale were central to understanding the relationship between teaching and learning and STC perceptions of growth.

Qualitative data sources. In this inquiry, qualitative data initiated the study, and were collected throughout the study. Sources of data included interviews, instructional 
artifacts, open-ended responses, and a research journal. A detailed discussion of each data source follows.

Secondary teacher educator interviews. These interviews served to establish the instructional practices and philosophical stance used by the UTEP in preparing its teacher candidates. I accomplished this by asking secondary teacher educators to participate in two semi-structured interviews of 45-60 minutes plus a member check for accuracy and clarification purposes (see Appendices J and K). I conducted these interviews at venues convenient to the participants and digitally recorded them. After each interview, each STE received a Thank you card with a $\$ 10$ gift card.

The first interview centered on the views these secondary teacher educators hold about the qualities successful teacher education programs with educational equity and social justice missions possessed. I listened to and took notes on these interviews so that follow up questions could be prepared for the second round of interviews. Once the second set of interviews began, transcription of the first interviews got underway.

The second series of interviews focused on the pedagogical strategies the teacher educators used to operationalize the UTEP's dual mission and prepare teacher candidates for the profession. As with the first set of interviews, I conducted these at venues convenient for the participants and digitally recorded them. Upon their completion, I listened to and took notes on these interviews. After this process, transcription began. Six to eight months later, I emailed each secondary teacher educator a copy of their transcribed interviews for their review and any additions, corrections, and subtractions they wanted to make. This process served as a means of determining the accuracy of the 
transcription (Creswell, 2008). Upon receiving the member checks, I corrected all errors brought to my attention.

Secondary teacher educator instructional artifacts. Another data source collected and analyzed was secondary teacher educator syllabi. These syllabi contained guidelines, assignments, and weekly content covered, as well as other pertinent information important for STC to know. I collected these artifacts to discover what the objectives and outcomes of the program were and how these became a part of the secondary teacher candidates' skill set in their student teaching experiences. Moreover, the assignment guides provided me with information about the instruction secondary teacher candidates received and the expectations they had to meet in order to complete their teacher education course work successfully.

This information helped in understanding what criteria teacher educators used to assess how successful secondary teacher candidates demonstrated competence with the course material and to understand how secondary teacher candidates met the outlined objectives of their program of study. Furthermore, the review of curriculum materials/readings provided insights and opportunities to see how the secondary teacher educators incorporated the dual missions in preparing its secondary teacher candidates. Finally, having access to this information from the participating teacher educators provided evidence and insight into how the UTEP envisioned infusing its dual missions in the content areas in which secondary teacher candidates received preparation.

Secondary teacher candidate pre-and post-open-ended responses. Written responses served an important role in the research study. The written responses secondary 
teacher candidates (STCs) provided served as an explanation or rationale for their rating of each Likert scale survey item. These also served to determine what changes occurred in the perceptions of STC resulting from their urban teacher education program experience. The open-ended responses also helped to determine whether the constructs that secondary teacher educators inculcate in their educational practices emerged in secondary teacher candidate practices during their student teaching.

Secondary teacher candidate final comments. In addition to open-ended written responses to the Learning to Teacher for Social Justice Beliefs-scale, I asked STCs to provide their final thoughts about their overall UTEP experience. In asking STCs to provide this information, I hoped to obtain less scripted and more open responses. These responses served as another means to form a clearer picture of how their UTEP experience informed and influenced their preparation (see Appendix C).

Research journal. I kept a journal as a means of reflecting and generating ideas and developing themes that emerged while engaged in collecting data, annotating transcripts, and discerning patterns before, during and after analysis. The journal served as an on-going dialogue between me and the activities occurring during the research study as well as an iterative process of reflection on ideas/thinking and generation of new ideas/thinking (Lincoln and Guba, 2002; Lewins \& Silver, 2007).

Quantitative data sources. The quantitative component of this research study served:

a) to provide a snapshot of the participants in this study;

b) to assess the association between themes that emerged from the qualitative 
component of this study; and

c) to generate greater understanding of participants' experiences of the UTEP

(i.e., perception of readiness using Likert scale response comparisons).

I displayed this data in the form of percentages and tables. Below is additional information about each quantitative data source.

Demographic information requested. All participants disclosed their age group, genders, ethnicities, socio-economic backgrounds, level of education and degrees along with the granting institution. Secondary teacher educators provided additional information, which I discuss in more detail below.

The collection of this data provided background information about the participants as well as insights into their experience and areas of interest and focus.

Secondary teacher educator demographic information. All participants provided this information. However, some information differed based on participant category. For the secondary teacher educators, I gathered this information during the initial interview. This information provided a snapshot of who the teacher educators are and their roles in preparing the candidates for entry into the profession.

Secondary teacher candidate demographic information. For the secondary teacher candidates, this information was part of the survey and was be gathered electronically upon the completion of each administration of the Learning to Teach for Social Justice-Beliefs scale. These data offered a descriptive snapshot of the UTEP participants, as well as provided insights into the STCs' thinking and teaching aspirations and experience of those who entered the program. 
Secondary teacher candidate electronic surveys. The teacher educator interviews served as a means of making sense of the responses to the Teaching for Social JusticeBeliefs (LTSJBs) scale that secondary teacher candidates completed. Secondary teacher candidates completed two (2) administrations of the LTSJBS-scale comprised of 12 items measured on a 5-point ordinal Likert scale (see Appendix C). The first administration occurred before the student teaching or field experience and the second administration at the end of the student teaching experience.

This information was crucial to determining whether there is an association between what teacher candidates learn and what they used and took away as practices that promote educational equity and social justice in their student teaching and beyond. In Table 3.2 I provide a visual of the data sources used in analysis.

Table 3.2

Sources of Data

\begin{tabular}{|c|c|c|}
\hline Data Sources & Qualitative Data & Quantitative Data \\
\hline \multirow[t]{2}{*}{$\begin{array}{l}\text { Secondary Teacher } \\
\text { Educators }\end{array}$} & $\begin{array}{l}\text { Instructional Artifacts } \\
\text { - Syllabi } \\
\text { - Materials } \\
\text { - Assignment } \\
\\
\text { Guides }\end{array}$ & None \\
\hline & Interviews & \\
\hline $\begin{array}{c}\text { Secondary Teacher } \\
\text { Candidates }\end{array}$ & $\begin{array}{l}\text { Learning to Teach for } \\
\text { Social Justice Beliefs } \\
\text { survey } \\
\text { - Pre-open-ended } \\
\text { Responses } \\
\text { - Post-open-ended } \\
\text { Responses } \\
\text { - Final UTEP } \\
\text { Comments }\end{array}$ & $\begin{array}{l}\text { Learning to Teach for } \\
\text { Social Justice Beliefs } \\
\text { survey } \\
\text { - Pre-Likert } \\
\text { Responses } \\
\text { - Post-Likert } \\
\text { Responses }\end{array}$ \\
\hline
\end{tabular}




\begin{tabular}{|c|c|c|}
\hline & & $\begin{array}{c}\text { Demographic } \\
\text { Information }\end{array}$ \\
\hline Researcher & Research Journal & \\
\hline
\end{tabular}

\section{Data Collection Procedures}

Approval from the Institutional Review Board (IRB) set the conditions and parameters for conducting the study at the research site. These affected how I collected and analyzed data. In an effort to reflect, note themes, and document interview exchanges, insights, and follow up questions, I kept a research journal (Creswell, 2007; Lewins \& Silver, 2007). I did this to create a space to reflect, question, and challenge my perceptions of the research process (Lincoln \& Guba, 2002). Interviews took place at various locations at the research site and were digitally recorded and later transcribed. To determine which constructs to investigate, I used eclectic coding. According to Saldana (2013), eclectic coding

[e]mploys a purposeful and compatible combination of two or more First Cycle coding methods, with the understanding that analytic memo writing and Second Cycles of recoding will synthesize the variety and number of codes into a more unified scheme. [Furthermore, Saldana states that this form of coding [is] [a]ppropriate for virtually all qualitative studies, but particularly for beginning qualitative researchers learning how to code data and studies with a wide variety of data forms. (pp. 262-263)

These criteria align well with my skill level as a researcher as well as with the data collected.

Below is a timeline that reflects the duration of the data collection procedures and analysis processes for the research study. 
Table 3.3

Timeline of Research Study Activities

\begin{tabular}{|c|c|}
\hline Research Timeline & Relevant Research Activities \\
\hline Late Fall 2014 & $\begin{array}{l}\text { IRB Application for the Research Study submitted and } \\
\text { approval received }\end{array}$ \\
\hline \multirow[t]{5}{*}{ Mid-Winter 2015} & $\begin{array}{l}\text { Initial contact with Dean of Education Department } \\
\text { made for meeting via letter (see Appendix D) }\end{array}$ \\
\hline & Meeting with Dean set up and conducted \\
\hline & Meeting with Associate Dean set up and conducted \\
\hline & $\begin{array}{l}\text { Meeting with Coordinator of Secondary Education set } \\
\text { up and conducted }\end{array}$ \\
\hline & Permission to conduct study at research site received \\
\hline \multirow[t]{3}{*}{ Mid-Spring 2015} & $\begin{array}{l}\text { Email disseminated to secondary teacher educator at the } \\
\text { UTEP }\end{array}$ \\
\hline & $\begin{array}{l}\text { Initial responses received and meetings to discuss } \\
\text { participation set up with UTEP faculty }\end{array}$ \\
\hline & First round of interviews begin \\
\hline \multirow[t]{8}{*}{ Summer 2015} & First round of interviews continues \\
\hline & Recruitment of secondary teacher candidates begins \\
\hline & $\begin{array}{l}\text { Class visits begins and are on-going during this time } \\
\text { until participants are identified }\end{array}$ \\
\hline & $\begin{array}{l}\text { Acceptable number of secondary teacher candidates } \\
\text { identified }\end{array}$ \\
\hline & $\begin{array}{l}\text { Informed consent forms emailed to secondary teacher } \\
\text { candidates }\end{array}$ \\
\hline & Signed informed consent forms received \\
\hline & $\begin{array}{l}\text { Link to first administration of the Learning to Teach for } \\
\text { Social Justice-Beliefs scale emailed to secondary } \\
\text { teacher candidates }\end{array}$ \\
\hline & Audio review of first round interviews begins \\
\hline Research Timeline & Relevant Research Activities \\
\hline \multirow[t]{4}{*}{ Fall 2015} & $\begin{array}{l}\text { Audio review of first round secondary teacher educator } \\
\text { interviews continues }\end{array}$ \\
\hline & $\begin{array}{l}\text { Second round of interviews with secondary teacher } \\
\text { educators begins }\end{array}$ \\
\hline & $\begin{array}{l}\text { Review of secondary teacher candidate open-ended } \\
\text { written responses continues and is completed }\end{array}$ \\
\hline & Transcription of first round interviews begins \\
\hline
\end{tabular}




\begin{tabular}{|c|c|}
\hline & $\begin{array}{l}\text { IRB Application for extension of research } \\
\text { study submitted }\end{array}$ \\
\hline \multirow[t]{6}{*}{ Winter 2016} & $\begin{array}{l}\text { First round interview conducted with secondary teacher } \\
\text { educator conclude }\end{array}$ \\
\hline & $\begin{array}{l}\text { Second round of interviews with secondary teacher } \\
\text { educators continues }\end{array}$ \\
\hline & $\begin{array}{l}\text { Review of secondary teacher candidate open-ended } \\
\text { written responses continues }\end{array}$ \\
\hline & Audio review of second round interviews begins \\
\hline & Transcription of first round interviews continues \\
\hline & IRB Approval for extension of research study received \\
\hline \multirow[t]{3}{*}{ Spring 2016} & Review of transcripts to determine patterns begins \\
\hline & $\begin{array}{l}\text { Second round of secondary teacher candidate } \\
\text { interviews completed }\end{array}$ \\
\hline & Review of open-ended written responses continues \\
\hline \multirow[t]{5}{*}{ Summer 2016} & $\begin{array}{l}\text { Email contact with secondary teacher candidates made } \\
\text { to solicit lesson plans and materials and to participate in } \\
\text { the second administration of the Learning to Teach for } \\
\text { Social Justice-Beliefs scale }\end{array}$ \\
\hline & $\begin{array}{l}\text { Audio review of second round of secondary teacher } \\
\text { educator interviews begins }\end{array}$ \\
\hline & $\begin{array}{l}\text { Notes on second round interviews taken and } \\
\text { transcription begins }\end{array}$ \\
\hline & $\begin{array}{l}\text { Link to second administration of the Learning to Teach } \\
\text { for Social Justice-Beliefs scale sent to secondary } \\
\text { teacher candidates }\end{array}$ \\
\hline & Transcription continues \\
\hline \multirow[t]{7}{*}{ Fall 2016} & $\begin{array}{l}\text { Final administration of the Learning to Teach for Social } \\
\text { Justice-Beliefs scale conducted }\end{array}$ \\
\hline & $\begin{array}{l}\text { Transcription secondary teacher educators' interviews } \\
\text { conclude }\end{array}$ \\
\hline & $\begin{array}{l}\text { The Learning Teach for Social Justice-Beliefs scale } \\
\text { closes }\end{array}$ \\
\hline & Qualitative and Quantitative data clean up begins \\
\hline & Qualitative data review and coding continues \\
\hline & Quantitative Analysis begins \\
\hline & Research study concludes \\
\hline \multirow[t]{2}{*}{ Winter 2017} & Final member checks conducted \\
\hline & Analysis of qualitative and quantitative data continues \\
\hline
\end{tabular}


Writing of the Findings begins

Upon receiving approval for the study, I followed the timeline above that provides an overview of all the relevant activities pertinent to conducting this inquiry. I devoted considerable time to investigating and determining what teacher education programs would be interested in participating in the study as well as identifying and securing participants. Once I successfully completed these important tasks, the research study began with interviews. Once I successfully conducted the first round of interviews, I listened to the digital recordings and took notes on them for the purpose of posing new questions and discerning themes that emerged.

Next, my attention turned to the recruitment of secondary teacher candidate participants. Recruitment of second teacher candidates took approximately 6 weeks to complete and required three visits to participating secondary teacher candidate classrooms where I introduced myself and discussed the purpose of my study and answered questions. I passed around a sign-up sheet and left the room to give students the opportunity to consider their participation. After an acceptable number of participants agreed, I emailed them the Informed Consent Form and asked them to read, sign, scan it and email it to me. After completing this process successfully, I emailed each individual who completed the Informed Consent Form the link to the survey instrument, and they initially were given three week by which to complete it. Periodically over that time, I sent reminder emails to the secondary teacher candidates about completing the survey. Completion of the survey by all 24 participants occurred during the fall of 2015. 
While secondary teacher candidates were taking the first administration of the survey instrument, transcription of the first round of secondary teacher educator interviews began. When the transcription process finished, I began reading the transcripts and creating a code list that reflected the content of the interviews. To assist in this process, I created three questions that guided my work. They were:

1. What interview question am I addressing?

2. How does what the UTEP teacher educator say translate into action?

3. Given the UTEP teacher educators' actions, how do they affect how teaching and preparing the secondary teacher candidates in achieving the UTEP's educational equity and social justice missions, improve readiness, and if there is an association between incorporate culturally responsive pedagogy and teacher candidate readiness?

While this phase of the research study was underway, and I began to read the Likert scale and open-ended responses of the Learning to Teach for Social JusticeBeliefs scale. After all teacher candidates responded electronically, I exported this data to an Excel spreadsheet for further review and ease of analysis. This iterative process continued until I had gathered all the research data. Once collected, I prepared the data for import into SPSS. The preparation required several steps that included sorting and hiding data, identifying reverse items, labeling variables and assigning values, reading and coding qualitative data as well creating syntax to analyze the collected data in a variety of ways and measure change over time associated with the Likert scale data responses. After all these tasks were completed, the final phases of the analysis began. 
Table 3.4 indicates the various data sources, research question each source is associated with, and the stakeholders providing the data.

Table 3.4

Units of Analysis

\begin{tabular}{|c|c|c|c|c|}
\hline Data Sources & RQ & Constructs & $\begin{array}{l}\text { Secondary Level } \\
\text { Teacher } \\
\text { Educators }\end{array}$ & $\begin{array}{l}\text { Secondary } \\
\text { Level } \\
\text { Teacher } \\
\text { Candidates }\end{array}$ \\
\hline \multicolumn{5}{|l|}{ Artifacts } \\
\hline $\begin{array}{l}\text { Syllabi } \\
\text { Curriculum } \\
\text { Materials }\end{array}$ & 1 & $\begin{array}{l}\text { Ed Eq, SJ, } \\
\text { CPR, }\end{array}$ & Multiple & Multiple \\
\hline Assignments & 1 & $\begin{array}{l}\text { Ed Eq, SJ, } \\
\text { CRP }\end{array}$ & Multiple & \\
\hline Interviews & $\begin{array}{l}1,2 \text { and } \\
3\end{array}$ & $\begin{array}{l}\text { Ed Eq, SJ, } \\
\text { CPR, } \\
\text { Readiness }\end{array}$ & $\begin{array}{l}\text { Two 45-60 } \\
\text { minute with } \\
\text { Multiple } \\
\text { Stakeholders } \\
\text { Member Checks }\end{array}$ & None \\
\hline $\begin{array}{l}\text { Demographic data } \\
\text { collected }\end{array}$ & & & Multiple & Multiple \\
\hline \multicolumn{5}{|l|}{ Surveys } \\
\hline $\begin{array}{l}\text { Survey \#1 } \\
\text { Using the LTSJBs } \\
\text { scale participant } \\
\text { demographic data } \\
\text { was collected to } \\
\text { describe the } \\
\text { sample as were } \\
\text { open-ended } \\
\text { responses to } \\
\text { capture STCs' } \\
\text { perception of their } \\
\text { UTEP experience }\end{array}$ & 1,2 and 3 & $\begin{array}{l}\text { Ed Eq, SJ, } \\
\text { CRP, } \\
\text { Readiness }\end{array}$ & & $\begin{array}{l}1 \text { session } \\
\text { with Multiple } \\
\text { Stakeholders } \\
\text { Beginning of } \\
\text { study }\end{array}$ \\
\hline $\begin{array}{l}\text { Survey \#2 } \\
\text { Participant demo- } \\
\text { graphic data }\end{array}$ & 1,2 and 3 & $\begin{array}{l}\text { Readiness, } \\
\text { CRP }\end{array}$ & None & $\begin{array}{l}1 \text { session } \\
\text { with Multiple } \\
\text { Stakeholders }\end{array}$ \\
\hline
\end{tabular}




\begin{tabular}{|l|l|l|l|l|}
\hline $\begin{array}{l}\text { collected to } \\
\text { describe the } \\
\text { sample } \\
\text { Open-end } \\
\text { responses } \\
\text { gathered to } \\
\text { capture STCs } \\
\text { perception of their } \\
\text { preparation } \\
\text { experience }\end{array}$ & & & & $\begin{array}{l}\text { After student } \\
\text { teaching }\end{array}$ \\
\hline
\end{tabular}

\section{Data Analysis Procedures}

The researcher analyzed the qualitative and quantitative data derived from the computer assisted qualitative data analysis software package, Statistical Package for the Social Sciences (SPSS). This software package assisted in analyzing and collecting both data types so that I could interpret and draw conclusions about the data and begin to write the narrative that unfolded.

Qualitative analysis. Once transcription finished for each interview, I read through each secondary teacher educator interviews several times. I performed this process for several purposes. One was to get the general feel for the tenor of the interview. The second reading was to develop questions for my second round of interviews with each secondary teacher educator. The additional readings of the transcripts were to recognize patterns, to assign descriptive codes and categories, to identify themes and to develop codes that would address the research questions for my study. The codes that emerged from STE data shed light on STC data.

I used the same process to code STC open-ended responses. First organizing them into categories, and then assigning codes. These codes served as guides to determining 
how to interpret secondary teacher candidate Likert scale and open-ended responses to the Learning to Teach for Social Justice-Beliefs scale. In analyzing these data, I was able to address the research questions by discerning the extent the constructs under investigation (e.g., CRP, educational equity, readiness and social justice) were a part of the secondary teacher candidates UTEP experience.

I investigated these constructs to identify what practices secondary teacher educators use to accomplish the UTEPs dual mission. These data also determined if secondary teacher educators' beliefs about their UTEP and the practices they used to prepare their candidates were practices that the secondary teacher candidates adopted and made their own. I corroborated practices secondary teacher educators informed me of in their interviews with the open-ended written responses of the teacher candidates before and after they embarked on their student teaching assignments.

Quantitative analysis. Using the statistical package for the social sciences (SPSS), I first established a demographic snapshot of the UTEP's secondary teacher educators and candidates. In addition, SPSS ascertained change over time by comparing before student teacher Likert responses to after student teaching Likert responses by a ttest. For reverse items, I changed the direction of the syntax so that negative scores would have a positive direction indicating STC beliefs were more aligned with disagreement with the item than agreement which would have been the expected outcome.

Triangulation. Performing a t-test allowed for a comparison of secondary teacher candidates' before and after responses to the Learning to Teach for Social Justice-Beliefs scale. The after-student teaching written responses served to corroborate their 
experiences based on their pedagogical practices and beliefs as well as the instruction STCs received throughout the course of their UTEP experience. The pre-and-post survey qualitative and quantitative responses permitted the research study to both qualify and quantify secondary teacher candidate experiences to help understand the role CRP played in preparing secondary teacher candidates for successful work with diverse learners. Determining if there existed a connection between data collected and analyzed from the stakeholders to answer the research questions was the central focus of the study.

Rationale for a mixed methods design. By using both quantitative and quantitative data a more comprehensive picture of secondary teacher candidates' UTEP experience emerged. By including a quantitative phase, the data contributed much to strengthening the study's construct validity and reliability. Finally, the use of both types of data sources enhance the depth and salience of the research study. Combined, they provide a depth of understanding that one source of data alone could not provide (Yin, 2009; Creswell, 2007, 2008; Creswell \& Plano-Clark, 2011; Morgan, 2014).

\section{Summary and Overview}

In explaining my research study, I presented a rationale for the study along with a need the study fulfills. In making a case, I reviewed the literature relevant to this discussion. In addition, I provided guidelines and procedures pertinent to the study's successful implementation along with procedures used to secure consent and protect participants' data and privacy.

Data collected and analyzed provided the most comprehensive and efficient means to investigate and discover how the UTEP being studied accomplished its dual 
mission and what pedagogical strategies it used to do so. Determining the intersection between curricular, co-curricular and instructional content, practices, and application was the goal of this research study. The mixed methods research design offered a valuable tool from which to investigate the research problem.

With these processes in place, this research study investigates how an urban teacher education program supports its secondary teacher candidates to work successfully with diverse learners and to determine if culturally responsive pedagogy plays a role in secondary teacher candidates' instructional practices and readiness. 


\section{Chapter 4-Findings}

\section{Introduction}

The purpose of this research study was three-fold. The first purpose was to learn how an urban teacher education program (UTEP) operationalized its educational equity and social justice missions. The second purpose was to understand how secondary teacher candidates' perceptions of their readiness to work successfully with diverse learners changed over time from the beginning of their teacher education program to its conclusion. The final purpose was to determine to what extent, if any, culturally responsive pedagogy (CRP) influenced secondary teacher candidates' perceptions of their readiness to work with diverse learners.

Implicit in these purposes of this research study are questions. To address these purposes, three questions gathered information that might inform practices to improve learning outcomes for our nation's culturally diverse learners. To engage these questions, I collected various types of data that I believe provide a way forward in improving educational outcomes for our nation's culturally diverse learners.

\section{Discussion of the Findings}

The Findings are organized in the following manner: I restate each research question being addressed and identify the data source that relates to the research question being answered (see Table 4.1). For each research question, I revisit the literature related to the construct being reported. This allows the subsequent finding to be contextualized within the literature in confirming and/or new ways. Finally, I share the findings from the data collected that relates to each research question being explored. It is important to note 
that the findings being shared contain the voices of both the Secondary Teacher

Educators and the Teacher Candidates of the UTEP being studied.

Table 4.1

Research Questions and their Data Sources

\begin{tabular}{|c|c|c|}
\hline Research question & $\begin{array}{l}\text { Quantitative data } \\
\text { sources }\end{array}$ & $\begin{array}{l}\text { Qualitative data } \\
\text { sources }\end{array}$ \\
\hline $\begin{array}{l}\text { 1. How does a UTEP } \\
\text { operationalize its educational } \\
\text { equity and social justice } \\
\text { missions in its efforts to prepare } \\
\text { secondary candidates? }\end{array}$ & & $\begin{array}{l}\text { Teacher educator } \\
\text { interviews \& artifact } \\
\text { review } \\
\text { Teacher candidate } \\
\text { Open-ended survey } \\
\text { responses }\end{array}$ \\
\hline $\begin{array}{l}\text { 2. Upon completing their teacher } \\
\text { preparation, how do secondary } \\
\text { teacher candidates' readiness to } \\
\text { work successfully with diverse } \\
\text { learners change over time from the } \\
\text { beginning to the conclusion of their } \\
\text { field experience? }\end{array}$ & $\begin{array}{l}\text { Teacher candidate } \\
\text { Likert scale item } \\
\text { responses to survey } \\
\text { (Belief } 1)\end{array}$ & $\begin{array}{l}\text { Teacher candidate } \\
\text { Open-ended survey } \\
\text { responses }\end{array}$ \\
\hline $\begin{array}{l}\text { 3. To what extent if any, is } \\
\text { culturally responsive pedagogy } \\
\text { (CRP) associated with secondary } \\
\text { teacher candidates' readiness? }\end{array}$ & $\begin{array}{l}\text { Teacher candidate } \\
\text { Likert scale item } \\
\text { responses to survey } \\
\text { (Beliefs } 1,2,3,4 \text { and } \\
\text { 10) }\end{array}$ & $\begin{array}{l}\text { Teacher educator } \\
\text { interviews \& artifact } \\
\text { review } \\
\text { Teacher candidate } \\
\text { Open-ended survey } \\
\text { responses }\end{array}$ \\
\hline
\end{tabular}




\section{Research Question One}

\section{How does a UTEP operationalize its educational equity and social justice missions in its efforts to prepare secondary candidates?}

The first question looked at the ways that teacher educators approached instruction for educational equity and social justice. This data was collected from the first interview. Before we examine the data, let us revisit the definitions of these terms before turning to answer this question. Briefly, educational equity is concerned with a systematic effort to make sure that learners have the resources they need to achieve academic success (www.educationnw.org); whereas social justice is concerned with people obtaining access to opportunities to live fully actualized existences (Bell, 1997). Thus, it is important to know the many components of a teacher education program to understand which particular components the UTEP priorities as well as how students feel these contribute to improving their ability as teaching professionals. When I asked secondary teacher educators (STEs) about their practices to prepare secondary teacher candidates (STCs), their answers varied.

\section{Secondary Teacher Educator and Teacher Candidate Voices}

Below are response each of the three teacher educators shared about the different ways their instruction intended to impress upon students the role diversity would play in their teaching lives. I offer a summary of their sharing along with quotes from their first interview on this question of operationalizing the UTEP's educational equity and social justice mission. Later, I share what STCs stated were facets of their instructional experience. 
From STE 1, modeling behaviors that educators want teacher candidate to emulate was important as well as engaging in observations of practice and discussion of these with their peers.

STE 1 stated:

You teach them and videotape themselves in class, in schools, and bring this back and we talk about this in class or vice versa. That way we have some microteaching assignments in the classroom that is focusing on culturally responsive teaching.

In addition, this teacher educator raised students' consciousness of who they were as individuals as well as making teacher candidates aware of the varying experiences learners have in and outside of the classroom. STE 1 offered, "We are starting right out from the beginning of helping our students understand what it means to work diverse students coming from our own perspective."

STE 2 discussed the importance of making teacher candidates aware of whose knowledge gets privileged and how that might influence students' self-concept — a key quality that Rubal-Lopez (2004) connects to learner motivation. In addition, STE 2 focused their instruction on drawing from students" "funds of knowledge" and showed STCs that it is possible to transfer what they learn in their teacher education program into the classroom.

On the other hand, STE 3 spoke of cultural responsiveness in aiding teacher candidates in having authentic relationships with students. This STE also mentioned the role of the school placement and the cooperating teacher as important to experience and exposure to the diversity that exists in the urban teaching setting. 
All three of the teacher educators mentioned the pedagogical stances of the UTEP as aligned with the values it endeavored to incorporate in its teacher candidates. These values included the belief that all children can learn; that students in their classrooms are not blank slates, but that learners have "funds of knowledge" from which to draw. Again, all three mentioned co-curricular experiences that allowed teacher candidates to engage with culturally diverse learners in meaningful ways in the schools where they observed and taught as crucial to understanding the urban classroom experience. The video-taping of their teaching along with debriefs with peers appeared to be another required component of the UTEP experience as well as activities that asked students to rethink their perceptions about knowledge, mastery, and learning.

I began with the voices of the secondary teacher educators (STEs) to establish a baseline of their beliefs, intentions and practices. It is in part their responsibility to inculcate in their secondary teacher candidates the dispositions and the instructional strategies that will hopefully improve educational outcomes for diverse learners.

The STEs shared an understanding that emerged and that I heard echoed during my interviews with them. Uniformity in thought and action is not a given in any teacher education program and depending on what questions you ask and who, you will get a different answer. However, STEs did share the attributes they felt were essential to operationalizing the UTEP's dual mission of educational equity and social justice. For STE 1, modeling was a means to impart practices to promote the UTEP mission, but not only that, but also consciousness raising and micro-teaching. For STE 2, it was making STCs aware of whose knowledge gets taught and that all learners bring knowledge to the 
learning experience. Finally, for STE 3, school placement and the cooperating teacher offer STCs the exposure to diversity and the life of a teacher as well as the importance of building authentic caring relationships with learners in their schools and classrooms.

Next, I present the voices of the secondary teacher candidates (STC). Their voices add a depth of understanding and a perspective of their instructional experience in the UTEP. When looking at the qualitative data collected from STCs when describing their UTEP experience, many teacher candidates used terms such as "consciousness raising", "awareness", "self-awareness" and "self-reflection" when discussing the focus of their educational experiences. Of the 19 participants who participated in the study, 10 participants offered pre-survey responses. They are discussed below.

For STCs, the UTEP helped her/him to become self-aware by influencing her/him to "keep an open mind and allow myself to become uncomfortable so that I can grow." Open-mindedness is an important quality of teaching and Dewey (1904) mentions it as an essential element of reflection. If teacher candidates bring pre-conceived notions about students into the classroom, they hold learners to them and limit the growth of their mind. As Dweck (2014) asserts, a growth mindset in learners provides an opportunity for possibility.

In both the pre-and post-open-ended responses to the Learning to Teach for Social Justice-Beliefs scale (see Appendix C), those terms repeatedly emerged. However, what struck me was a sense that many STCs seemed surprised by the educational predicament that exists in our nation's classrooms and the learning environments students are subjected to in in order to receive an education. When it came to issues of access to 
curriculum, materials, and resources and meeting the unique needs of the students in their charge, teacher candidates mentioned terms associated with special populations who have a history of underachievement.

Other teacher candidates mentioned key tenets of culturally responsive pedagogy as the touchstones for being able to insure all students had an opportunity to learn from and teach each other. For this group of secondary teacher candidates, creating a safe learning environment was central to learning. This is what STC 4 offered in their presurvey response to Research Question 1.

STC 4 stated:

I have gained some additional awareness of issues of social justice, but, I was a believer and supporter of social justice before [UTEP] - Prior to the program I did understand systemic racism and did not buy into the myth of meritocracy. I have grown in learning more about how I will support students of color and students with disabilities. Also, I have a better appreciation and understanding of LGBQT issues and the necessity to create safe harbors for students who are forming their identities, whatever they may be. I am more appreciative and respectful of learning more about research-based methods for creating effective engagement with all students. I found that methods have improved since I was educated, and, I am more appreciative of group learning, the role of autonomy in learning, and specific tools for supporting English Language Learners. I recently spent considerable time studying how to close the achievement gap between Hispanics and White students, and Blacks and White students. I appreciate "good" teaching as a learned craft that requires commitment to staying educated about advances in methods and techniques.

There were also teacher candidates who singled out professors whose openheartedness and willingness to share left an imprint on their souls and inspired these future educators to take the challenge of not thinking in deficit terms, but in asking what can I do? Here is what one STC had to say about their UTEP experience. 
STC 11 shared this:

The program has really shown me how important it is, as a future educator, to not assume anything about anyone. I think in the back of all our minds, we know this to be important, but until we're confronted with the extent to which this is applicable with regard to education, that notion is general when it should be paramount.

In this regard, secondary teacher candidates disclosed a number of pedagogical practices they believed would improve outcomes for their students. These practices were derived from STC open-ended responses to the Learning to Teach for Social Justice-Beliefs scale. I open this section of the discussion with another pre-survey open-ended response. STC 3 in their comments makes an eloquent case for a different approach to educating learners:

The first course I took [a foundational course] as part of my teacher education program greatly influenced my beliefs about learning to be a teacher. This course prompted me to critically reflect on issues I had not previously given much thought. Reflecting on one's attitudes and beliefs on issues such as race, class, gender, disabilities, and sexual orientation is essential to becoming a teacher. I believe that as a teacher it is our job to support each student. In order to do this we must be prepared to support students from varying backgrounds.

Accommodations. This term is generally associated with students who have learning and/or physical disabilities. Accommodations provide these learners supports that increase their likelihood of success at given tasks. As such, accommodations are a means of providing students with the tools they need to be successful and would fall under the category of education equity.

Certainly, no one would openly deny these opportunities to an individual with an obvious disability. So why would poverty, homelessness, lack of access to the means to successfully complete learning tasks not qualify for special consideration. Some teacher candidates expressed a belief in the importance of extending accommodations on a case- 
by-case basis to all students who experienced impediments to their ability to succeed at schoolwork due to circumstances beyond their control.

This is an excellent place to begin addressing the educational equity issues schools encounter. Many might see this practice as unfair to expect students who are culturally diverse to meet the same standards as their White middle class peers, especially given the historic inequities that persist in our nation's schools (Darling-Hammond, 2010a; Kozol, 1991, 2005). By giving culturally diverse learners additional support and/or time to complete assigned work, we give them what they most need to be successful - access to resources, opportunity to work at their own pace, and the needed support to complete assigned schoolwork. In addition, doing so de-stigmatizes the notion of accommodations by giving all learners the additional support and attention needed. Many will recognize this as universal design for learning (UDL). Others might see it as a culturally responsive response for learning.

Universal design for learning emerged out of the civil rights movement and the American with Disabilities Act. Its tenets work well within the CRP framework. Its efforts are to reduce barriers to learning whether they be physical, linguistic or sociocultural. Recent research using UDL with English language learners has shown promise (Murphy-Lopes, 2012); their research advocates for its inclusion in the education and preparation of future teachers. Including accommodations and universal design as strategies for instruction creates equity and provides a pathway for diverse learners and all learners to realize their fullest potential in entering mainstream society. 
Education is compulsory in this country. Thus, it makes sense to embrace practices that provide additional support without the stigma that is oftentimes associated with the notion of accommodations. Allowing culturally diverse learners accommodations will give them the space they need to thrive without having to assimilate to expectations of American society's standard and expectations of what all students should be able to do and know.

Providing all students with accommodations has benefits for teachers as well. Setting up assessment that is staggered and flexible permits several deadlines. In addition, accommodations have the potential to reduce the grading load so that teachers have the time to thoughtfully and thoroughly read, comment, question and provide useful feedback for the students in their charge. Thoughtful, meaningful feedback is just as important if not more so for cultural diverse learners because it gives these learners tangible ways to improve their skills as well as offer suggestions for closing knowledge and achievement gaps.

Differentiation. Another means STCs stated that they gained exposure to the notions of educational equity and social justice was through instruction that "asks teachers to continually strive to know and to respond to each students' needs to maximize learning" (excerpt from Robb 2008, https://www.scholastic.com/teachers/articles /teaching-content/what-differentiated-instruction/, para 2). Differentiation is a central tenet of culturally responsive pedagogy. By drawing on the diverse experiences of students, greater breadth and depth of understanding of the material is possible. 
But not only are depth and breadth possible, differentiation also allows for students who are working from a different knowledge base to show what they know instead of being required to work above the level of their skills and understanding. In essence, differentiation is really important "in order to make subjects accessible to a broad spectrum of learners" (STC 16, post-opened survey response).

Culturally responsive practices. These ideas mentioned by both STEs and STC made clear that there is an awareness of and need to meet the unique needs of diverse students. I discuss the pedagogical practices often mentioned below open with a postsurvey open-ended response.

Getting to know one's students. This practice took numerous forms over the course of STCs' preparation program. STC 8 shared their experience in the UTEP regarding the learners encountered in the schools, stating:

The professor did a wonderful job of helping me see people as humans first and foremost. Another professor targeted this well. I've come to really reflect on my own view[s] and try to find ways to treat students equitably and give equal access, without letting habits /opinions/prejudices from my past bias how I treat individuals.

In the beginning field experience, getting to know one's students took the form of observations of the students and cooperating teachers engaged in teaching and learning. These observations served as discussion points in their course work as well as reflection opportunities related to practice. All of these activities were a part of the UTEP's overall goal of developing culturally responsive teaching practices.

Incorporating culturally responsive pedagogy requires the teacher to not only know the student within the classroom, but outside the classroom as well. STC 14 shared 
this about their UTEP experience with this theme, saying, "The program opened my eyes to the kinds of situations my students may be dealing with at home and to never assume anything."

As the field experience continued, getting to know students took on greater importance as these efforts became larger and larger portions of their UTEP experience. In secondary teacher educators' syllabi, it was clear that inculcating an awareness of and a practice in support of culturally diverse learners was paramount. Mini-lessons and lesson plans were opportunities created by the teaching faculty to engage STCs in the process of thinking, planning, instruction and reflection. These required assignments were opportunities for STCs to learn, reflect, and develop the necessary attitudes, dispositions and skills needed in our nation's diverse classrooms. One STE required students to shadow a student in order to "consider all factors that impact the student's connection to the school" (STE 1, syllabus).

Consciousness raising. As mentioned earlier, many secondary teacher candidates seemed surprised by or unaware of the conditions of the secondary educational levels in which they conducted their field experiences. However, this may be due to many secondary teacher candidates' lack of secondary teaching experience. Of the 19 STC over $50 \%$ entered with some kind of teaching experience which was either elementary, postsecondary or private instruction. As a tool, consciousness raising has value, but only if it leads to action.

Therefore, the content of instruction becomes important to changing the life conditions of the oppressed (Gay, 2003; Ladson-Billings 1994). In culturally responsive 
pedagogical terms, critical consciousness refers to how knowledge is used and what knowledge gets privileged. In hearing the voices of STCs, it appeared that discussing and hearing about inequities and their roles in creating an equitable and socially just society were noble aims, but not at the expense of their subject matter. What occurs in the school has an influence on students within and outside of school. How school grapples with new knowledge, policies and legislation directly affects the work of the teacher as well as the lives of the learners and their communities.

In some ways, this understanding of critical consciousness received attention in the UTEP's secondary teacher educators' curriculum choices and assignments that laid the foundation for a greater understanding of the contemporary American classroom. However, though secondary teacher candidates received instruction in this information, many still felt unprepared to handle critical conversations about race and/or felt that the UTEP overemphasized the importance and/or occurrence of engaging in these types of conversations as a part of their pedagogical responsibility. This is what one STC experienced. STC 16 stated, “It didn't really prepare me for HOW they should be addressed in the classroom, just that they should be." Another STCs believed that these conversations were more commonplace than they actually were. This is what STC 14 shared, "I feel the program got it into my head that everyday my students and I would be having conversations about race or inequity so the classes almost seemed . . . not really connected to teaching." One STC was not sure there had been instruction at all, stating, "I don't remember if they did. . Not with actual scenarios." And finally, STC 16 had this to 
share: I don't feel fully prepared, but I feel like I've been given resources and connections to fall back on."

In analyzing the syllabi more closely, it was clear that diversity is a strong focus of the UTEP; however, instructional materials and processes tended to reflect the dominant culture. Only one STE used instructional materials that included the voices of diverse scholars. STC 13 stated that the lack of diversity was ". . . a huge miss."

Self-reflection/self-awareness. An additional tool the UTEP educators used to infuse an understanding of the educational settings the STCs would enter into in their preparation program was self-reflection. As a critical component of culturally responsive pedagogy, self-reflection serves to advance the ideals of social justice and equity (Zeichner, 2009).

A critical component of a teacher's practice, self-reflection encourages and engages teachers in the process of determining what is happening in the classroom and focuses teachers on asking themselves difficult questions about attitudes, dispositions and pedagogical skill. The purpose of the reflective process is to engage in self-critique that will align teachers with the core values of their work, student learning and engagement on the many levels an education is purported to afford them.

For the UTEP STCs, many became aware of their challenges in becoming a teacher. STC 12 stated,

In our [Foundations] class, we reflected and wrote a critical paper examining our own prejudices, privileges, and background and how our past influences who we are today. I examined my childhood and the position I was born into and how this has affected my views on my fellow humans. 
In some cases, this discussion of the ongoing art and practice of teaching occurred in a class on action research or a methods class. However, if self-reflection is to matter, it must be sustained and take on the importance that scholars (Dewey 1904; Freire, 2000; Schon, 1983; Zeichner \& Liston, 1996) envisioned it to be. Self-reflection is a critical component of developing into a reflective practitioner. STC 13 shared this about their UTEP experience as it relates to self-reflection and self-awareness:

I have become much more aware of social issues as they pertain to institutional racism and systemic inequities. Additionally, white privilege and its powerful impact on sustained inequalities has been an issue that has been fully revealed to me. Therefore, I feel this program has helped me reach a subjective and objective understanding of such issues in a way to make me a more effective and fair educator.

The above-mentioned scholars attested to the importance of self-reflection as a life-long process of self-exploration, critique of pedagogical practice and a thorough understanding of the teaching context. By having teacher educators make self-reflection an ongoing process of the UTEP experience, STCs observed their cooperating teachers, observed students interact with teachers, video-taped their own teaching efforts, and got to know at least one student. In addition, STCs were to familiarize themselves with the school's ethos about learning and their roles within these institutions and participate in discussions of their peers' microteaching experiences. These interactions within the secondary institutions and amongst themselves provided opportunities for STCs "to practice being multi-culturally reflective and critically conscious" (Gay \& Kirkland, 2003, p. 185).

These kinds of intentional practices provide the foundation for improving outcomes for our culturally diverse learners (Gay 2003). As Leavell et al. (1999) commented, we cannot expect teachers to do things they have no experience doing. 
Drawing on the work of other scholars who value reflection, Gay (2003) asserts that engagement in these kinds of activities are "an essential part of being reflective practitioners" (p. 185).

At its best, self-reflection normalizes the practice so that it becomes a way of being, thinking and doing by insuring the ongoing process of teacher growth (Dewey, 1904 as cited in Alder, 1990, p.3). In realizing how important self-reflection/selfawareness are to teaching, STC 18 shared this about the UTEP experience: "I learned, by reading articles on ableism, that such a thing exists and that I have participated in it. "Our first class, $[. .$.$] , has caused me to think about my own thinking ...."$

Anti-deficit thinking. Gay (1993) and Ladson-Billings (1994) advocated for the use of CRP as a tool to support teacher education programs. They believed the mission to prepare teachers who could work with all learners required teachers to possess the following skills: critical self-reflection, consciousness raising and the ability to know one's students. These scholars viewed these skills as the pre-requisites for countering deficit thinking towards culturally diverse learners. Having such a mindset could enhance a teacher's capacity, by allowing them to see students as holding promise and finding ways to build on existing schema to construct new learning.

STC 19 shared this about seeing students as holding promise: "So far, the program has taught us that we have to examine our own beliefs and practices strongly on a regular basis to help us best help our students."

For the UTEP's STCs, a focus on equity and social justice throughout the program drove home the need to constantly reflect back on myself so I can grow as an educator and better serve my students. I must reflect on myself personally 
and professionally to be able to respect and teach each student as well as learn from each student. (STC 14, pre-survey open-ended response)

This definitely is an important step in becoming the change agents necessary for the paradigm shift culturally responsive pedagogy and critical race theory call for, but it is clearly not enough.

One does not only have address the self as part of the equation in the teaching and learning process, but also what is being taught and how. As discussed in addressing Question 1, clearly teacher educators engaged in a myriad of activities and strategies to assist their teacher candidates in being able to meet the educational needs of all students. However, much of the success of the UTEP not only relies on the preparation secondary candidates receive, but also on their perceptions of their readiness.

Given their preparation, STCs must be ready to assume their responsibility to meet the academic needs of all learners, but in particular, those who have a history of underachievement. Teachers' actions are not random, but are a result of experiences and/or lack of experience. The discussion now turns to Research Question 2, which addresses teacher candidate readiness.

\section{Research Question Two}

\section{Upon completing their teacher preparation, how do secondary teacher} candidates' readiness to work successfully with diverse learners change over time from the beginning to the conclusion of their field experience?

In addressing Research Question 2, a combination of qualitative and quantitative data is used to explore how teacher candidates assess their programming experience as 
well as the attitudes, beliefs, knowledge, and skills they bring into the UTEP experience. However, I provide a bit of context for how readiness is established.

Modeling. Much of what is involved in learning to teach is modeling the attitudes, behaviors, beliefs, depositions, mindsets, practices and values that will hopefully carry over into teaching practice. There is never a guarantee this will happen, but the more these qualities are displayed and show results, the more likely STCs embrace them. This is no small undertaking since it is a widely held belief that teachers and teacher educators tend to teach to what they know and feel comfortable doing (Melnick \& Zeichner, 1997). As STC 4 so eloquently stated, "There is no middle in the classroom." Students entering classrooms bring with them their histories of life and schooling. There was a belief that teaching to the middle would suffice if you ascribe to learners falling into a bell curve. Today's classroom are far more complex and diverse for the middle to hold.

Asking teacher candidates to try on new ways of being and thinking can be challenging, but it is necessary. Gay and Kirkland (2003) and Thao (class lecture, 2011) emphasize that instruction must be critiqued so that teacher educators and teacher candidates get the benefit of knowing and understanding how to improve their practice and how it meets the expectations for engaging culturally diverse learners in discussions that build knowledge critical to their survival.

In order for this to happen, Gay and Kirkland (2003) contend that teacher education programs must "create learning climates and expectations where self-reflection 
and critical consciousness are part of the routine, normative demands of the [teacher candidates]"' (p. 184).

Here is one STC experience in modeling the behaviors observed and which this STC wants to pass on to their students. Here is STC 8's post-survey response: "I think that having these kinds of difficult conversations in our college classes gave me the experience to be okay being uncomfortable so that I am more willing to go there with students." STC 19 in their post-survey response had this to share about the role of modeling behaviors: "If we openly discuss [issues] with respect and love, we teach our students to do the same." Gay and Kirkland (2003) expand on this notion by affirming the importance of students of teaching knowing what will be expected of them and how "what they are learning will be of use with the students they will teach" (p. 184).

With this information stated in advance as part of the teacher education program's professional expectations, the most effective means of conveying these values was through showing, demonstrating and modeling the practices and processes teacher educators hope to instill in their teacher candidates. By modeling the kinds of thinking, discussion, and engagement teacher educators expect from the teacher candidates, they experience first-hand the impact these types of learning opportunities have on their developing competence as teaching professionals.

STC 11 had this to say about experiencing first-hand the kind of thinking and support necessary for teaching to go well: "My university supervisor gave me guidance on how to talk about cultural appropriation before I had my students read A Raisin in the 
Sun aloud (we were trying to avoid students using stereotypical accents while reading the play)."

As Gay and Kirkland (2003) attest, it is essential for students of teaching "to engage in genuine opportunities to practice being multi-culturally reflective and critically conscious" (p. 185). Gay and Kirkland conclude their discussion by asserting the importance of teacher candidates to "assess the quality of their efforts and continue to improve them" (p. 186). The medium they believe is most effective is "an approach to teaching [that] models techniques that they, in turn, can use with their own students to teach similar skills" (p. 186).

The importance of teacher beliefs about their students' ability to learn is of upmost importance. The attitudes, beliefs, knowledge, and skills teachers possess have a direct impact on learning. For this research study, I assessed these by using teacher candidate qualitative and quantitative data responses to items on the Learning to Teach for Social Justice-Beliefs scale (see Appendix C).

In determining secondary teacher candidate readiness, Belief 1 was chosen as the primary indicator of this construct. Belief 1 asked secondary teacher candidates to identify their position on the following belief: "An important part of learning to be a teacher is examining one's own attitudes and beliefs about race, class, gender, disabilities, and sexual orientation." (Ludlow, et al., 2008)

I selected this belief because of its ability to include the various dimensions of human qualities salient in the teaching and learning relationship. Thus, this belief spoke 
directly to the concerns about a teacher's capacity to participate in pedagogical practices and embrace a mindset that promotes educational equity and social justice.

\section{Belief 1: Statistics and Discussion}

Table 4.2

Paired Sample

Statistics

Mean Std. Deviation Std. Error Mean

\begin{tabular}{|l|l|l|l|l|l|}
\hline Pair 1 & B1aT2 & 4.63 & 0.761 & 0.175 \\
\hline & B1aT1 & 4.84 & 0.375 & 0.086 \\
\hline
\end{tabular}

1) An important part of learning to be a teacher is examining one's own attitudes and beliefs about race, class, gender, disabilities, and sexual orientation.

\begin{tabular}{|l|l|l|l|l|}
\hline 1 & 2 & 3 & 4 & 5 \\
\hline $\begin{array}{l}\text { I Strongly } \\
\text { Disagree }\end{array}$ & I Disagree & Uncertain & I Agree & $\begin{array}{l}\text { I Strongly } \\
\text { Agree }\end{array}$ \\
\hline
\end{tabular}

B1T1. In what ways has your teacher education program influence your beliefs about learning to be a teacher? Please explain.

Belief 1T2 Open-ended follow up question: In what ways did your teacher education program influence your beliefs about learning to be a teacher?

Please explain and provide examples.

Secondary teacher candidates provided their responses to the Learning to Teach for Social Justice-Beliefs scale by using a 5-point Likert scale. The following points were associated with each response:

I Strongly Disagree equals 1; I Disagree equals 2; I am Uncertain equals 3; I Agree equals 4, and I Strongly Agree equals 5. 
T-test scores indicate that STCs' perceptions of their readiness to work with diverse learners moved in a negative direction over time from the beginning to the conclusion of their teacher education program.

The t-test score for Belief 1 was -.211. This score indicated that pre-survey scores leaned more towards agreeing with this statement. However, upon the second administration of the Learning to Teach for Social Justice-Beliefs scale, secondary teacher candidates' value of the importance of this belief changed slightly indicating some change, but not significant change. Both pre- and post-Likert scale responses on Belief 1indicated agreement. The mean on the pre-survey was 4.84 , and the post-survey mean was 4.63 .

In terms of the qualitative data collected, secondary teacher candidates were asked to write their responses to the following question associated with Belief 1: Pre-survey: In what ways has your teacher education program influenced your beliefs about learning to be a teacher?

Post-survey: In what ways did your teacher education program influenced your beliefs about learning to be a teacher?

Secondary teacher candidates' (STCs) responses ranged from a focus on awareness to self-reflection to no response at all. I used both pre-and-post-survey responses to report this data. In the pre-survey opened ended response to Belief 1, STC 1 did not respond to this item; however, this same secondary teacher candidate had this to say upon completing the program, "I think the program revealed the gaps and 
uncertainties for me to then wrestle with personally." In their pre-survey open-ended response, STC 3 had this to say,

The [foundation classes] ... prompted me to critically reflect on issues I had not previously given much thought. Reflecting on one's attitudes and beliefs on issues such as race, class gender, disability and sexual orientation is essential to becoming a teacher.

It is clear from STC 3's response that the UTEP is not only raising awareness, but is also creating opportunities for its secondary teacher candidates to reflect on their attitudes and beliefs about these particular student populations in the hopes of preparing them for these eventual encounters and to improve outcomes. Our nation's classrooms are educating learners whose lives and ways of being intersect across race, language, gender, sexual orientation, religion and class. It is imperative that teachers enter the profession with a deep understanding of the heterogeneity that will be present in their classrooms.

In STC 3's post-survey open-ended response, this is what was stated, "[The program] helped shape my teaching philosophy in that it revealed how schools and society at large perpetuate inequities. Based on that knowledge I am able to create curriculum that is diverse and designed to meet multiple intelligences."

In terms of self-reflection, many secondary teacher candidates spoke to how this new awareness made them think differently about themselves. In STC 18's pre-survey response, this is what was mentioned:

The program has really shown me how important it is, as a future educator, to not assume anything about anyone. I think in the back of all our minds, we know this to be important, but until we're confronted with the extent to which this is applicable with regard to education, that notion is general when it should be paramount.

Again, awareness combined with reflection brings STCs closer to the praxis that will 
quite possibly define their professional careers. STC 18 concluded with this comment, "My teacher education program showed me that there are many parts to being a teacher that I had never considered." This emerging awareness has the potential to crystalize into an appreciation of not only the others in the classroom, but a self-awareness of the otherness the STC will bring into the classroom as well. It is this dynamic which creates the possibility for mutual understanding and support of otherness to become a vehicle for caring, for learning and increased engagement in the classroom so that true inclusion is possible (Gay, 2003, 2010a; Ladson-Billings, 1994). This is the way teacher candidates can begin to disrupt social dominance by creating a learning environment that values each learner and supports the process of learning.

In coming to understand the unique make-up of the urban classroom, it is important to lay a strong foundation for the role of public education. While all STCs have experienced some form of education, there is no uniformity in its delivery, experiences or outcomes. Schools are not created equally. This is especially so for urban public schools. Therefore, it is important that STCs narrow the gaps that may exist in what they know, what they value and what they believe in order to be able to teach and have students learn. STC 19 had this say in their pre-survey open-ended response.

I have gained some additional awareness of issues of social justice, but, I was a believer and supporter of social justice before [the UTEP] - Prior to the program I did understand systemic racism and did not buy into the myth of meritocracy. I have grown in learning more about how I will support students of color and students with disabilities. Also, I have a better appreciation and understanding of LGBQT issues and the necessity to create safe harbors for students who are forming their identities, whatever they may be. I am more appreciative and respectful of learning more about research-based methods for creating effective engagement with all students. I found that methods have improved since I was 
educated, and, I am more appreciative of group learning, the role of autonomy in learning, and specific tools for supporting English Language Learners. I recently spent considerable time studying how to close the achievement gap between Hispanics and White students, and Blacks and White students. I appreciate "good" teaching as a learned craft that requires commitment to staying educated about advances in methods and techniques.

In their post-survey response, STC 19 returned to that which has been woven throughout the research study_reflection. "Reflection! Multiple classes asked teacher candidates to reflect on teaching practices, readings, colleagues or to keep a personal journal." These are clearly desirable teacher traits and when combined with a powerful means of teaching, they become transformative.

Though awareness is important and self-reflection intends to aid in a teacher's growth, collectively they matter only when combined with a way of teaching that utilizes them for the improvement of learning. From a culturally responsive pedagogical stance, awareness is only valuable if you act on emerging consciousness, and self-reflection is operational only when the teacher candidate views their knowledge and skills, as well as those of their students as mutually emerging (Ladson-Billings, 1994).

Dweck (2014), in her TED Talk, calls this "The power of yet." This notion of "not yet" places the teacher and the student on a "path into the future", and is an essential component of a growth mindset perspective. It is from the interplay and intersections within this dynamic relationship between students and teacher that improved educational outcomes for the teacher, diverse learners and all learners are possible. Dewey (1904), as cited in Adler (1990, p. 3) believed that immediate success in the profession limited a teacher's growth overall. 
However, not all the secondary teacher candidates experienced the UTEP in the same ways. For secondary teacher candidate (STC) 16, the experience was slightly different. In their pre-survey open-ended, this is what was expressed:

I have become more aware of my advantages and disadvantages within a stratified social system. I have noticed my own knee jerk prejudices and assumptions that challenge my perceptions and actions around others. I have ultimately realized that teaching is a precious asset and children need teachers who they can trust and relate to, especially youth who are struggling within the system.

This STC not only possesses an awareness of self and others, but also brings this awareness to bear on the system that works not at liberating learners, but at making learners feel that the problem lies within them. In this STC's post-survey response, this was stated, 'It didn't influence my beliefs, but it influenced how I show my beliefs. For example, I've become much more cautious about things I might say or do that may convey some of my beliefs.”

I include this quote to convey the possibility that for some teacher candidates, educational equity and social justice were already apart of their mindset and the UTEP offered this STC a different means of expressing it.

Attention now turns to the role that culturally responsive pedagogy plays in secondary teacher candidates' perceptions of their readiness to work successfully with diverse learners.

In approaching this discussion, I use the voices of secondary teacher educators and candidates drawn from their interviews and pre-and post-survey open-ended responses. In addition, where possible, quantitative data is included as well to paint a 
clearer picture of the factors that influenced these findings when addressing the final research question.

\section{Research Question Three}

\section{To what extent if any, is culturally responsive pedagogy (CRP) associated with secondary teacher candidates' readiness?}

In addressing research question 3 , which is central to secondary teacher candidates' experience when it comes to working with culturally diverse learners, I first look at secondary teacher educators' interview responses and artifacts to understand how instruction, curriculum choices and assessment align with culturally responsive pedagogical practices. Next, I look at secondary teacher candidate data in order to understand the extent to which they acknowledged CPR's relevance in their teaching or discussed any of CRP's central tenets. To understand this, I examine their quantitative and qualitative responses to the Learning to Teach for Social Justice-Beliefs scale by looking at their pre-and-post-survey Likert and open-ended responses.

\section{Secondary Teacher Educator Artifacts}

In analyzing secondary teacher educator artifacts, my main data source are syllabi. The syllabi serve as the contract of expectation for the UTEP's secondary teacher candidates. Though presented in a rather top-down orientation, the syllabi serve as the roadmap to UTEP participants' programs of study. It is important to note that over the course of the UTEP experience, teacher candidates learned pedagogical strategies germane to their subject matter, received instruction from various educators, and performed tasks that addressed specific programmatic and certification requirements. In 
addition, the syllabi presented secondary teacher candidates opportunities to dialogue with teacher educators, secondary students, cooperating teachers, supervisors and amongst themselves.

To make sense of their role as teachers and understand the magnitude and responsibility of that role, secondary teacher candidates engaged in fieldwork early in their UTEP experience. This fieldwork was instrumental to understanding a teacher's life and work. Thus, this opportunity in its various forms of observation, practice, and reflection connected the UTEP curriculum and classroom coursework and overall program vision: "to prepare teachers to meet the unique needs of students and communities in which they serve" (UTEP, syllabi). With this notion in mind, I looked at syllabi from three different lenses to see how the documents as written might go about connecting the UTEP's curriculum, coursework, and core vision.

First, I look at the role observation played to ascertain how this practice aligns with culturally responsive pedagogical practice. Then, I examine assigned coursework and its intent in preparing teacher candidates to build expertise in practice in terms of creating and delivering instruction and professionalism to meet the unique needs of diverse learners. I conclude my discussion of secondary teacher educator artifacts by looking at the role of reflection.

What a teacher education program includes in its curriculum and instructional agenda has a purpose. Course syllabi are a reflection of that purpose. Realizing that purpose connects naturally to what curriculum teacher candidates are exposed and are not exposed to. In addition, what experiences and dispositions they bring to the teacher 
education program greatly influences their willingness to embrace the philosophical stance the UTEP promotes. Finally, the degree to which teacher candidates are willing to change their thinking about working with culturally diverse learners makes all the difference.

Each of these constructs plays an important role in whether or not the UTEP, the secondary teacher educators and candidates fulfill their obligation to meet the educational needs of future learners and the communities in which these learners live and secondary teacher candidates serve.

\section{Tools for Learning}

Observation as a tool for learning. As a tool for learning, observation serves many purposes. It can serve a practical purpose of initiating the teacher candidate into the role and world of a teacher. It can serve as a blueprint for one's own practice. It can be a means of self-discovery about one's own teaching beliefs. In this way, observation serves the secondary teacher candidate in developing potential practices or tools and dispositions to incorporate in their future instructional development. According to STE 1 observation serves to "[d] eepen an understanding of proficiency in the 5 skills [of the content area]".

This is an admirable outcome but for observation to have greater value, it must look at the influence instruction has on its learners. To do less is to miss an important role of observation, learning. When we turn our gaze away from the teacher, we get a better sense of the learner's experience. How this is usually determined is by student engagement. However, to understand the relationship observation has on engagement, 
there are some enduring questions that need consideration. Does one's practice create a sustained environment that promotes positive outcomes? Do practices address the unique needs of students? How does practice position the teacher? Answers to these questions served as a baseline for determining the likely incorporation of culturally responsive pedagogy. In terms of engagement and incorporation of culturally responsive pedagogy, STE 3 viewed observation as an opportunity to "[a]ppreciate learners as individuals with diverse personal and family backgrounds and unique skills, abilities [and] perspectives."

The immersion in fieldwork served as a means of learning through multiple ways. Next, the nature of practice as explicitly included in their preparation is addressed. Both observation and practice are forms of secondary teacher candidate engagement that introduced secondary teacher candidates evermore deeply to the complex nature of teaching and learning.

Practice as a tool for learning. Every component of the UTEP has a purpose. That purpose is the intentional preparation of students of teaching to work in urban schools whose student population is diverse in a multitude of ways. Based on the syllabi I analyzed, these two modes reflected this intentionality; they are microteaching and the professional dispositions essential to learning how to teach. These are discussed below. Professional dispositions. This term speaks to what Dewey (1904) calls a "way of being as a teacher" (as cited in Zeichner \& Liston, 1996, p. 9). According to Dewey, teachers who possess professional dispositions embrace their practice with openmindedness. Open-mindedness, according to Dewey (1904), refers in part to “. . . the confrontation of different beliefs" (as cited in Zeichner and Liston, 1996, p.10). Whereas 
a sense of responsibility, according to Dewey (1904), refers to "the consideration of the consequences to which an action leads which could be personal, academic, social and political"' (as cited in Zeichner and Liston, 1996, p. 10). These are Dewey's central tenets of reflective teaching. When combined, they lead to wholeheartedness and are "central to the prolific life of a reflective teacher" (as cited in Zeichner \& Liston, 1996, p. 10).

These qualities were present in obvious and hidden ways. As a component of secondary teacher candidate coursework, secondary teacher educators modeled and engaged in practices that promoted these qualities. Their syllabi reflected a willingness to work collaboratively with students of teaching, impressing upon them the need to negotiate, to be flexible, and a readiness and willingness to meet the unique needs of each teacher candidate. STEs emphasized the importance of professionalism in all syllabi I analyzed as a key concept to becoming and developing as a teacher. Not only was it stressed, but it was also a graded component of each class syllabus analyzed with qualities such as "integrity, punctuality, preparedness, respect and attendance" highlighted as exemplars of professionalism" (UTEP, syllabi).

Microteaching. A teacher education program is incomplete without the opportunity for students of teaching to gain experience in inhabiting the world of a teacher. Microteaching opportunities allowed for that kind of engagement. Creating and delivering instruction in a low stakes situation, microteaching is an iterative process of observing peers and one's self in the teaching and learning process as well as situating the self in the role of cooperating teacher to assist peer secondary teacher candidates in becoming and developing as teachers. 
Providing their peers with feedback afforded secondary teacher candidates the opportunity to think critically about the instruction delivered in ways that engaged students, or as STE 1 called it, "the hook". From there, secondary teacher candidates had the opportunity to view their instruction from the learners' perspectives. Watching one's self teach is crucial to understanding one's beliefs as exhibited in practice. This is a new view of instruction, which gives way to the potential for changing or maintaining practices. An additional benefit of microteaching is its capacity to raise questions not considered under other circumstances. These questions may serve to re-evaluate the benefit of the use of activities and/or materials, or to re-assert beliefs in the relevance or appropriateness of an activity or material used in instruction or better yet, to question the appropriateness of the subject under construction.

Construction is used intentionally here. It is done so to remind the reader of one of the central tenets of culturally responsive pedagogy_ building on the background knowledge of the learners. When the teacher allows for voices of learners to be heard, the potential for greater understanding of student schema/background knowledge arises that can make learning accessible and inclusive. But perhaps more importantly, microteaching gives secondary teacher candidates the opportunity to grapple with their practice in situations where given the right environment and support, secondary teacher candidates can grow.

Of the three STEs only one syllabus had the requirement of micro-teaching. For STE 2, micro-teaching served multiple purposes. In one instance it was used to "[i]dentify, discuss and evaluate trends in teaching the subject area to middle and high 
school students." In another instance micro-teaching was used to [d]evelop assessment plans and instructional plans based on assessment that incorporates instructional strategies that promote differentiation and the learning of the content area." And finally, a purpose of micro-teaching was to [c]ollaboratively develop and teach a lesson that focuses on student engagement and learning." This is an example of the iterative nature of micro-teaching in the development of teacher candidates.

Placement. As Leavell et al. (1999) assert we cannot expect teachers to be able to do something with which they have no experience. Therefore, where the UTEP placed its secondary teacher candidates in order to complete the student teaching requirement matters. It mattered for the practical purpose of fulfilling a programmatic and certification requirement, but also as an experience in a setting that would mirror that of an authentic urban teaching experience. Authentic exposure is the most essential component a UTEP can offer its teacher candidates.

Placement is important because its variety gives teacher candidates exposure to different schools, students, and school cultures that in the future will serve them well. If they embrace their roles wholeheartedly, they may come to view their work as incremental growth much like the work they engage in with their culturally diverse learners. I do not mean to imply that wholeheartedness is the solution to the issues involved with teaching, but it does have the transformative potential for placing secondary teacher candidates and culturally diverse learners in a mutually beneficial relationship, which is crucial to teaching and learning. 
Student teaching. A sustained engagement in the teaching and learning process is essential if secondary teacher candidates are to enter the profession with the basic dispositions, knowledge and skills to teach. I believe it is in this arena that the UTEP has it greatest potential for the most positive effect. Thus, where secondary teacher candidates conduct their student teaching is extremely important.

Student teaching was the culminating event of the teacher preparation program, and for the secondary teacher candidates, it was an opportunity to put into practice the lessons learned, activities performed, observations made, and the dispositions developed or honed over the course of their UTEP experience. It is in practice that questions arise, that situations occur for which one is unfamiliar, where doubt rises, and confidence wanes.

Consequently, student teaching is the location where all teachers decide their professional futures, or where their professional futures get decided. As such, it required the combined support of cooperating teachers, supervisors, advisors and peers to maintain one's passion for the profession. To remain in the profession, secondary teacher candidates through their courses and practice must view themselves as novices mentored and supported by all engaged in the art of becoming to be a teacher. This evolves over time and materializes through the practice of reflection.

Self-reflection as a tool for learning. According to Zeichner and Liston (1996), reflective teaching does the following:

[It] examines, frames and attempts to solve the dilemmas of classroom practice; is aware of and questions the assumptions and values he or she brings to teaching; is attentive to the institutional and cultural contexts in which he or she teaches; takes 
part in curriculum development and is involved in school change efforts and takes responsibility for his or her own professional development. (p. 6)

In order for the professional outcomes for the secondary teacher candidate to materialize, most practitioners believe that reflection must be an ongoing component of one's professional development and practice (Dewey, 1904; Gay and Kirkland, 2003; STE 1, 2015). Of the many components Zeichner and Liston state are important, the one that is central in the education of diverse learners is teachers having an "aware[ness] of and question[ing of] the assumptions and values he or she brings to teaching" (p.6). Lenski et al., (2005) citing Cochran-Smith's (1995) work, stated “Only through . . . reflective analysis of their own beliefs and systematic inquiry into diverse cultures can preservice teachers and teacher educators begin to construct a pedagogy that makes diversity an explicit part of the curriculum" (p. 85).

What is even more important to note is the role of the teacher educator. For the UTEP secondary teacher educators who participated in this study, reflection played an important role in developing secondary teacher candidates' competence and confidence to work with diverse learners. It was their influence and how they framed their own practice that mattered most in the degree to which the need for educational equity and social justice was infused into the entire teacher education program and in every instance that preparation instruction occurred. One would expect this focus since reflection was one of the key dispositions teacher candidates expected to learn and practice as a component of their UTEP experience.

I now turn to interview data to examine how inclusion of self-reflection materialized in curriculum instruction. I share what each second teacher educators' 
comments were about their practices and the outcomes they hoped for in the UTEP's secondary teacher candidates. I begin with a discussion of interview data from STE 1 and follow with the data for STE 2 and STE 3.

\section{Secondary Teacher Educators' Voices}

The voices of secondary teacher educators were key to understanding the role CRP plays in readying secondary teacher candidates (STC) for their roles and responsibilities as teachers as well as their perceptions of their readiness to enter diverse classrooms.

Secondary teacher educator 1 (STE 1). For STE 1, self-reflection was a key component in the grading criteria and activities teacher candidates engaged in for the syllabi I analyzed. Quoting STE 1, "We are starting right out from the beginning [in] helping our students to understand what it means to work with diverse students from our own perspective". In raising secondary teacher candidates' self-awareness about working with diverse learners, they can begin to see that they indeed bring certain attitudes, beliefs, and dispositions into the classroom.

Self-awareness/reflection. Who we are is a critical component in moving toward what Gay and Kirkland (2003) call critical consciousness and self-reflection. They claim, amongst other things that, "teachers need to develop deeper knowledge and consciousness about what is to be taught, how and to whom" (p.181). Continuing, they draw on the work of other scholars who also affirmed the importance of "teachers knowing who they are as people, understanding the context in which they teach, and questioning their knowledge and assumptions are as important as mastery of techniques 
for instructional effectiveness" (p. 181). Given the high stakes, STE 1 asserted, "Then going from there, how [does] our diversity impacts us as a teacher?” This question raises an additional layer of complexity that highlights the role culture plays in the teaching and learning relationship.

Not developing these important teaching traits over the course of their teacher education program experience leaves teacher candidates with the only knowledge they know - their own experiences in school. Unfortunately, these are not a reflection of the current make-up of the American classroom. Without knowledge and skills, secondary teacher candidates may create and experience obstacles to being able to reach and teach to the diversity learners bring into the classroom.

Thus, according to STE 1,

Therefore, if they look at [who they are] first, and understand what their own culture is and how their culture affects them as a learner, they understand how it helps them as a teacher as well. Then going from there, looking into who are other people, other in the sense of the people around them, and seeing them as persons, not necessarily putting labels on people, but the person has a background and paying attention to who this person is and why is this specific person the person [she or he] is.

As mentioned earlier, teacher educators have their own ways of being when it concerns their work with diverse learners. Thus, it may be difficult for them to convey the importance of these issues; therefore, there are many ways for the UTEP to accomplish its goal of preparing teacher candidates to be effective with diverse student populations.

For STE 1, self-reflective practices take on many forms. Self-reflection can take place after classes to look at what occurred during instruction to determine where improvement can happen. Another way is to "relinquish control of what students learn 
and how." This lets the teacher draw on the knowledge she or he possesses about the students and their interests to make instruction meaningful and relevant to their lives.

Moreover, STE 1 believes that it is not enough to reflect on the classes you teach, but who one is as a teacher is equally important. Continuing, STE 1 stated that

[T] here is a lot of reflection going on .... who you are right now as a teacher and as a person .... They are basically tired at the end of the program of being reflective and writing another reflective [essay], but those reflections should become the habit of our students.

For STE 1, this reflective mindset played a central role in group and peer-to-peer interactions as well as in activities and assignments teacher candidates participated in. The goal of all of the various forms of self-reflection from STE 1's perspective is: "to raise awareness of teacher candidates having a culture; to display caring; and to create opportunities for all learners."

Secondary teacher educator 2 (STE 2). For STE 2, self-reflection was not as prevalent a feature in one class syllabus I analyzed, but for another it was. Reflection was an instructional tool employed to learn about content and to make it inclusive. By stating this, there is no implication that learning to be a teacher and learning to teach content are separate entities. In many ways and to a certain degree, one's content dictates practices, but it should not determine how teachers engage with their students.

According to STE 2, the real purpose of self-reflective action and teaching is to improve at one's practices of inclusion, classroom engagement, and teacher-student interactions through the lens of privilege and intersectionality. "I am interpreting reflection as looking inward. [Teacher candidates] think they need to look outward"' (STE 2, 2016). 
Reflective writing. Engagement in reflective writing were opportunities for the teacher educator to relinquish control of what teacher candidates learn (STE 1, Brouwer and Korthagen, 2005). STE 2's syllabus stated it this way: "to find something that intrigues you, interests you, compels you and then write about it. Consider how it inspires your own teaching and write about it or about connections to past experiences as a student ...."Allowing teacher candidates more control of their questions and their interests is a powerful tool of inclusion, engagement, and classroom interactions. According Brouwer and Korthagen (2005) in their longitudinal study of teacher occupational socialization, these kinds of activities are essential to teachers' developing competence.

In sharing these reflections with teacher educators and peers in their classrooms, supervisors, and cooperating teachers, secondary teacher candidates are made aware of “other people's stories and understanding other people's journeys and their struggles and then reading the theory" (STE 2). Brouwer and Korthagen (2005) claim that this practiceto-theory approach has value as a tool for stabilizing teaching competence.

For STE 2, the practices that teacher candidates engaged in during their teacher education program were extremely important. For this educator,

[T]hey should provide a non-dominant cultural perspective and an understanding of how different cultures navigate education. In addition, teacher candidates need opportunities to push back to show that all content has a cultural component and to inform of the bias in curriculum delivery and content for greater awareness and transformation is the outcome.

At the heart of this teacher educator's practice is critique of educational givens that continue to view people who are other as less than and/or incapable. For this teacher 
educator, self-reflection is not about "navel gazing," but transformation.

Secondary teacher educator 3 (STE 3). Although STE 3 did not speak directly about reflection in the interview, there exists an ongoing dialogue between what the STCs observed and engaged in. This dialogue addressed instances of observation, practice, and questions that arose in the field placement experience. In this way, the classroom became a laboratory much like any approach taken to examine and understand the nature of the dynamics of instruction on the acquisition of knowledge.

Reflection. When the context and the learner enter the equation, a dynamism emerges that requires teachers to engage in what Schon (1983) calls reflection in-action and reflection on-action. By guiding teacher candidates through this process of reflection and deconstructing an experience, many options become available to the teacher candidate for use in furthering their knowledge and skills by examining thinking, and sharing their understanding or perspective of a situation.

Given the opportunity to hear and understand different perspectives gave teacher candidates the awareness and the capacity to consider many approaches and answers, not just one. This approach, though different from what one usually considers reflective practice, aligned itself with a number of ways to learn and develop as a teaching professional and centered ones teaching on promoting equity and social justice. Zeichner (2009) contends that a central quality of reflection is just that, promoting equity and social justice. However, how this shows itself in the classroom is equally important.

Drawing on the work of Villegas and Lucas (2002a), Zeichner (2009) contends that reflection is key because it offers teacher candidates a space to look at what they 
know about educational processes in order to create an environment where students' culture is a basis for constructing and deepening knowledge. Not only that, it also requires of teachers to take responsibility for "bringing about educational change that will make schools responsive to all students" (p. 26).

\section{Secondary Teacher Preparation and the Role of Culturally Responsive Pedagogy}

Secondary Teacher Candidates' Voices. In attempting to answer RQ 3, I delve into the role culturally responsive pedagogy played in secondary teacher candidates' (STCs) perceptions of their readiness to work with culturally diverse learners, using their voices to gain knowledge of their experience and to make sense of its impact on their developing competence.

Though a belief-by-belief treatment of this data might seem an appropriate approach to analyzing it, the qualitative analysis looks at the Beliefs that best align themselves with the issues relevant to the classroom experience-diversity and race. Using pre-and-post-open-ended responses to the Learning to Teach for Social JusticeBeliefs scale (see Appendix C), I chose qualitative and quantitative data from Beliefs 1, 2, 3, 4 and 10 as the information most relevant to addressing RQ3: To what extent if any, is culturally responsive pedagogy (CRP) associated with secondary teacher candidates' readiness?

In addressing this question, I take each Belief individually, pulling together the qualitative data that directly speaks to this research question. Only the data from the 19 participants who completed both the pre-and-post surveys are considered. I discuss the 
five beliefs that speak to this research question and attempt to shed light on the secondary teacher candidates' perception of their readiness.

The data included in the table below shows the mean scores for all 19 participants who completed both administrations of the Learning to Teach for Social Justice-Beliefs (LTSJ-Bs) scale. Beliefs 1, 2, and 4 are standard items whereas Beliefs 3 and 10 are reverse items. It is expected that standard items will be easier for participants to agree with, while participants will find reverse items more difficult to embrace.

Reading the Beliefs as they are presented will aid in understanding the statistics involved as well as the interpretation of the intention of the Belief analyzed. T1 refers to the pre-teaching administration of the LTSJ-Bs scale, and T2 refers to the post-teaching administration. As the means data indicate, the first administration by the 19 participants had a higher mean than the second administration. Though the decrease is not significant, it is interesting to note.

Table 4.3

\begin{tabular}{|c|c|c|c|c|}
\hline \multicolumn{2}{|c|}{ Paired Samples Statistics } & Mean & $\begin{array}{c}\text { Std. } \\
\text { Deviation }\end{array}$ & $\begin{array}{l}\text { Std. Error } \\
\text { Mean }\end{array}$ \\
\hline \multirow{2}{*}{ Pair 1} & B1aT2 & 4.63 & 0.761 & 0.175 \\
\hline & B1aT1 & 4.84 & 0.375 & 0.086 \\
\hline \multirow[t]{2}{*}{ Pair 2} & B2aT2 & 4.58 & 0.507 & 0.116 \\
\hline & B2aT1 & 4.42 & 0.961 & 0.221 \\
\hline \multirow[t]{2}{*}{ Pair 3} & B3aT2R & 1.68 & 1.057 & 0.242 \\
\hline & B3aT1R & 1.63 & 1.065 & 0.244 \\
\hline \multirow[t]{2}{*}{ Pair 4} & B4aT2 & 4.63 & 0.955 & 0.219 \\
\hline & B4aT1 & 4.47 & 0.964 & 0.221 \\
\hline \multirow[t]{2}{*}{ Pair 10} & B10aT2R & 2.37 & 1.012 & 0.232 \\
\hline & B10aT1R & 1.89 & 0.937 & 0.215 \\
\hline
\end{tabular}




\section{Belief 1: Statistics and Discussion}

Table 4.4

Paired Sample Statistics

Mean Std. Deviation Std. Error Mean

\begin{tabular}{|c|c|c|c|c|}
\hline \multirow[t]{2}{*}{ Pair } & B1aT2 & 4.63 & 0.761 & 0.175 \\
\hline & B1aT1 & 4.84 & 75 & 0.086 \\
\hline
\end{tabular}

1) An important part of learning to be a teacher is examining one's own attitudes and beliefs about race, class, gender, disabilities, and sexual orientation.

\begin{tabular}{|l|l|l|l|l|}
\hline 1 & 2 & 3 & 4 & 5 \\
\hline $\begin{array}{l}\text { I Strongly } \\
\text { Disagree }\end{array}$ & I Disagree & Uncertain & I Agree & $\begin{array}{l}\text { I Strongly } \\
\text { Agree }\end{array}$ \\
\hline
\end{tabular}

B1T1. In what ways has your teacher education program influence your beliefs about learning to be a teacher? Please explain.

Belief 1T2 Open-ended follow up question: In what ways did your teacher education program influence your beliefs about learning to be a teacher? Please explain and provide examples.

Only the data I deemed relevant to answering this question and addressed in some way the tenets of culturally responsive pedagogy were included in the discussion.

Awareness and self-awareness. These themes wove their way throughout the pre-and-post open-ended responses. In STC 12 pre-survey response, this comment emerged:

I learned, by reading articles on ableism, that such a thing exists and that I have participated in it. Our first class, [. . . ] has caused me to think about my own thinking with regard to the issues you mention here. 
The issues to which this STC referred to have to do with race, class, disabilities, and sexual orientation. As has been previously mentioned, knowing who learners are and how they experience the world is important to including them in the world of learning. Valuing learners and their cultures makes for greater classroom engagement, mutual cultural exchange and an increase in general knowledge and understanding. For the learners in today's classroom, there is potential to travel and understand the world without leaving the country. Cultural exchange in the classroom has the potential to bring us closer on so many different levels.

This sentiment is expressed in STC 12's post-survey comment:

[The equity] class seriously altered my view on the world and really made me reflect on my own life and how my experiences have formed my current beliefs. Being able to recognize this in myself is paramount. Furthermore, it helps me understand that my students come with their own previous experiences and beliefs.

From this passage, it is clear that this student's awareness of issues affecting learning changed because of the UTEP experience. The benefits are greater awareness and a better sense of how the self transforms in light of experience. This awareness is a tremendous move toward empathetic understanding. This understanding has the potential to give rise to the key elements of a teacher's developing competence. According Zeichner and Liston (1996), these elements derive from Dewey's key tenets of reflective teaching: openheartedness, responsibility, and wholeheartedness. These dispositions make possible teachers' growth/development as teaching professionals.

No all STCs are alike. STC 16's pre-survey open-ended response spoke to that difference. "I wouldn't say that it has influenced much. It definitely has informed me how 
to go about addressing difficult topics. I've always been very passionate about equity." It is important to point out that some STCs entered the UTEP with teaching experience and may have had exposure to some of the topics addressed in this particular belief related to race, class, disability and sexual orientation. What is important to note is the STC's acknowledgement of how to address these topics from an instruction or discussion point of reference.

In the post-survey response, this is what STC 16 shared about their UTEP experience. "It didn’t influence my beliefs, but it influenced how I show my beliefs. For example, I've become much more cautious about things I might say or do that may convey some of my beliefs." This kind of commitment to awareness and being self-aware can bring about educational experiences that meet the unique needs of all learners by not seeing them in deficit terms, but as experiencing difficult life circumstances.

As STC 15 stated: "This program helped me understand how prevalent inequity is and how big a problem it truly is." Awareness is a good start, but as STC 4 concedes, one must appreciate "good teaching as a learned craft that requires commitment to staying educated about advances in methods and techniques."

The circumstances and conditions inherent in teaching demand that teachers remain committed to their own growth and their learners' growth. This commitment allows for awareness and self-awareness to galvanize into action. Thus, action has the potential to change the educational experiences and outcomes for our nation's growing population of diverse learners and all learners. 
As STC 19 asserted,

As teachers, we teach our student through of actions and our attitudes more than anything else. Through classes [that dealt with issues of social justice], we took a long hard look at ourselves, our schools, and the world around us.

Finally, STC 4 had this to share:

When I got to the classroom, I was amazed by the diversity of proficiency among learners. There is no middle ground in a classroom. The experience reinforced that it is really important to differentiate in order to make subjects accessible to a broad spectrum of learners.

\section{Belief 2: Statistic and Discussion}

Table 4.5

Paired Samples Statistics

Mean Std. Deviation Std. Error Mean

\begin{tabular}{cc|c|c|c|}
\hline Pair 2 & B2aT2 & 4.58 & 0.507 & 0.116 \\
\hline & B2aT1 & 4.42 & 0.961 & 0.221
\end{tabular}

2) Issues related to racism and inequity should be openly discussed in the classroom.

\begin{tabular}{|l|l|l|l|l|}
\hline 1 & 2 & 3 & 4 & 5 \\
\hline $\begin{array}{l}\text { I Strongly } \\
\text { Disagree }\end{array}$ & I Disagree & Uncertain & I Agree & $\begin{array}{l}\text { I Strongly } \\
\text { Agree }\end{array}$ \\
\hline
\end{tabular}

B2T1. In what ways has your teacher education program prepared you to address these issues in the classroom? Please explain.

Belief 2T2. Open-ended follow up question: How did your teacher education program prepare you to address these issues [Race and Racism] in the classroom? Please explain and provide examples.

For Belief 2, participant means scores were higher, though not significantly. This increase in the second administration could be due in part to the developing awareness of 
race as a factor in the schooling experience. As both CRP and CRT contend, we cannot improve educational outcomes for diverse learners until we are willing to openly acknowledge race as a factor in educational outcomes for these learners. That secondary teacher candidates acknowledge race affirms the fact that racism is indeed a feature engrained in the educational experience of culturally diverse learners in our society.

Acknowledgement and awareness of race as an educational factor. The discussion begins with a scenario shared by STC 8, "Both classes I've taken so far [have] addressed oppression in the classroom, including racist oppression. I feel informed but not prepared to take action on these issues." At the end of STC 8's UTEP experience their comments changed.

I think that having these kinds of difficult conversations in our college classes gave me the experience to be okay being uncomfortable so that I am more willing to go there with my students. For example, a student of mine had a cartoon drawn on the back of their sheet music that was the 'island of races' filled with stereotypes. . . . I felt very strongly about removing it and talking with the student about why it wasn't appropriate and how they felt about it being [B]lack and Latino students, instead of just quietly throwing it away or letting it slide.

This is exactly what most teachers would not have done. Race is a topic that most people are uncomfortable talking about in education. However, if we are to move towards an equitable and socially just society, it is important to speak to the ways that race serves to marginalize people of diverse backgrounds.

This is what STC 13 had to say about how the UTEP prepared them for handling issues of race and racism. It prepared me "[b]y having open and frank discussions about these issues and showing how they have real world implications in our everyday environments." However, in their post-survey response, STC 13 expressed a 
disconnection between what they felt was an important, yet missing component of the program.

Again, the [introductory course] was the primary preparation I had for these issues. Though at times, I struggled with the information because the faculty was not diverse. So issues were often delivered through articles and other secondary sources rather than shared directly from the person or a primary source. This was a huge miss!

Though this situation is untenable, we must endeavor to ensure that teachers are prepared to assume their roles as mentors, teachers and partners with the students and communities in which they serve. Realizing this goal requires that teachers are ready to navigate some difficult encounters, but they also need to engage with educators who possess authentic knowledge and experience which can inform their practice.

As STC 14 stated in their pre-survey response,

Thus far, [m]y education has given me tools to stay respectful and calm in situations that may arise in the classroom that have to do with racism and inequity. These situations are very difficult to discuss which is why they need to be addressed earlier in school to young minds so they can begin to understand these issues before they are expected to make a difference about them in the world.

This is exactly one of the purposes of a teacher education program and is implicitly implied as a value of the UTEP. In their post-survey response, STC 14 shared this:

Again the program opened me to different inequities in our culture I was previously un-aware of. I feel like it is good to be able to discuss these things openly, it is not like you do this in every class. . . The skills to discuss these things are necessary and important, but this will not be the bulk of your teaching.

STC 6 made an extremely important point and added, "While we are just starting our program, I know that there is more than one class focused on beginning our journey 
already thinking about issues that will affect our teaching and our personal lives." In their post-survey response, STC 6 shared this critique of the yearlong program in this way:

[Two professors] have both demonstrated how a teacher provides culturally relevant inclusive instruction. They both pushed for and have been the genesis of true deep reflection on who I am as a person and also as a student. This will influence my teaching for years to come.

Providing STCs with instruction that aids in preparing them for their roles as teachers is the goal of a teacher education program. However, STCs do not all have the same experience. STC 7 shared this about the UTEP experience:

In the summer and fall quarters we learned about culturally responsive teaching. In the fall through spring during our field placement, many experienced culturally diverse classrooms. However, there was a lack of continuity of deep, thoughtfully equity training throughout the year to connect the theory with practice of equitable instruction and assessment.

Here is what STC 15 had to say in their pre-survey response:

I am only beginning the process of becoming a teacher. However, I've been introduced through classwork, discussions, reading, etc. to a wealth of ideas and experiences. I've gained fresh insight and had frank and helpful conversations. At this point, the discussions have been largely about seeing how racism and other "isms" can be present all around, yet we might be totally unaware of it. By drawing attention to it, we can discuss and acknowledge. I think in the future we will delve into those experiences within the classroom environment. At this point, it hasn't necessarily been tied to the classroom, but rather trying to explain the perspectives and inequality that we face without realizing it.

In their post-survey response, STC 15 had this to say, "Racial inequity—especially—was a central part of every class and almost every conversation." In STC 17's pre-survey response, this is what they stated, "I have been introduced to a new understanding of the depths of racism."

The acknowledgement of the exist of racism and the scope of its impact on the educational of experience of culturally diverse learners is an important connection to the 
teacher candidates' understanding of the important role they can play as change agents or maintaining the status quo. In STC 17's post-survey response, ones gets a glimpse of how these understandings were made apparent.

I feel the program prepared me to scaffold the topics of race and inequity in order to create a safe and enduring environment in which to have open discussions. I was given resources to use in class that help prepare students (and potential colleagues) to accept discomfort and respectfully respond to diverse perspectives.

Finally, STC 3 stated this in their pre-survey response:

[The foundation class] prompted me to critically reflect on issues I had not previously given much thought. Reflecting on one's attitudes and beliefs on issues such as race, class, gender, disability and sexual orientation is essential to becoming a teacher.

All these disparate voices have one thing in common. It is the desire to develop the dispositions, skills and knowledge to be effective teachers of diverse learners and all learners. Grappling with one's self-concept in light of new understandings and awareness provides the opportunity for a synthesis of ideas and a transformation of beliefs and practices to emerge. In preparing teacher candidates, teacher education programs must sometimes change hearts and minds. STC 3, in their post-survey response spoke to this notion of change: "My teacher education program prepared me to address these issues by acknowledging that inequities exist and giving students the opportunity to share their experiences with peers." The open dialogue which can occur in these situations are teachable moments that can have a powerful impact on relationships in and outside of the classroom and begin to empower an inclusive pedagogy whereby all learners share and develop through genuine and meaningful discourse. 
Modeling. In some way, shape, or form, the issues that are germane to education have much to do with race and class and how those intersect in ways that marginalize those who do not yet have access to mainstream U.S. society. Because education is compulsory at the K-12 level, it is here that education plays its greatest role in determining the mindset of our people, our politics, and our global relationships. Discussions about these all-important issues in content area classrooms present opportunities for genuine discourse to occur. Having chances to exchange ideas and see these modeled in positive ways serves as blue prints for future occasions.

As STC 9 shared in their pre-survey response,

Information is key, because without the knowledge that racism and other isms still exist and negatively impact learning, the problem of inequity in education remains invisible. How can we as educator address these issues if we remain blind to them, due to the messages our culture propagates? After recognizing the issues, we are learning to address them in ways that are constructive. For instance, we watched a video on how to call someone out if they make a racist statement. This video instructed us to inform the individual that their comment was offensive or hurtful and explain why. The focus was to educate and inform rather than to attack the speaker by labeling them a racist. Labels, especially those associated with the "isms and ists", close minds and shut the doors of open communication. Another video taught us how to respond if someone calls us out. Instead of making excuses about why you said what you said, own it; acknowledge the other's hurt and your part in causing that hurt. Then sincerely apologize remembering the adage to think before you speak to avoid injuring others with your words in the future.

STC 9's comments speak directly to the powerful impact that teachers have on creating a society and world that is equitable and just. Education provides a vehicle and culturally responsive teaching is the transformative tool to potentially improve educational outcomes for our culturally diverse learners. We just need educators who are unafraid to reveal and share their stories of overcoming their own personal barriers. STC 9 goes on to 
make this point:

[One professor] was not afraid to share openly about herself, which really made a difference in our cohort's willingness to share very personal stories about themselves and their experiences not only with racial issues, but also gender issues and struggles with depression and mental health.

When we are openhearted and share of our deepest selves, it gives others permission to do so as well. It is these professional exchanges in teaching and learning about race and its influence on learners who are culturally diverse that are needed.

As STC 14 previously stated in their pre-survey response, "My education has given me tools to stay respectful and calm in situations that may arise in the classroom that have to do with racism and inequity." In STC 14's post-survey response however, tools gave way to action. "[W]hen those topics [race and racism] came up in class, we could talk about them openly." Fear can no longer keep us silent or uncomfortable. It is time to hear the voices of culturally diverse learners so that education may yet secure their future.

As STC 19 states in their post-survey response, "If we openly discuss [race and racism] with respect and love, we teach our students to do the same. No problems are ever solved by brushing them under the rug."

\section{Belief 3: Statistics and Discussion}

Table 4.6

Paired Samples Statistics

Mean Std. Deviation Std. Error Mean

\begin{tabular}{|l|l|l|l|l|}
\hline Pair 3 & B3aT2R & 1.68 & 1.057 & 0.242 \\
\cline { 2 - 3 } & B3aT1R & 1.63 & 1.065 & 0.244 \\
\hline
\end{tabular}


3) For the most part, covering multicultural topics is only relevant to certain subject areas, such as social studies and literature.

\begin{tabular}{|l|l|l|l|l|}
\hline 1 & 2 & 3 & 4 & 5 \\
\hline $\begin{array}{l}\text { I Strongly } \\
\text { Disagree }\end{array}$ & I Disagree & Uncertain & I Agree & $\begin{array}{l}\text { I Strongly } \\
\text { Agree }\end{array}$ \\
\hline
\end{tabular}

B3T1R. In what ways has your teacher education program influenced your thoughts about how multicultural topics can be used in other subject areas? Please explain. Belief 3T2R Open-ended follow up question: How did you teacher education program influence your beliefs and prepare you to incorporate multicultural topics in other subject area? Please explain and provide examples.

As a reverse item, one would expect STCs to largely disagree with the premise of Belief 3. The statistics for this belief clearly indicate disagreement. In listening to the voices of the STCs, they spoke of a shift in education, which is essential to improving educational outcomes for culturally diverse learners. This shift was an outgrowth of greater awareness of the educational experiences of our nation's culturally diverse learner as much as it was about STC's developing mindsets related to educational equity and social justice. As our nation's classrooms have become more diverse, STCs view assimilation playing less and less a role in integrating culturally diverse learners into mainstream American society. For the UTEP's STCs, inclusion of the various cultures is the only way to make learning relevant, relatable and meaningful. As a number of scholars have stated and as STC 14 declared, "The classes in the program showed the elements of culture weave through every single subject area, even ones (like math) where you would not expect to find them." 
Inclusion. Diversity is a given. One need not look far to understand this phenomenon. Yet, our education system promulgates a "one size fits all" approach that values the knowledge of the White, patriarchal male (STE 2, 2016). STC 13 echoed a similar sentiment in their pre-survey response.

The way the entire educational system, which includes the disciplines it teaches, is based on a western aesthetic and construction makes every component involved in it biased toward that construction. Therefore, any student not associated or from this culture is at a distinct disadvantage in such a system.

Acknowledging that curriculum as "master script" is inherently biased gives credence to the need for a more expansive and inclusive curriculum that values the knowledge construction of all civilizations. The incorporation of multicultural knowledge and ways of knowing provides an entrance into learning that has relevance and which acknowledges the contributions of diverse peoples. As STC 13 expressed in their postsurvey response, "Multicultural issues extend to all areas of education." This STC also quoted Keith Gilyard: "[T]his is a problem of being [a student of color] and attempting to cope with the instruction offered in a school controlled by those of another background.

The reason why inclusion is important is that exclusion only serves the underdevelopment of those populations pushed to the margins (Bell, 1973 Marable, 2002, 2000; McIntosh, 1998).

King (2010) eloquently asserts, "[I]t is rationally unsound and sociologically untenable to use traffic effects of segregation as an argument for its continuation" (p. 5). Recognizing this, STC 15 contends:

Even in a subject like math, there are multicultural issues. Math is not simply performing operations in a vacuum. Students come to class with a variety of different backgrounds. They might have trouble with the language in which math 
concepts are explained. They might go to a poorer school full of minorities, which might inform their perceptions of themselves and their ability to succeed. They might be perpetrators or victims of stereotypes like "girls are bad at math, boys are good at math." These problems can impact their success rate in the classroom but also in life.

It is for these reasons and more that our culturally diverse learners need a more inclusive educational experience. As STC 9 intimated, "isms and ists" close minds and shut the doors of open communication." The intention of open dialogue is to bring people together. Inclusion of multicultural curriculum as an educational imperative serves as a bridge to understanding and learning.

In STC 15's post-survey response, they stated the following: “[My program] showed me that incorporating different cultures and opinions need to be part of every aspect of class." To go a step further, STC 4 in their post-survey response believed it even more important "to give students access to roles models that share their cultural backgrounds." STC 4's comment aligns with their pre-survey beliefs stating, "All subjects require that we, as teachers, make them relevant and engaging to our students."

\section{Belief 4: Statistics and Discussion}

Table 4.7

Paired Samples Statistics

Mean Std. Deviation Std. Error Mean

\begin{tabular}{|l|l|l|l|l|}
\hline Pair 4 & B4aT2 & 4.63 & 0.955 & 0.219 \\
& B4aT1 & 4.47 & 0.964 & 0.221
\end{tabular}

4) Good teaching incorporates diverse cultures and experiences into classroom lessons and discussions.

\begin{tabular}{|l|l|l|l|l|}
\hline 1 & 2 & 3 & 4 & 5 \\
\hline $\begin{array}{l}\text { I Strongly } \\
\text { Disagree }\end{array}$ & I Disagree & Uncertain & I Agree & $\begin{array}{l}\text { I Strongly } \\
\text { Agree }\end{array}$ \\
\hline
\end{tabular}


B4T1. In what ways has your teacher education program influenced your thoughts about incorporating diverse cultures and experiences in your teaching? Please explain.

Belief 4T2 Open-ended follow up question: What did you teacher education program do to prepare you to incorporate diverse cultures and experiences in your teaching? Please explain and provide examples.

It would be impossible to have an educational equity and social justice mission whereby some aspect of culture did not play a major role in its explication. The central goal of culturally responsive pedagogy is to use the background knowledge or schema that culturally diverse learners possess to improve their educational outcomes. How the mission gets accomplished speaks to the kind and quality of the educational experience teacher candidates receive. As previously mentioned, awareness wove its way throughout the voices of the STCs.

Awareness of the need to be inclusive. Many STCs felt that inclusion is the right and best way to insure that culturally diverse learners have their cultures presented and to "make the classroom inclusive and comfortable to all students" (STC 4, post-survey response, 2016). The big concern with that thinking is how teachers include the diverse cultures in a meaningful and positive way.

View diversity as an asset. Here is where the teacher has a pivotal role to play in making sure that all learners feel a sense of belonging. One way to create that sense of belonging is through the sharing of learners' cultures. This is where equitable relationships with all learner is essential. In order to build trust, a mutual relationship of 
positive regard is the bedrock. Consequently, as STC 9 asserts, it is important to include "the face of the 'other', the voice history books left out, overlooked or glossed over ...., because these stories are a part of our history and should be heard." In STC 9's presurvey response, they asserted, "I believe students will be more engaged and connected to their learning if it reflects their own reality." One might ask how it can. The real question is: how can it not? A central concern of social justice education is to give students the opportunity to engage in matters that affect their lives and present learning opportunities that contextualizes and enhances the meaning of these events and ways to address them. STC 2 stated in their pre-survey response that [incorporating diverse culture and experiences] "is critical for preparing our students for their life now but also after school, once they've graduated." Implied in this STC's response is the belief that education is not just the acquisition of facts, but is an application of facts that have life implications. Consequently, this STC went on to say that teachers should, "Go beyond the textbook. Incorporating diverse cultures into your teaching allows students to find the answer for themselves [by] comparing and contrasting views and perspectives.” Incorporating critical thinking skills is an essential skill of learning and for actively participating in a democracy. These skills are intended to serve the public good and are learned and further honed primarily through schooling. The increased value of the Belief 4 in the second administration of the LTSJ-Bs scale is a testament to recognizing our interdependence. 


\section{Belief 10: Statistics and Discussion}

Table 4.8

Paired Samples Statistics

Mean Std. Deviation Std. Error Mean

\begin{tabular}{|c|c|c|c|c|}
\hline \multicolumn{2}{|c|}{ B10aT1R } & 1.89 & 0.937 & 0.215 \\
\hline Pair 10 & B10aT2R & 2.37 & 1.012 & 0.232 \\
\hline \multicolumn{5}{|c|}{$\begin{array}{l}\text { 10) Although teachers have to appreciate diversity, it's not their job to change } \\
\text { society. }\end{array}$} \\
\hline 1 & 2 & 3 & 4 & 5 \\
\hline $\begin{array}{l}\text { I Strongly } \\
\text { Disagree }\end{array}$ & I Disagree & Uncertain & I Agree & \begin{tabular}{|l|} 
I Strongly \\
Agree
\end{tabular} \\
\hline
\end{tabular}

B10T1R. In what ways has your teacher education program influenced your thoughts about the teacher's role in changing society? Please explain.

\section{Belief 10T2R. Open-ended follow up question: How did your teacher education} influence your role as a teacher and your role in changing society? Please explain and provide examples.

As a reverse item in the Learning to Teach for Social Justice-Beliefs scale, I think this statement lies at the heart of the issue that surrounds the direction of education and the capacity of our teaching professionals to be the catalysts for the kinds of changes needed. If our culturally diverse learners are to become contributing citizens in their communities, in their country and in the global community, teachers play an indispensable role. Here are some of the themes that emerged from secondary teacher candidates' voices. 
Teachers as influential/role models. A common sentiment expressed by many who are teachers or laypeople is that teachers are/should be role models. The fact that teachers are viewed as the purveyors of knowledge places them at the center of the socializing role education plays in a society. For the UTEP STCs, many embrace this role simply because they understand the nature and the magnitude of its importance.

Three themes merged from the responses STCs offered as related to being a change agent. They are a focus on teaching content; a focus on the responsibility of teaching to our society; and a focus of teaching for the future generation.

Focus of teaching. Gay (2003) and Ladson-Billings (1994) as well as other scholars have envisioned teaching as a service of giving back to the community wherein the teaching occurs. The STCs, who focused more on the teaching of content, saw the value of trying to improve society, but did not necessarily see that as their primary concern. As STC 8 stated in their pre-survey response, "Being a teacher is literally molding and shaping the leaders of tomorrow, which I hope is always on the verge of change and improvement for everyone." This STC's response affirms the value of a teacher's capacity in two respects - the shaping of young minds and the hope for a better future. This comment speaks to the transformative role that teachers play and the promise and purpose of an education.

This same STC added this in their post-survey response. "We were taught that we have a powerful role to play and can influence society as a whole, but I don't think that it's fair to put a responsibility to change society squarely on our shoulders." Responses of 
this kind are associated with STCs who primarily see "teaching as a job...not as their life's work" (Anonymous teacher, 2017).

There are a number of reasons for holding such a conception of teaching. A discussion of these will occur later. In addition to a reluctance to the change agent role, there was a focus on content. For STC 14, the tension between content and changing society is clear. In their pre-survey response, they stated,

Teachers have so much power to inspire and shape everyone who walks into their classroom. While it is good to appreciate diversity, teachers must encourage equity in the classroom and the world. I am not sure how teachers can actively do this aside from leading by example.

The program put a lot of emphasis on how to work to change society and what degree that it is important to discuss and learn about how to make our society a better, but we still have our subject area to teach. I feel like the program at times didn't respect that we have our subject and . . . teach both our subject and equity in tandem. . . . , but I feel they [the professors] tried too hard to make that our focus rather than our subject area. Both are important, but there needs to be a balance.

While content is important, STCs need to understand how the teaching of their content fits within the lives of the students, their families and the community. Without this kind of understanding of the impact of content in diverse students' lives and experiences, education becomes a process of socialization that maintains the status quo. STC 10 captured this sentiment perfectly in their response: "Teachers are a socializing agent. What they do and how they do something affects how students will approach the world because they learn a great deal from us." This response acknowledged the influence that teachers have without a specific focus on one's content, but implicit in this response is an understanding that teachers do more than simply teach content. They serve as role models and guides to how students can contribute to the world (Darling-Hammond 1997). 
In their pre-survey response, STC 13 shared this:

The teacher's role is not to convey facts and statistics but to invent situations that allow students to realize the unique potential that is within them. Doing so, creates individuals that bring substantive assessment actions that positively work within external environments.

In this STC's pre-survey response, we see a focus not on factual knowledge, but procedural knowledge which draws on experience as well as the situation to determine a course of action. This focus on experience in and of itself is not useful unless extended to other situations and circumstances learners encounter. In their post-survey response STC 13 stated, "The program stressed the importance of shaping responsible and contributing members of society." This clearly articulates the vision the UTEP holds for its STCs. As Ladson-Billings (2006a) and Sleeter (2013) so powerfully state, all learners must benefit from education in particular those who historically have been underserved.

Focus on teaching as a responsibility to society. It has been repeatedly mentioned that education intended to be the great equalizer but as we know, disparities in access, opportunity, and resources are well-documented flaws in the educational experience of culturally diverse learners (Darling-Hammond, 2010a; Kozol, 1991, 2005). Therefore, it is important that new teachers understand the responsibility they have not only to their students, but also to the society as a whole to improve the life circumstances of our culturally diverse learners and all learners in order to create a better world.

Some STCs in the study embraced the role compulsory education is expected to play and saw their actions as teachers essential to fulfilling that role. As STC 7 acknowledged in their pre-survey response, "The teacher has a foundation role in society. Because their teaching has both the intention and impact on learners in public school 
systems, they are changing society whether it was their intent or not." This is a classic conundrum because education is a passage from not knowing to knowing, from few skills to more skills and from understanding to sounder understanding. When performed with the ideals of educational equity and social justice in mind, teachers can indeed change society one student, one class at a time. STC 7's post-survey response clearly recognizes this truism.

I believe teachers do impact society because they influence the attitudes, beliefs, intelligence, and resulting actions of so many young people. Because we are so impactful, I believe we have a responsibility to uphold as teachers. Students learn through imitation, and teachers demonstrate what kind of person to be. Character traits such as respect, self-control, appreciation, patience, optimism, curiosity and perseverance (or the converse) WILL be transferred from teacher to students as students are told to learn from their teachers.

These ideas place teachers typically as role models, but more than role models, this STC implies that teachers have a responsibility to fulfill in this capacity. What teachers do and do not do has an impact on students. How teachers handle situations within the classroom speaks volumes about the attitudes, beliefs and disposition a teacher holds. What curriculum choices a teacher makes speaks to what she or he values. Relationships that develop between learners and teachers determine the bond of trust that is possible. All offer clues that determine the degree of effectiveness she or he will have when it comes to their work with culturally diverse learners.

STC 1 summarized the belief that teaching comes with responsibility nicely:

We learned that we are, in fact, shaping society. When we fail our students, we fail an entire generation of students who will then shape society and different environments. Although we cannot change what happens in schools, in many ways teachers can make a difference in making all [emphasis added] students successful. 
STC 1 in their pre-survey response had a different perspective stating,

It is important to stand up for yourself, your coworkers, your students and parents. Perhaps not at the risk of losing your job; there are always boundaries, but showing your students and parents that you care and making small change can go a long way.

STC 1's post-survey response displays a maturity not present in their pre-survey response. Connecting students to parents and parents to communities allowed for a greater understanding of the depth of their influence not just on students but society as well. STC 6 reiterated STC 1's perspective by stating, "Teachers are a HUGE influence on the next generation of people that will become doctors, lawyers, bus drivers, politicians, scientists and so much more." This STC clearly expressed the importance of teaching not only shaping society, but in also shaping the lives of the students in their charge.

Education at its core is about transformation. A quality education is the vehicle by which that transformation occurs and that teachers are the instrument by which transformation is realized. However, we know that not all people who are transformed by education have an equal opportunity to enter mainstream society easily ( Bell, 1973; Marable, 2000).

Focus on teaching as an investment in the future. A quote attributed to Eleanor Roosevelt captures this idea well. She believed that the future belongs to those who follow their dreams. Education provides the foundation upon which to build those dreams.

Having not submitted a pre-survey response to this item, STC 6 offered several statements that are worth noting. STC 6 stated: 
Every influential person had a teacher that likely helped to shape their future attitudes and beliefs about the world. Teaching is the only profession where you get a window into a person's life and can actively help to shape that person.

What an enormous responsibility and opportunity exists in the teaching and learning situation, not to mention the interpersonal relationship that evolves between the learner and the teacher. If we are to look forward to the future, we need teachers who are capable and invested in serving all students, and willing to advocate for the equitable distribution of financial, material, and human resources to ensure their success.

As STC 19 stated, “Today’s kids are tomorrow’s society. We'd better make sure we're creating a good one!"

\section{Secondary Teacher Candidates' Final Comments}

As part of a culminating critique of their UTEP experience, secondary teacher candidates were asked to speak to their experience by responding to the following prompt: Please feel free to share any final thoughts you have about your teacher education experience and your readiness to work with diverse learners (see Appendix C). Ten of the 19 participants responded. Their responses are important to note. Two themes emerged that are considered. They are discussed below.

Treatment of educational equity and social justice constructs. Educational equity and social justice serve as the UTEP's mission. Concerns and/or issues related to these constructs influence the readiness of secondary teacher candidates (STCs) to assume their roles and responsibilities as in-service professionals.

Several STCs believed the introduction of the educational equity and social justice content was invaluable. However, one STC stated that the four weeks spent "is 
certainly only enough time to scratch the surface on those topics" (STC 1). Likewise, STC 7 expressed a disappointment in that "the overall equity training fell short in that we didn't address equity throughout the year in instructional time, learning activities, and course assignments.” Another candidate stated,

I feel like I was only to put some of these ideas and concepts into practice, because some of these topics ... were only mentioned or introduced to us in the program, but not given any kind of solution or way to deal with them in the workplace. (STC 14, open-ended response, 2016)

These secondary teacher candidates' shared concerns are at the center of the new expectations being placed on colleges and schools of education-graduate teaching professionals who can improve the educational outcomes of our poorly performing student populations, our nation's culturally diverse learners (Carter Andrews, Richmond \& Stroupe, 2017).

Educational Equity. For STC 4 there were inconsistencies in what the program expected of STCs and what was possible. They stated, "The program encouraged us to know our students, but I feel like the schools we worked in and the program are short on strategies for engaging students' families." This STC raised a very valid point. Teachers are responsible for helping students learn. If engagement is an issue, then from an equity perspective, there should be strategies and programs in place to connect with parents of students who need additional supports of various kinds. This STC went on to claim, "Of course teachers and resources are limited with the present status quo, but I think students' parents and families are a great untapped resource in improving learning." I would have to agree. An educational equity stance requires that districts, schools, teacher, staff and administrators have a role to play in every student's school experience. 
An additional point raised had to do with inclusion of the various populations who historically have not been successful in K-12 education—our males, lesbian, gay, bisexual, transgender and queer students, culturally diverse learners and students in poverty. While these populations intersect on many different levels, their lack of academic success is clearly an equity issue. STC 15 felt that teacher educators discussed cultural, linguistic and racial diversity a great deal, but other types of diversity were not. They stated,

[W] didn't really address other important areas .... I felt that when I brought up how boys are achieving less in schools, I received a kind of 'polite shrug off.' I suspect that addressing the needs of male students (including some white male students) seemed somehow counter toward equity at least to the UTEP faculty. I also think the program was very light on strategies. We had a lot of nice conversations about the challenges that diverse populations face and how much better the [world] SHOULD be. ... I feel that to have true equity, we need to move beyond [jokes and being subversive] it just doesn't get us anywhere and it tends to alienate allies who truly want to make the world a better place.

As previously mentioned, those engaged in the teaching and learning enterprise have a special and crucial responsibility to students and society because what they/we do as educators has a ripple effect.

Placement of secondary teacher candidates. Placement is an important tool for learning about teaching. It is the place where future teachers learn about the profession, how to teach their content and understand themselves as emerging professionals. The extent to which a teacher education program can fulfill its equity and social justice missions relies to some degree on where teacher candidates are placed. To be in homogenous teaching settings does not serve students who will encounter varying levels of diversity across students. This was a topic raised by a few of the STCs. 
STC 6 conceded "that overall, the UTEP has classwork designed to expose us to a variety of learners, I just wish that I had more contact with some diversity during my student teaching." Teaching and preparing future teacher to teach to diversity is central to mission of the UTEP studied. This is a concern that the UTEP needs to address. If STCs are to receive the best chances to understand what it means to teach culturally diverse learners, they need access to these types of learners and opportunities to engage in the meaningful educational engagement. STC 16 stated, "I think most of the learning I did was in the field. Actually working with kids from different backgrounds, rather than just reading about it in class.” And as STC 9 stated,

I truly believe feel as future teachers during our student teaching we need to focus solely on student teaching, not data crunching, .., but actually teaching. Readiness to work with diverse learners I am pretty sure cannot be learned from a book, etc. .., but actually teaching.

When students of teaching feel that the classroom does not serve their needs to learn about the profession, teacher education programming runs the risk of losing its credibility as a viable social institution for preparing educators, but not only that, it loses its prestige as a profession for transformation in societies. We need only look at the direction our current administration is taking when it comes to public education to understand how important it is for education to realize its potential as the nation's "great equalizer."

\section{Summary and Overview}

In this chapter, I discussed the findings of the three research questions posed by this research study. Both qualitative and quantitative data were used to interpret and understand the relationship between an urban teacher education program's mission and 
instructional practices and how those practices affected secondary teacher candidate readiness and if culturally responsive pedagogy played a role.

In the final chapter of the research study I place the findings of this study within the broader context of education today. I discuss the limitations, offer suggestions for next steps and summarize this research study for the reader. 


\section{Chapter 5-Discussion}

\section{Introduction}

The question of how to improve educational outcomes for our nation's diverse learners is a longstanding one. The continued underachievement of culturally diverse learners affects the very fabric of our democratic values and the strength of our society.

Government efforts to improve educational outcomes for culturally diverse learners and improve test scores resulted in two major legislative efforts. President Bush's No Child Left Behind Act (2001) heralded in the high stakes testing and higher teacher quality standards as a means of improving the kind and quality of instruction in K-12 education culturally diverse learners received. President Obama's efforts placed the responsibility of improving educational outcomes of this student population in the hands of states with his Every Student Succeeds Act (2015).

To narrow the achievement gap between White students and their culturally diverse peers, Gay (2002) proposed the use of culturally responsive teaching as a means of "improving the school success of ethnically diverse students . . . and for preparing teachers in preservice education with the knowledge, attitudes, and skills needed to do this" (p. 106). This remains the call of our nation. Thus, the question becomes: Can an Urban Teacher Education Program (UTEP) with an educational equity and social justice missions make a difference in preparing teachers to meet the educational needs of learners so that outcomes improve for all learners and in particular, our nation's culturally diverse learners? 


\section{Revisiting the Findings}

The purpose of this study was to investigate how an urban teacher education program (UTEP) with an educational equity and social justice mission prepared its secondary teacher candidates (STCs) to work successfully with our nation's growing culturally diverse learner populations and to discover what role if any culturally responsive pedagogy played. In order to understand the nature of the UTEP's instructional practices, the following research questions to were posed to try to understand the secondary teacher educators' (STE) and teacher candidates' experience.

1. How does a UTEP operationalize its educational equity and social justice missions in its efforts to prepare secondary candidates?

2. How does the secondary teacher candidates' readiness to work successfully with diverse learners change over time from the beginning to the conclusion of their field experience?

RQ2 Hypothesis: Because of their teacher preparation program, secondary teacher candidates would perceive themselves to be more prepared to work with diverse learners.

3. To what extent if any, is culturally responsive pedagogy (CRP) associated with secondary teacher candidates' readiness?

RQ3 Hypothesis: I would expect that high levels of perceived readiness are associated with high levels of culturally responsive pedagogical practices. In posing each of these research questions, the purpose was to determine how the UTEP prepared it secondary teacher candidates. To realize this, a multiphase mixed 
methods case study research design was used. This design allowed me to collect both qualitative and quantitative data in an effort to understand the secondary teacher educators (STEs) and secondary teacher candidates (STCs) roles and experiences.

Table 5.1

Research Questions and a Summary of Findings

\begin{tabular}{|c|c|}
\hline $\begin{array}{l}\text { Research } \\
\text { Question }\end{array}$ & Summary of Findings (Themes) \\
\hline 1 & $\begin{array}{l}\text { Operationalizing the UTEP Mission through the following } \\
\text { instructional/educational practices: } \\
\text { - Awareness } \\
\text { - Engagement } \\
\text { - Observation \& Shadowing } \\
\text { - Micro- \& Student Teaching } \\
\text { - Self-reflection }\end{array}$ \\
\hline 2 & $\begin{array}{l}\text { Readiness to work with diverse learners - across time in UTEP program } \\
\text { STCs highlighted the following instructions/educational practices: } \\
\text { - Awareness } \\
\text { - Self-Reflection }\end{array}$ \\
\hline 3 & $\begin{array}{l}\text { Culturally Responsive Practices associated with STCs' readiness? } \\
\text { - Awareness } \\
\text { - Self-reflection } \\
\text { - Modeling } \\
\text { - Inclusion }\end{array}$ \\
\hline
\end{tabular}

\section{Research Question One}

This question spoke to how the UTEP operationalized its dual missions; I relied on the data which was collected from STEs and corroborated by STCs. The following themes emerged from the data collected from these stakeholders.

Operationalizing the UTEP missions. No coherent understanding of a program is possible without a discussion of the values the UTEP endeavors to inculcate in its 
teacher candidates: educational equity and social justice. Central to understanding the extent to which the UTEP fulfills its dual missions depends in large part on the degree to which secondary teacher candidates embrace them.

By returning to the definitions of educational equity and social justice, these terms framed the practices and mindsets needed to understand the intentions of the UTEP and what teacher educators did to align their curriculum and instruction with the goals of the program. According to Education Northwest, educational equity refers to:

the principles of fairness and justice in allocating resources, opportunities, treatment, and success for every student. Educational equity programs promote the real possibility of equality of educational results for each student and between diverse groups of students. Equity strategies are planned, systemic, and focused on the core of the teaching and learning process. (www.educationnorthwest.org)

Bell (1997) states that social justice is an educational philosophy that attempts to "challenge oppressive systems" so that "full and equal participation of all groups in a society" (p. 3) is realized. In order for these principles to become a part of the secondary teacher candidate repertoire of knowledge and mindset, instruction and practices occurred that highlighted the following instructional strategies.

Awareness. In this study, awareness took two forms: self-awareness and cultural awareness. As STE 1 stated, encouraging secondary teacher candidates to see themselves as exhibiting a culture is tantamount to them appreciating other people's cultures. This awareness negates the idea that "I don't have a culture" (STE 1). Seeing their way of being as normalized necessarily ignores the fact that people in the world are different. STC 6 had this to say about awareness: "[The professors] both pushed for and [have] 
been the genesis of true and deep reflection on who I am as a person and also a student. This will influence my teaching for years to come."

Recognizing one's cultural tendencies has the potential to make one aware that who a teacher is influences what she or he does in the classroom. Villegas and Lucas (2002a, 2002b) hold that teacher candidates tend to teach what they experienced as students or what they think is best, with little regard in some cases, to the make-up of the class. This type of colorblind instruction leaves culturally diverse learners at a distinct disadvantage. If there is very little of them reflected in the curriculum they are taught, it leaves them out. STC 4 admitted to being "amazed by the diversity of proficiency among learners, and stated "[t]here is no "middle" in a classroom." This STC's comment speaks to the wide range of learners teachers encounter in their classrooms. This student diversity requires that teachers are equipped with the skills, knowledge, and dispositions ready to work successfully with students from diverse backgrounds. These understandings led STCs to embrace inclusion and anti-deficit mindsets.

To enhance this mind-set further, the UTEP involved its STCs in field observations that offered them opportunities to engage in meaningful interactions within diverse schools and classrooms and an opportunity to incorporate the values that the UTEP espouses.

Engagement. For the UTEP secondary teacher candidates, engagement took the form of observation of experienced teachers, micro-teaching by themselves and their peers. In addition, this engagement took the form of discussions of classroom materials, experiences, as well as shadowing and full-time instruction. 
Observations. Field study served as the initial stage of understanding the complexity of teaching and learning. Being observers offered STCs the opportunity to think about teaching and learning in different ways through the lenses of STCs with no teaching experiences and those with experience. This dynamic allowed for the posing of questions about practice as well as discussions about interactions that occurred in their classrooms. The byproducts of observation served as a laboratory as STE 3 stated whereby STCs test thinking and practices in order to create optimal learning conditions for all learners.

Shadowing. Another form of engagement the UTEP faculty employed to help students better understand students' cultures was shadowing and interacting with students. According to the STCs in Lenski et al.'s research study (2005), spending time in the community gave STCs an understanding of the people and the relationship between the community and the school. Shadowing students brought about several positive outcomes among UTEP STCs as well. Positive outcomes were a better understanding of the community in which the student lived and an understanding of the students life outside of school. Possessing this knowledge of students adds complexity and serves as building blocks to creating authentic caring relationships.

A similar understanding developed among the STCs as documented by openended responses. For example, comments like these emerged. "I gave a student the benefit of the doubt. Teachers see first-hand what students are going through" (STC 14); "As a teacher you are not only teaching your subject, but you are also acting as an advocate and ally to and for your students" (STC 2). 
Micro-and student teaching. These combined opportunities served to socialize STCs into the profession in low-stake environments. Being able to teach lessons periodically and build to full teaching responsibilities gave STCs the opportunity to teach and learn from each experience they had. In particular, microteaching gave STCs a 360degree view of their teaching from multiple perspectives, which had the potential to add richness and depth of understanding to their own practice. These kinds of experiences (e.g. student, observer, peer reviewer, and colleague) provide a context to teaching and offers experiences from which to build and develop expertise.

Furthermore, student teaching offered the opportunity to incorporate practices and ideas engendered in their UTEP experience. The ability to switch back and forth between theory and practice and practice and theory is paramount to STCs or pre-service teachers' developing competence (Brouwer and Korthagen, 2005).

Self-reflection. As I discussed in the Findings chapter, reflection was a highly emphasized component of the UTEP experience. Its inclusion in almost all of the syllabi I analyzed implied the importance this construct played in promoting the UTEP's dual missions of educational equity and social justice. Reflection was an important vehicle for developing teacher competence. STE 1 expressed the importance of reflection being a normal activity of teaching. Other academics shared this belief; however, Gay and Kirkland (2003) promote the importance of self-reflection to improving educational outcomes for culturally diverse learners because "teaching accountability involves being more self-conscious, critical and analytical of one's own teaching beliefs and behaviors" (p. 181). In this new age of pre-service program accountability, it is no longer sufficient 
to master content. Program accountability requires that cultural awareness and selfawareness be mastered in "both pre-service teacher education and in-service professional development" (Gay and Kirkland, 2003, p.181). In this way self-reflection serves as a means of disrupting the social reproduction of the status quo in schools.

\section{Research Question Two}

In looking at Research Question 2, which looks at STC readiness to work successfully with diverse learners and change over time from the beginning to the conclusion of their field experience, qualitative and quantitative data from the Learning to Teach for Social Justice-Beliefs scale were used (see Appendix C). In particular, Belief 1 was used to determine STCs' understanding of the vastness of human qualities needing consideration in the teaching and learning enterprise. Belief 1 stated, "An important part of learning to be a teacher is examining one's own attitudes and beliefs about race, class, gender, disabilities, and sexual orientation.”

Table 5.2

Paired Samples

Statistics

Std.

Pair 1

Mean

\begin{tabular}{|l|l|l|}
\hline B1aT2 & 4.63 & 0.761 \\
\hline B1aT1 & 4.84 & 0.375 \\
\hline
\end{tabular}

\begin{tabular}{|l|l|l|}
\hline B1aT2 & 4.63 & 0.761 \\
\hline B1aT1 & 4.84 & 0.375 \\
\hline
\end{tabular}

Deviation
Std. Error Mean

\begin{tabular}{|c|c|c|c|c|}
\hline 1 & 2 & 3 & 4 & 5 \\
\hline $\begin{array}{l}\text { I Strongly } \\
\text { Disagree }\end{array}$ & I Disagree & \begin{tabular}{|l|} 
Uncertain \\
\end{tabular} & I Agree & \begin{tabular}{|l} 
I Strongly \\
Agree
\end{tabular} \\
\hline
\end{tabular}


From a quantitative perspective, the table showed there to be no significant difference between pre-and-post Likert scale survey responses. By adding a qualitative component to the survey item, I posed this open-ended prompt after Belief Statement 1: In what ways did your teacher education program influence your beliefs about learning to be a teacher? Please explain and provide examples.

STC voices highlighted the value of awareness of the conditions in schools that lead to disparate outcomes as well as the systemic nature of these conditions. Again, selfreflection repeatedly emerged as a means for STCs to institute a shift away from practices that continue to have negative effects for our nation's culturally diverse learners.

In addressing the hypothesis for Research Question 2, the quantitative data showed that STC displayed a high level of agreement on the importance of being a teacher for all of the complexity and diversity that learners bring into the classroom. This confidence is exemplified in STCs' ability to identify the kinds of pedagogical strategies they could employ such as accommodations, differentiation and culturally responsive teaching to achieve the aims of their instruction. Furthermore, readiness is predicated on one's awareness of self and others as well as the interplay between self and others. Readiness is also predicated on self-reflection. As Kirkland and Gay (2003) claim, it is important for teachers to reflect on what they do in the classroom because what they do and don't do impacts learners.

\section{Research Question Three}

It is and has been my contention that culturally responsive pedagogy (CRP) is the vehicle by which to achieve social justice and educational equity in our nation's K-12 
school system. In explaining my rationale for the use of CRP as the theoretical framework for this study with influences from critical race theory (CRT), the tenets of both were presented to give value to their interplay and of CPR to improve the educational outcomes for culturally diverse learners.

The discussion now turns to Research Question 3, which investigated what role, if any, CRP plays in STC readiness to work with culturally diverse learners. In this discussion, 5 Beliefs were used to address this research question. These five beliefs were discussed individually in the previous chapter and are discussed collectively as they relate to $\mathrm{CRP}$ and its role in STC readiness.

Table 5.3

Paired Samples

Statistics

Std. Mean Deviation

\begin{tabular}{llll}
\hline Pair 1 & B1aT2 & 4.63 & 0.761 \\
\cline { 1 - 3 } & B1aT1 & 4.84 & 0.375 \\
\hline
\end{tabular}

4.84

0.375

Std. Error Mean

0.175

0.086

1) An important part of learning to be a teacher is examining one's own attitudes and beliefs about race, class, gender, disabilities, and sexual orientation.

\begin{tabular}{|l|l|l|l|l|}
\hline 1 & 2 & 3 & 4 & 5 \\
\hline $\begin{array}{l}\text { I Strongly } \\
\text { Disagree }\end{array}$ & I Disagree & Uncertain & I Agree & $\begin{array}{l}\text { I Strongly } \\
\text { Agree }\end{array}$ \\
\hline
\end{tabular}

In Belief 1 data were collected from the UTEP STEs and STCs to discover what activities and thinking were engaged in to understand the role CRP played in STC readiness. Using qualitative and quantitative data, they showed awareness playing a key role in STE instructional practices and in STCs emerging understanding of the dynamics 
of the classroom. One way awareness was actualized was by placing STCs in diverse schools where they had the opportunity to observe, engage in, and reflect on their encounters with culturally diverse learners as well as the school culture. In their UTEP classrooms their STE educators modeled practices they wanted their students to emulate and carry with them into the classrooms.

Table 5.4

Paired Samples

Statistics

Std.

Mean Deviation
Std.

Error

Mean

\begin{tabular}{lll|l|l|}
\hline Pair 2 & B2aT2 & 4.58 & 0.507 & 0.116 \\
\cline { 2 - 3 } & B2aT1 & 4.42 & 0.961 & 0.221 \\
\hline
\end{tabular}

2) Issues related to racism and inequity should be openly discussed in the classroom.

\begin{tabular}{|l|l|l|l|l|}
\hline 1 & 2 & 3 & 4 & 5 \\
\hline $\begin{array}{l}\text { I Strongly } \\
\text { Disagree }\end{array}$ & I Disagree & Uncertain & I Agree & $\begin{array}{l}\text { I Strongly } \\
\text { Agree }\end{array}$ \\
\hline
\end{tabular}

In Belief 2, a second way the UTEP conveyed awareness was by the curriculum STE taught and modeled to help STCs develop facility in these pedagogical practices for use in their micro-teaching and student teaching experiences.

Table 5.5

Paired Samples

Statistics

\begin{tabular}{|c|c|c|c|c|}
\hline \multicolumn{3}{|c|}{ Mean } & $\begin{array}{c}\text { Std. } \\
\text { Deviation }\end{array}$ & $\begin{array}{l}\text { Std. Error } \\
\text { Mean }\end{array}$ \\
\hline \multirow[t]{2}{*}{ Pair 3} & B3aT2R & 1.68 & 1.057 & 0.242 \\
\hline & B3aT1R & 1.63 & 1.065 & 0.244 \\
\hline
\end{tabular}


3) For the most part, covering multicultural topics is only relevant to certain subject areas, such as social studies and literature.

\begin{tabular}{|l|l|l|l|l|}
\hline 1 & 2 & 3 & 4 & 5 \\
\hline $\begin{array}{l}\text { I Strongly } \\
\text { Disagree }\end{array}$ & I Disagree & Uncertain & I Agree & $\begin{array}{l}\text { I Strongly } \\
\text { Agree }\end{array}$ \\
\hline
\end{tabular}

In Belief 3, reflection and self-reflection were other skills that the UTEP STEs and STCs maintained were central to STCs' instructional experiences. This component of the UTEP took different forms. Students could be asked to observe the cooperating teacher and reflect on the classroom experience, or the STC could be asked to revisit their own instruction through reflective practice. An additional means of reflection could also be to ask the STC to reflect on the delivery of instruction by one of her or his peers as a means of honing their practice. Inherent in the act of reflection is a focused activity with the intent of learning from it and improving practice.

Table 5.6

Paired Samples Statistics

Mean Std. Deviation

\begin{tabular}{|lr|r|r|r|}
\hline Pair 4 & B4aT2 & 4.63 & 0.955 & 0.219 \\
\hline & & & \\
\hline B4aT1 & 4.47 & 0.964 & 0.221 \\
\hline
\end{tabular}

4) Good teaching incorporates diverse cultures and experiences into classroom lessons and discussions.

\begin{tabular}{|l|l|l|l|l|}
\hline 1 & 2 & 3 & 4 & 5 \\
\hline $\begin{array}{l}\text { I Strongly } \\
\text { Disagree }\end{array}$ & I Disagree & Uncertain & I Agree & $\begin{array}{l}\text { I Strongly } \\
\text { Agree }\end{array}$ \\
\hline
\end{tabular}


Belief 4 presents the final theme to be discussed, which is inclusion. From the UTEP STEs' and STCs' perspectives, inclusion is extremely important, and thus it matters in significant ways. Inclusion is about whether or not a learner feels welcomed and a sense of belonging at school and in the classroom. Inclusion is also about seeing one's culture reflected in the instructional materials teachers use for student learning. Perhaps even more important is that inclusion is about seeing all learners as holding promise and not in deficit terms.

Table 5.7

Paired Samples

Statistics

Mean Std.

Std. Error

Deviation

Mean

\begin{tabular}{ll|l|l|l} 
& B10aT1R & 1.89 & 0.937 & 0.215 \\
\hline Pair 10 & B10aT2R & 2.37 & 1.012 & 0.232 \\
\hline
\end{tabular}

10) Although teachers have to appreciate diversity, it's not their job to change society.

\begin{tabular}{|l|l|l|l|l|}
\hline 1 & 2 & 3 & 4 & 5 \\
\hline $\begin{array}{l}\text { I Strongly } \\
\text { Disagree }\end{array}$ & I Disagree & Uncertain & I Agree & $\begin{array}{l}\text { I Strongly } \\
\text { Agree }\end{array}$ \\
\hline
\end{tabular}

If culturally responsive pedagogical practices were tools to promote the UTEP's dual missions, then my hypothesis stated that CRP would be an instructional tool used to insure teacher candidate readiness. However, the role that culturally responsive pedagogy played in the preparation of STCs is inconclusive.

Many of the themes discussed could be considered components of culturally responsive pedagogical practice because they possess the values and qualities that CRP 
ascribes to. However, very few of 19 STCs acknowledged it as part of their instructional practices. The small sample size of participants makes it impossible to affirm whether or not the UTEP STCs readiness can be attributed to culturally responsive pedagogy. There are a number of reasons for this. As the focus of the UTEP was on its dual mission of educational equity and social justice, it is quite possible that these constructs morphed into the embodiment of CRP. Also, some STCs already had an educational equity and social justice mindset that included these tenets/themes as part of their awareness as well as practice. A final conception is the idea that "good teaching is culturally responsive teaching" (STE 1, 2016). Such a position would account for so few STC s acknowledging it by name as a method of instruction.

\section{Interpreting of the Findings}

The findings in this research study have several implications for teacher education programming and preparation. It has become clear through analysis and discussion that the UTEP has many positive attributes to impart upon its secondary teacher candidates (STCs). It has clearly engaged in many practices aimed at improving secondary teacher candidate readiness. It has embraced practices that are central tenets of culturally responsive pedagogy such an embracing educational equity and social justice on the macro-level and getting to know one's students, their communities and daily lives on a micro-level. The UTEP has prioritized self-reflection as a means of being aware of and sensitive to the cultures that inhabit the class, and explicitly as an "imperative to improving the educational outcomes of students of color" (Gay and Kirkland, 2003, 
p.182). However, the UTEP needs to address the need for strategies for "teaching to and through diversity" (Gay, 2013).

Exposure to diversity. Diversity needs to be more than an idea or notion, but a programmatic focus infused within its philosophical stance. As previously mentioned, some STCs received instruction on the concepts of culturally responsive pedagogy; however, all STCs need the benefit of this tool in their toolkits. Because at some point in their career, STCs will encounter some form of diversity. This was an area that STCs repeatedly expressed an unpreparedness. Many expressed a lack of expose in their field experience, which is a necessity for every teacher candidate if they plan to work in an urban setting. Additionally, STCs need strategies and opportunities to engage in and manage the kinds of difficult conversations about difference that are becoming more and more a common theme in their learners' lives. STCs also need a level of comfort around engaging in these kinds of conversations. More focus and integration of these skills and habits of mind would provide STCs with the confidence they need to be effective in the diverse classrooms they will enter.

Incorporation of an array of diversity strategies. Another area I believe this research study has implications for teacher education programming and preparation is in embedding the strategies of accommodations, differentiation and universal design for learning throughout the entirety of the program. For far too long these concepts have been sequestered in the domain of special education. However, all students could benefit from these types of learning configurations and environments by challenging students, aiding in remediation and working with students where they are. Giving STCs the 
additional benefit of these types of instructional strategies gives all students better opportunities to learn and improve academic, social and emotional outcomes.

\section{Limitations of the Study}

Though the goal of the multiphase mixed methods case study research study was not generalizability, the number of participants affected the ability of the study to address its intended goals. Every effort was made to secure an acceptable number of participants deemed sufficient to obtain recommended research standards and to collect sufficient data. However, these proved difficult to achieve. As a result, the findings of the study may have limited or no relevance.

Concomitant to the small sample size and data gathered was also a lack of diversity among secondary teacher candidates. Teaching continues to remain a predominately White, female profession, and the participants in this study reflected this truism.

A final limitation of the study has to do with the skills of the researcher. My lack of foresight contributed to the small sample size upon which I based the study and affected its quality. Additionally, my limited knowledge of the research processes may have resulted in a misinterpretation of the data.

\section{Implications for Future Research}

This research study would have benefited from many things. One would have been additional time to follow students into their first in-service teaching assignment and through the crucial $5^{\text {th }}$ year in the profession. In reading literature on teacher loss, much remains unknown about teacher experiences that can inform how teacher education 
programs can meet the preparation and professional development needs of K-12 educators.

Originally, I believed the stakeholders to be only the secondary teacher educators and secondary teacher candidates. Including the voices of others who exert great influence on developing competence and practice would add an additional layer of depth and breadth. Currently absent are the voices of cooperating teachers, practicum supervisors, and the learners who are supposed to reap the benefits of the educational enterprise. Including their voices would expand our knowledge and broaden our gaze to find ways that education for educational equity and social justice is a real possibility.

A final implication is the need to bring more teachers of color into the profession. Sleeter (2017) states that historically black colleges and universities (HBCUs) graduate over fifty percent of their students who seek entry into the teaching profession. Yet this population makes up only $3 \%$ to $4 \%$ of the teaching force. According to Sleeter (2017), some ways to increase diversity would be to remove some of the barriers that limit theirs and others access to the profession such as tuition, cost of testing and other factors. These trends must change if education intends to meet the learning needs of all students especially those who have a history of underachievement.

\section{Conclusion: Making a Case for the Use of Culturally Responsive Pedagogy}

In framing the research study from a culturally responsive pedagogical lens with support from critical race theory, I presumed that the nation's educational system is and has been historically discriminatory and perpetuates the knowledge and values of the dominant culture at the expense of culturally diverse learners. This study was conducted 
because I believe that a new approach to preparing teachers is necessary. One that shifts the paradigm from the "way things were done way back when" (Ladson-Billings, 1999, p. 220) to one that recognizes a new American demographic reality. A reality that embraces the challenge of ensuring that "classroom teachers and educators must provide students from all ethnic groups with the education they deserve" (Gay, 2004, p. 34). That new approach is culturally responsive pedagogy wherein the realization of social justice and educational equity are possible.

The Relationship between SJE and ED EQ and CRP/CRT. As more and more research begins to show the value of culturally responsive teaching/pedagogy as a framework for improving educational outcomes for diverse learners and as legislation and accreditation focus their efforts to improve the educational experience of culturally diverse learners, this research study emerged. Gay (2002) states that when "academic knowledge and skills are situated within the lived experiences and frames of reference of [culturally diverse] students, they are more personally meaningful, have higher interest appeal, and are learned more easily and thoroughly" (p. 106).

\section{The intersections of social justice education and culturally responsive}

pedagogy. Hackman (2005) asserts that "social justice education encourages students to take an active role in their own education and supports teachers in creating empowering, democratic and critical educational environments" (p. 103). Gay (2010a) contends that CRP has "pedagogical potential" for creating the educational outcomes it seeks for culturally diverse learners as well as creating the conditions for education equity and social justice education to be the result of its use. Thus, I contend that CRP with the 
support of CRT provides the best opportunity for both educational equity and social justice education to achieve their intended goals_-improved achievement for culturally diverse learners, the creation of agents of change and appropriate investments in education that consider the historical and lived experiences of culturally diverse learners.

Content mastery. Social justice education views content mastery as "a vital aspect" (p. 104). Hackman (2005) describes the three different types of content mastery needed to fulfill this requirement: factual information, historical contextualization and macro-to-micro content analysis. These forms of content mastery are important because they serve to disrupt the reproduction of dominant hegemonic ideologies - a tenet of CRT that is central to social change. As Hackman states, information must "represent a range of ideas and information that go beyond those usually presented in mainstream media or educational materials" (p. 104-105). Furthermore, Hackman asserts that for social justice education to be effective, it must "represent broad and deep levels of information so that students can not only critically examine content but also effectively dialogue about it with others" (p. 105). Since acquiring and understanding information is central to learning, it becomes incumbent upon teachers to "provide students with enough information to do so effectively" (p.105); here is one area where culturally responsive pedagogy supports SJE in its work.

According to Gay (2002), it is a widely held assumption that "effective teaching requires mastery of content knowledge and pedagogical skills" (p. 106). To ensure the academic achievement of culturally diverse learners, Gay suggests that developing a cultural diversity knowledge base is imperative. Asserting that teacher education 
programs need to go beyond the niceties of diversity to acquire "detailed factual information about the cultural particularities of specific ethnic groups" (p. 107) allows for the potential of a variety of perspectives as well as the robust exchange of ideas that is a requirement of a social justice-minded classroom environment.

By focusing on content mastery that infuses the cultural qualities and characteristics of culturally diverse learners, the greater the likelihood, that educational equity and social justice stances can be realized. The outcome of positioning content within this frame of reference allows for the depth and breadth of social justice education to emerge. Again, these ideals align very well with the potential of culturally responsive pedagogy.

Hackman (2005) contends that content mastery knowledge that initiates connection to students' lived lives as well as contextualizes the information within the economic, social and political spirit of the times is instrumental in meeting a stated goal of SJE — social change. Moreover, Hackman asserts that content knowledge that allows learners to consider the impact this information has on them personally as well as globally is a pre-requisite for action. In order for this understanding to occur teacher education programs must position their teacher candidates for meaningful engagement with diverse learners through curricular and extracurricular opportunities that are relevant, meaningful and consider the intersection of the economic, political and social climate of the time.

Critical thinking and the analysis of oppression. Hackman (2005) goes on to assert that knowledge is insufficient to bring about the social change inherent in social 
justice education; therefore, critical thinking and analysis of oppression are necessary for knowledge to serve its intended goal—social change. Accordingly, knowledge must be critiqued, not as fact or truth, but as an idea subject to the political, economic, and social trends that gives it life. Therefore, students' lives become the embodiment by which content is examined, providing greater depth of knowledge and analysis to be performed (Ladson-Billings, 1994).

Gay (2010a) views culturally responsive teaching/pedagogy as holding a transformative potential in part because of its focus on validating and affirming students' lives. It does this by utilizing students' experiences, cultural attributes and home cultures to build connections between these and the content of the classroom. Moreover, it uses instructional strategies that considers students' learning styles, builds community and incorporates students' cultural backgrounds to insure that learning is meaningful and relevant. A potential outcome of this kind of educative experience is greater critical thinking and analysis of oppression. This pedagogical paradigm shift is necessary if we are to live, work and learn in an equitable and just society.

Action and social change. Gay (2010a) asserts, "The features and functions of culturally responsive pedagogy meet the mandates of high-quality education for ethnically diverse leaners" (p. 36). This is accomplished through teachers being prepared to not only share content knowledge, but to also develop curriculum that incorporates the cultures of the learners in ways that value this knowledge. Not only that, but curriculum must affirm their potential as learners. This curriculum must reflect the contributions of cultures other than the dominant culture; thus, it must build learning communities that are 
safe and supportive and create the conditions for caring relationships between and among group members to develop. Quoting Banks (1991), Gay writes: “Being transformative involves helping students to develop the knowledge, skills, and values needed to become social critics who can make reflective decisions and implement their decisions in effective personal, social, political and economic action" (pp. 36-37). In this sense education fuels our democratic values.

Thus, using culturally responsive pedagogy to educate culturally diverse learners allows these learners to use their frames of reference to accomplish the explicit purpose of social justice education, which according to Hackman (2005) is to "learn that social action is fundamental to the everyday workings of their lives" (p. 106). In order for students to fulfill this goal, they need teachers to model and embody that spirit. This is where teacher education programs and the teacher educators within them play a major role.

Personal reflection. Though Gay (2002) does not speak directly to this concept in her seminal article, she frames this notion in terms of displaying caring relationships with students and building a learning community that seeks to deliver integrated learning through care. However, in Culturally Responsive Teaching: Theory, Research and Practice, Gay (2010a) asserts the importance of personal reflection by stating "a critical element of culturally responsive teaching is cultural self-awareness and consciousnessraising for teachers" (p. 70, italics in original). Caring is related to personal reflection in that it requires the teacher to examine her/his own culture as a prerequisite for being able to build relationships with culturally diverse learners. Quoting her previous work on this 
topic, Gay (2002) claims that "[c]ulturally responsive caring places teachers in ... a partnership that is anchored in respect, honor, integrity, resources sharing, and a deep belief in the possibility of transcendence" (p. 109). This partnership is only possible according to Hackman (2005) when "teachers . . . reflect critically on themselves and the personal qualities that inform their practice" (p. 106).

Hackman (2005) discusses the blindness that teachers may have due to a lack of introspection or self-interrogation, which West (2013) states "takes courage" (p. 625). According to Hackman, personal reflection is important because it "can serve as a motivator, as it knocks teachers out of complacency and steers them in the direction of the solution instead of the problem" (p.107). This is crucial in order for SJE and CRP to achieve their stated and implied intentions_-access to high quality curriculum and instruction, improved academic achievement through greater rigor, and the opportunity to realize its CRT goal—greater participation in mainstream society.

Awareness of multicultural dynamics. The final tenet examined is awareness of multicultural dynamics, which according to Hackman (2005) combines the previous tenets of social justice education, and is central to teaching and learning, building the caring relationships between students and teachers and the communities wherein they serve. The criticism most often levied at our nation's current educational beliefs and practices is a "one size fits all approach" to instruction. Howard (2012) asserts such an approach gives rise to deficit-based thinking. This arises because as Howard writes, "In short, deficit theorist have advocated seeking ways to change student knowledge, language, culture and behavior in ways that are more consistent with mainstream ways of 
being” (pp. 2-3). Doing so diminishes that which makes students unique and asks them to leave their culture at the classroom door. This does a disservice to students and teachers alike. Hackman contends that if teachers fail to understand and know who their students are, "they miss the true potential of student-centered teaching and social justice education" (p. 108). Here is another means by which CRP has the potential to improve teaching and learning.

Howard (2012) quotes Gay (2000) when he speaks to the impact of deficit-based beliefs in light of the power of CRP to circumvent them. Gay explains that CRP is essential because " $[\mathrm{t}]$ he validation, information, and pride it generates are both psychological and intellectually liberating” (p. 3). Gay (2002) explains that there is more to teaching than a "mere awareness of, respect for, and general recognition of the fact that ethnic groups have different values or express similar values in various ways" (p. 107). Hackman (2005) states "that who is in the room has an effect on content and process" (p. 108) which in turn impacts whether or not the students' needs get met. Thus, a studentcentered educational experience is essential to improving academic outcomes, which is why CRP holds promise. In conclusion, if our nation is committed to providing all learners with a quality public education, then culturally responsive pedagogy must play a role. CRP has potential because of it values the lives, cultural knowledge and lived experiences of our culturally diverse learners in a way that is inclusive, transformative, equitable and socially just. 


\section{References}

Achievement gap. [Definition]. Retrieved from http://www.advocacy.collegboard.org.

Achinstein, B. \& Anthanases, S. (2005). Focusing new teachers on diversity and equity: Towards a knowledge base for mentors. Teaching and Teacher Education, 21, 843-862.

Adler, S. A. (1990, February 8). The reflective practitioner and the curriculum of teacher education. US Department of Education, Washington, D.C. ERIC (ED 319 693, 3-29).

Allen. L. (2006). The moral life of schools revisited: Preparing educational leaders to "build a new social order" for social justice and democratic community. International Journal of Urban Educational Leadership, 1, 1-13.

Americans with Disabilities Act of 1990, 42 U.S.C.A. § 12101 et seq.

Anonymous educator, April 2013

Anonymous educator, June 2014

Anonymous educator, August 2017

Bales, B.L. \& Saffold, F. (2011). A new era in the preparation of teachers for urban schools: Linking multiculturalism, disciplinary-based content, and pedagogy. Urban Education, 46(5), 953-974.

Ball, A. \& Tyson, C. (2013). [Foreword]. In Christine Sleeter, Power, teaching, and teacher education (pp. vii-x). New York, NY: Peter Lang.

Bartolome, L. I. (1994). Beyond the methods of fetish: Towards a humanizing pedagogy. Harvard Educational Review, 64(2), 173-195.

Barton, P. (2003). Parsing the achievement gap: Baselines for tracking progress. Retrieved from http://www.ets.org/Media/Research/pdf/PICPARSING.pdf

Barton, P. \& Coley, R. J. (2010). The black-white achievement gap. Retrieved from http://www.ets.org/research/pic

Bell, D. (1973). Race, racism, and American law. Boston, MA: Little, Brown and Company. 
Bell, D. (2009). Brown v Board of Education and the interest convergence dilemma. In Edward Taylor, David Gillborn \& Gloria Ladson-Billings (Eds.). Foundations of critical race theory in education, (pp.73-84). New York, NY: Routledge.

Bell, L. A. (1997). Theoretical foundations for social justice education. In Maurianne Adams, Lee Ann Bell \& Pat Griffin (Eds.), Teaching for diversity and social justice: A sourcebook (pp. 3-29). New York, NY: Routledge.

Bell, L. A. (2010). Storytelling for social justice: Connecting narrative and the arts in antiracist teaching. New York, NY: Routledge.

Bowles, S. \& Gintis, H. (1976). Schooling in capitalist America. New York, NY: Basic Books.

Brouwer, N., \& Korthagen, F. (2005). Can teacher education make a difference? American Educational Research Journal, 42(1), 153-224.

Brown v. Board of Educ., 347 U.S. 483 (1954).

Carter Andrews, D. J., Richmond, G., \& Stroupe, D. (2017). [Editorial]. Teacher education and teaching in the present political landscape: Promoting educational equity through critical inquiry and research, Journal of Teacher Education, 68(2), 121-124. doi: 10.1177/0022-487117691243

Chisholm, I. M. (1994). Preparing teachers for multicultural classrooms. Journal of Educational Issues of Language Minority Students, 14, 43-68.

Cochran-Smith, M. (1997). Knowledge, skill, and experience for teaching culturally diverse learners: A perspective for practicing teachers. In Jacqueline Jordan Irvine (Ed.). Critical knowledge for diverse teachers and learners (pp. 27-87).

Washington, DC: American Association of Colleges for Teacher Education.

Cochran-Smith, M. (2002). What's preparation got to do with it? Journal of Teacher Education, 53(2), 99-101.

Cochran-Smith, M. (2005). Teacher educators as researchers: Multiple perspectives. Teaching and Teacher Education, 21, 219-225.

Coleman, J. S. (1966). Equality of educational opportunity. Washington, DC: U. S. Government Printing Office.

Correa, V. (1991). Teaching culturally diverse students. Preventing School Failure, 35(3), n.p. 
Creswell, J. W. (2007). Qualitative inquiry and research design: Choosing among five approaches (2nd ed.). Thousand Oaks, CA: Sage.

Creswell, J. W. (2008). Educational research: Planning, conducting, and evaluating quantitative and qualitative research (3rd ed.). Upper Saddle River, NJ: Pearson Education.

Creswell, J. W. \& Plano-Clark, V. L. (2011). Designing and conducting mixed methods research. ( $2^{\text {nd }}$ ed.). Thousand Oaks, CA: Sage.

Cross, W. E. (1998). Black psychological functioning and the legacy of slavery. In Yael Danieli (Ed.), International handbook of multigenerational legacies of trauma (pp. 387-403). New York, NY: Plenum Press.

Cruishank, D. R. (n. d.). Models for the preparation of America's teachers. Bloomington, IN: The Phi Delta Kappa Educational Foundation.

Daniel, B. J. (2009) Conversations on race in teacher education cohorts. Teaching Education, 20(2), 175-188.

Darling-Hammond, L. (1997). [Foreword]. In Joyce King, Etta R. Hollins, Warren C. Hayman (Eds.), Preparing teachers for cultural diversity (pp. vii-xi). New York, NY: Teachers College Press.

Darling-Hammond, L. (2000). How teacher education matters. Journal of Teacher Education, 51(3), 166-173.

Darling-Hammond, L. (2002). Educating a profession for equitable practice. In Linda Darling-Hammond, Jennifer French, \& Silvia Paloma Garcia-Lopez. Learning to teacher for social justice, (pp. 201-212). New York, NY: Teachers College Press.

Darling-Hammond, L. (2006). Constructing $21^{\text {st }}$ century teacher education. Journal of Teacher Education, 57(3), 300-314. doi: 10.1177/0022487105285962

Darling-Hammond, L. (2010a). The flat world and education. New York, NY: Teachers College Press.

Darling-Hammond, L. (2010b). Teacher education and the American future. Journal of Teacher Education, 61(1-2), 35-47. doi:10.1177/0022487109348024

Darling-Hammond, L. \& Berry, B. (2006). Highly qualified teachers for all. Educational Leadership, 64(3), 14-20. 
Delpit, L. (2006). Other people's children: Cultural conflict in the classroom. New York, NY: New Press.

Delpit, L. (2012). Multiplication is for white people: Raising expectations for other people's children. New York, NY: New Press.

Dewey, J. (1904). The relation of theory to practice in the education of teachers. Chicago, IL: University of Chicago.

Dewey, J. (2008). The need for a philosophy of education. In Marilyn Cochran-Smith, Sharon Feiman-Nemser, D. John McIntyre \& Kelly E. Demers (Eds.), The handbook of research on teacher education: Enduring questions in changing contexts (3rd ed.), (pp. 96-101). New York, NY: Routledge/Taylor \& Francis Group \& the Association of Teacher Educators.

Douglass, F. (2007). Learning to Read and Write. In Samuel Cohen (Ed.), 50 essays: A portable anthology (pp. 144-149). Boston, MA: Bedford/St. Martins.

DuBois, W. E. B. (1994). The souls of black people. Mineola, NY: Dover.

Duncan, A. (2011, September 30). A new approach to teacher education reform and improvement. Retrieved from http://www.ed.gov/news/speeches/new-approacheducation

Dweck, C. (2014, September 12). [TED Talk]. The power of yet. Retrieved from https://www.youtube.com/watch?v=J-swZaKN2Ic

Educational equity. [Definition]. Retrieved from http://www.educationnorthwest.org

Elementary and Secondary Education Act of 1965, 20 U.S.C $\$ 2701$ et seq. (U. S. Government Accountability Office).

Equiano, O. (1999). The life of Olaudah Equiano, or Gustavus Vassa, the African. Mineola, NY: Dover.

Fetters, M. D., Curry, L.A. \& Creswell, J. W. (2013). Achieving integration in mixed methods designs-Principles and practices. Health Services Research 48(6), 2134-2155. doi:10.1111/1475-6773.12117

Flaxman, E. (2003). Closing the achievement gap: Two views from the current research. Eric Digest, (Publication No. ED482919), 1-5. 
Fraser, J. (1997). [Preface]. In Jacqueline Jordan Irvine (Ed.). Critical knowledge for diverse teachers and learners (pp. v-x). Washington, DC: American Association of Colleges for Teacher Education.

Freeman, K. (2006). If only my eyes were different. International Review of Education, 52(1-2), 49-65.

Freirè, P. (2000). Pedagogy of the oppressed. New York, NY: Continuum.

Futrell, M. H. (1999). Recruiting minority teachers. Educational Leadership, 56(8), 3033.

Futrell, M. H. (2010). Transforming teacher education to reform America's P-20 education system. Journal of Teacher Education, 61(5), 432-440. doi:10.1177/0022487110375803

Gale, T., Mills, C. \& Cross, R. (2017). Social inclusive teaching: Belief, design, actions as pedagogic work. Journal of Teacher Education, 68(3), 345-356. doi: 10. $1177 / 0022-487116685754$

Garcia, E., Arias, M. B., Murri Harris, N. J., \& Serna, C. (2010). Developing responsive teachers: A challenge for a demographic reality, Journal of Teacher Education, 61(1-2), 132-142. doi:10.1177/0022487/09347878

Gay, G. (1993). Building cultural bridges: A bold proposal for teacher education. Education and Urban Society, 25(3), 285-299.

Gay, G. (2002). Preparing for culturally responsive teaching. Journal of Teacher Education, 53(2), 106-116.

Gay, G. (2003-2004). The importance of multicultural education. Educational Leadership, December-January, 30-35.

Gay, G. (2010a). Culturally responsive teaching: Theory, research, and practice (2nd ed.). New York, NY: Teachers College Press.

Gay, G. (2010b). Acting on beliefs in teacher education for cultural diversity. Journal of Teacher Education, 61(1-2), 143-152. doi:10.1177/0022487109347320

Gay, G. (2013). Teaching to and through cultural diversity. Curriculum Inquiry, 43(1), n. p.

Gay, G. \& Kirkland, K. (2003). Developing cultural critical consciousness and selfreflection in pre-service teacher education. Theory into Practice, 42(3), 181-187. doi:10.1201/s15430421tip4203_3 
Giroux, H. A. (2009). Teaching education and democratic schooling. In Antonia Darder, Marta Baltodano \& Rodolfo D. Torres (Eds.), The critical pedagogy reader (2nd ed.), (pp.438-459). New York, NY: Routledge.

Gorski, P. (2006). The unintentional undermining of multicultural education: Educators at the equity crossroads. In Julie Landsman \& Chance W. Lewis (Eds.), White teachers/diverse classrooms (pp. 61-78). Sterling, VA: Stylus.

Grant, C. A. (1997). Critical knowledge, skills and experiences for the instruction of culturally diverse learners: A perspective for the preparation of preservice teachers. In Jacqueline Jordan Irvine (Ed.). Critical Knowledge for diverse teachers and learners (pp. 1-26). Washington, DC: American Association of Colleges for Teacher Education.

Grant, C. A. (2008). Teacher capacity. In Marilyn Cochran-Smith, Sharon FeimanNemser,D. John McIntyre \& Kelly E. Demers (Eds.), The handbook of research on teacher education: Enduring questions in changing contexts (3rd ed.), (pp. 127-133). New York, NY: Routledge/Taylor \& Francis Group \& the Association of Teacher Educators.

Grant, C. A. \& Agosto, G. V. (2008). Teacher capacity and social justice in teacher education. In Marilyn Cochran-Smith, Sharon Feiman-Nemser, D. John McIntyre \& Kelly E. Demers (Eds.), The handbook of research on teacher education: Enduring questions in changing contexts (3rd ed.), (pp. 175-200). New York, NY: Routledge/Taylor \& Francis Group \& the Association of Teacher Educators.

Green, A.K. (2009). The politics of literacy: Countering the rhetoric of accountability in the Spellings Report and beyond. College Composition and Communication, 61(1), 367-384.

Griner, C. A. \& Stewart, M. L. (2012). Addressing the achievement gap and disproportionality through the use of culturally responsive teaching practices. Urban Education, 48(4), 585-621.

Guinier, L. (1995). Groups, representation, and race-conscious districting: A case of the emperor's clothes. In Kimberlè Crenshaw, Neil Gotanda, Gary Peller \& Kendall Thomas (Eds.), Critical race theory: The key writings that formed the movement (pp. 205-235). New York, NY: The New Press.

Haberman, M. (1991). The rationale for training adults as teachers. In Christine Sleeter, Empowerment through multicultural education. (pp 275-286). Albany, NY: State University of New York Press. 
Hackman, H. W. (2005). Five essential components for social justice education. Equity \& Excellence in Education, 38, 103-109. doi:10.1080/10665680590935034

Hawley, W. D. \& Irvine, J. J. (2011, December 6). [Commentary]. The teaching evaluation gap: Why students' cultural identities hold the key. Education Week, 31(13), 30-31.

Herrnstein, R. J. \& Murray, C. (1994). The bell curve: Intelligence and class structure in American life. New York, NY: Free Press.

Hill, D. K. (2009). A historical analysis or desegregation and racism in a racially polarized region: Implications for the historical construct, a diversity problem, and transforming teacher education toward culturally relevant pedagogy. Urban Education, 44(1), 106-139.

hooks, b. (1994). Teaching to transgress: Education as the practice of freedom. New York, NY: Routledge.

Howard, G. R. (2006). We can't teach what we don't know: White teachers, multiracial schools (2nd ed.). New York, NY: Teachers College Press.

Howard, T.C. (2010). Why race and culture matters in schools: Closing the achievement gap in America's classrooms. New York, NY: Teachers College Press.

Howard, T.C. (2012). Culturally responsive pedagogy. In James A. Banks, (Ed.), Encyclopedia of diversity in education (pp. 1-7). Thousand Oaks: Sage

Howard, T. C. \& Aleman, G. R. (2008). Teacher capacity for diverse learners: What do teachers need to know? In Marilyn Cochran-Smith, Sharon Feiman-Nemser, D. John McIntyre \& Kelly E. Demers (Eds.), The handbook of research on teacher education: Enduring questions in changing contexts (3rd ed.), (pp. 157-174). New York, NY: Routledge/Taylor \& Francis Group \& the Association of Teacher Educators.

Individuals with Disabilities Education Act of 1975, 20 U.S.C. $§ 1400$ (2004).

Jackson, F. R. (1994). Cultural diversity in a teacher education program. The High School Journal, 77(3), 240-246. Retrieved from http://www.jstor.org/stable/40364797

Jamieson, S. (2004). Likert scales: How to (ab)use them. Medical Education 38, $1217-$ 1218. doi:10. 1111/j.365-2929.2004.02012

Johnson, A. S. (2007). An ethics of access: Using life history to trace preservice teachers' 
initial viewpoints on teaching for equity. Journal of Teacher Education 58(4), 299-314. doi:10.1177/0022487107305604

Kincheloe, J. L. (2004). The bizarre, complex, and misunderstood world of teacher education. In Joe L. Kincheloe, Alberto Bursztyn \& Shirley R. Steinberg (Eds.), Teaching teachers: Building a quality school of urban education (pp.1-49). New York, NY: Peter Lang.

King, M. L. (2010). Strength to love. Minneapolis, MN: Fortress Press.

Kohn, A. (1998). Only for my kid. Phi Delta Kappan. April, 569-577.

Kozol, J. (1991). Savage inequalities: Children in America's schools. New York, NY: Harper Collins.

Kozol, J. (2005). The shame of the nation: The restoration of apartheid schools in America. New York, NY: Crowne.

Ladson-Billings, G. (1994). The dreamkeepers: Successful teachers of African American children. San Francisco, CA: Jossey-Bass.

Ladson-Billings, G. (1995a). But that's just good teaching! The case for culturally relevant pedagogy. Theory into Practice, 34(3), 159-165.

Ladson-Billings, G. (1995b). Toward a theory of culturally relevant pedagogy. American Educational Research Journal, 32(3), 465-491. Retrieved from http://www.jstor.org/ stable/163320

Ladson-Billings, G. (1998). Just what is critical race theory and what is it doing in a nice field like education? Qualitative Studies in Education, 11(1), 7-24.

Ladson-Billings, G. (1999). Preparing teachers for diverse student populations: A critical race theory perspective. Review of Research in Education, 24(1), 221-247. doi:10.3192/0091732X024001211

Ladson-Billings, G. (2005). Is the team all right? Diversity and teacher education. Journal of Teacher Education, 56(3), 229-234. doi:10.1177/0022487105275917

Ladson-Billings, G. (2006a). Yes, but how do we do it?: Practicing culturally relevant pedagogy. In Julie Landsman \& Chance W. Lewis (Eds.), White teachers/diverse classrooms (pp. 29-42). Sterling, VA: Stylus.

Ladson-Billings, G. (2006b). From the achievement gap to the education debt: Understanding achievement in U.S. schools. Educational Researcher, 5(7), 3-12. 
Ladson-Billings, G. (2013, October). Culturally responsive pedagogy 3.0. Teaching with a Purpose Conference, Portland, OR.

Ladson-Billings, G. \& Tate, W. F. (1995). Toward a critical race theory of education. Teachers College Record, 97(1), 47-68.

Landsman, J. \& Lewis, C. W. (2006). White teachers/diverse classrooms. Sterling, VA: Stylus.

Larabee, D. F. (2000). On the nature of teaching and teacher education: Difficult practices that look easy. Journal of Teacher Education, 50, 228-233. doi: $10.1177 / 0022487100051003011$

Latham, S. A., Gitomer, D. \& Ziomek, R. (1999). What tests tell us about new teachers. In Association for Supervision and Curriculum Development, Educational Leadership, 56(8), 23-26.

Lau v. Nichols, 414 U.S. 563 (1974)

Layton, L. (2013, October 16). Study: Poor are now the majority in American public schools in South, West. The Washington Post. Retrieved from http://www.washingtonpost.com

Leavell, A. G., Cowart, M. \& Wilheim, R. W. (1999). Strategies for preparing culturally responsive teachers. Equity \& Excellence in Education, 32(1), 64-71.

Lenski, S. D., Crumpler, T. P., Stallworth, C., \& Crawford, K. M. (2005). Beyond awareness: Preparing culturally responsive preservice teachers. Teacher Education Quarterly, 40, 194-215.

Lewins, A., \& Silver, C. (2007). Using software in qualitative research: A step-by-step guide. Thousand Oaks, CA: Sage.

Lewis, A. E. (2003). Race in the schoolyard: Negotiating the color line in the classroom and communities. New Brunswick, NJ: Rutgers University Press.

Lincoln, Y. S. \& Guba, E. G. (2002). Judging the quality of case study reports. In A. Michael Huberman \& Matthew B. Miles (Eds.). The qualitative researcher's companion (pp. 206-215). Thousand, Oaks, CA: Sage.

Liston, D. P. \& Zeichner, K. M. (1996). Culture and teaching. Mahwah, NJ: Lawrence Erlbaum. 
Lopes-Murphy, S. (2012). Universal design for learning: Preparing secondary education teachers in training to increase academic accessibility of high school learners. Journal of Educational Strategies, 85(6), 226-230.

Ludlow, L. K., Enterline, S. E. \& Cochran-Smith, M. (2008). Learning to teach for social justice-belief scale: An application of Rausch measurement principles. Measurement and Evaluation in Counseling Development, 40, 194-214.

Marable, M. (2000). How capitalism underdeveloped Black America. Cambridge, MA: South End Press.

Marable, M. (2002). The great wells of democracy: The meaning of race in American life. New York, NY: Basic Civitas Books.

Marable, M. (2009). Beyond black and white: From civil rights to Barack Obama. New York, NY: Verso.

Marshall, C. \& Gerstl-Pepin, C. (2005). Reframing educational politics for social justice. Boston, MA: Pearson.

Marbley, A. F., Bonner, F. A., McKisk, S., Henfield, M. S. \& Watts, L. M. (2007). Interfacing culture specific pedagogy with counselling: A proposed diversity training model for preparing pre-service teachers for diverse learners, Multicultural Education, 14(3), 8-16.

Maxwell, J. (2005). Qualitative research design: An interactive approach ( $2 \mathrm{nd}$ ed.). Thousand Oaks, CA: Sage.

McDiarmid. G. W. \& Clevenger-Bright, M. (2008). Rethinking teacher capacity. In Marilyn Cochran-Smith, Sharon Feiman-Nemser, D. John McIntyre \& Kelly E. Demers (Eds.), The handbook of research on teacher education: Enduring questions in changing contexts. (3rd ed.), (pp. 127-133). New York, NY: Routledge/Taylor \& Francis Group \& the Association of Teacher Educators.

McIntosh, P. (1998). White privilege, color and crime: A personal account. In Coramae Richey Mann and Marjorie S. Zatz, Images of color, images of crime: Readings, (Chapter 18). Los Angeles, CA: Roxbury Publishing Company.

McKinsey \& Company. (2009). The economic impact of the achievement gap in America's Schools: Summary of findings. Social Sector Office: Author

McLaren, P. \& Farahmandpur, R. (2006). Pedagogy of oppression. Monthly Review, 58(3), 94-99. 
McKinsey \& Company Summary Report (2009). The economic impact of the achievement gap in America's schools. Retrieved from http://www.achievement_gap_report.pdf

McKown, C. \& Weinstein, R. S. (2008). Teacher expectations, classroom context, and the achievement gap. Journal of School Psychology, 46, 235-261.

Melnick, S. L. \& Zeichner, K.M. (1997). Enhancing the capacity of teacher education institutions to address diversity issues. In Joyce King, Etta R. Hollins, Warren C. Hayman (Eds.), Preparing teachers for cultural diversity (pp. 23-39). New York, NY: Teachers College Press.

Merryfield, M. M. (2000). Why aren't teachers being prepared to teach for diversity, equity, and global connected? Teaching and Teacher Education, 16, 429-443.

Mills, C. (n. d). Pre-service teacher education and the development of socially just dispositions: A review of the literature (Publication No. MIL06221, 1-11).

Miles, M. B. \& Huberman, A. M. (1994). An expanded handbook: Qualitative data analysis (2nd ed.). Thousand Oaks, CA: Sage.

Milner, H. R. (2003). Reflection, racial competence, and critical pedagogy: How do we prepare pre-service teachers to pose tough questions? Race, Ethnicity, and Education, 6(2), 193-208. doi:10.1080/136133203200006472

Milner, H. R. (2005). Stability and change in the U.S. prospective teachers' beliefs and decisions about diversity and learning to teach. Teaching and Teacher Education $21,767-786$.

Milner, H. R. (2006). Preservice teachers' learning about culture and racial diversity: Implications for urban education. Urban Education, 59(4), 332-346.

Milner, H. R. (2008). Critical race theory and interest convergences as analytical tools in teacher education policies and practices. Journal of Teacher Education, 59(4), 332- 346.

Milner, H. R. (2010). What does teacher education have to do with teaching? Implications for diversity studies. Journal of Teacher Education, 61(1-2), 118131. doi:10.1177/022487109347670

Milner, H. R. (2011). Culturally responsive pedagogy in a diverse urban classroom. Urban Review 43, 66-89. doi:10.1007/s11256-009-0143-0 
Morgan, D. L. (2014). Integrating qualitative and quantitative methods: A pragmatic approach. Thousand Oaks, CA: Sage.

Morning Edition. (National Public Radio). (2013a, November 22). Ongoing series on education [Radio broadcast]. Available from

http://www.opb.org/radio/programs/morning-edition/

Morning Edition. (National Public Radio). (2013b, December). Ongoing series on education [Radio broadcast]. Available from

http://www.opb.org/radio/programs/morning-edition/

Moultrie, J. P., Magee, P. A., Scribner Paredes, S. A. (2017). Talk about a racial eclipse: Narratives of institutional evasion in an urban school-university partnership. Journal of Cases in Educational Leadership, 20(1), 6-21.

Myrdal, G. (1944). An American dilemma: The Negro problem and modern society. New York, NY: Harper.

National Commission on Excellence in Education. (1983). A nation at risk: The imperative for educational reform: A report to the nation and the Secretary of Education, United States Department of Education. Washington, D.C: The Commission: [Supt. of Docs., U.S. G.P.O. distributor]

Nieto, S. (2000). Placing equity front and center: Some thoughts for transforming teacher education for a new century. Journal of Teacher Education, 51(3), 180-187.

Nieto, S. (2003). What keeps teachers going. New York, NY: Teachers College Press.

Nieto, S. (2006). [Foreword]. In Gary R. Howard, We can't teach what we don't know: White teachers, multiracial schools (2nd ed.). New York, NY: Teachers College Press.

Noguera, P. A. (2008). Creating schools where race does not predict achievement: The role and significance of race in the racial achievement gap. Journal of Negro Education, 71(2), 90-103.

Noguera, P. A. \& Wing, J. Y. (2006). Unfinished business: Closing the racial achievement gap in our schools. San Francisco, CA: Jossey-Bass.

Oakes, J. (2005). Keeping track: How schools structure inequality (2nd ed.). New Haven, CT: Yale University Press.

Orfield, G. (2004). Dropouts in America. Cambridge, MA: Harvard Education Press. 
Oregon Equality Act (2007). Retrieved from http://www. lambdalegal.org

Plano Clark, V.L. \& Badiee, M. (2010). Research questions in mixed methods research. In Abbas Tashakkori and Charles Teddlie (Eds.) Sage handbook of mixed methods in social and behavioral research. (2nd ed.), (pp. 265-304). Thousand Oaks, CA: Sage.

Plessy v. Ferguson, 163 U.S. 536, 537 (1896).

Quintanar-Sarellana, R. (1997). Culturally relevant teacher preparation and teachers' perception of the language and culture of linguistic minority students. In Joyce King, Etta R. Hollins, Warren C. Hayman (Eds.), Preparing teachers for cultural diversity (pp. 40-52). New York, NY: Teachers College Press.

Ravitch, D. (2010). The death and life of the great American school system. New York, NY: Basic Books.

Readiness (1978). [Definition]. American heritage dictionary of the English language. Boston, MA: Houghton, Mifflin Company.

Reiter, A. B. \& Davis, S. N. (2011). Factors influencing pre-service teachers' beliefs about student achievement: Evaluation of a pre-service teacher diversity awareness program. Multicultural Education, 18(3), 41-46.

Robb, L. (2012). What is differentiated learning? In Differentiating reading instruction: How to teach reading to meet the needs of each student. Retrieved from www.scholastic.com/teachers/articles/teaching-content/what-differentiatedinstruction/

Rothstein, R. (2004). Reforms that could help narrow the achievement gap. Retrieved from http://www.wested.org/online_pubs/pp-06-02.pdf

Rubal-Lopez, A. (2004). Who I am informs my teaching. In Joe L. Kincheloe, Alberto Bursztyn \& Shirley R. Steinberg (Eds.), Teaching teachers: Building a quality school of urban education (pp.103-111). New York, NY: Peter Lang.

Saldana, J. (2013). The coding manual for qualitative researchers, (2nd ed.). Thousand Oaks, CA: Sage.

Salkind, N. J. (2008). Statistics for people who (think they) hate statistics, (3rd ed.). Thousand Oaks, CA: Sage.

Santos-Regol, M. A. \& Nieto, S. (2000). Multicultural/Intercultural teacher education in two contexts: Lessons from the U.S. and Spain. Teaching and Teacher Education, $16,413-127$. 
Schon, D. (1983). The reflective practitioner: How professionals reflect in action. New York, NY: Basic Book.

Secondary Teacher Educator 1. (2016). Class syllabus. Portland, OR: Urban Teacher Education Program.

Sleeter, C. (2001). Preparing teachers for culturally diverse schools: Research and the overwhelming presence of whiteness. Journal of Teacher Education, 52(2), 94106.

Sleeter, C. (2008). Equity, democracy and neoliberal assaults on teacher education. Teaching and Teacher Education, 24, 1947-1957.

Sleeter, C. E. (2013). Power, teaching and teacher education. New York, NY: Peter Lang.

Sleeter, C. E. (2017). Critical race theory and the whiteness of teacher education. Urban Education, 52(2), 155-169.

Steele, C. (2009). A threat is in the air: How stereotype threat shapes intellectual identity and performance. In Edward Taylor, David Gillborn \& Gloria Ladson-Billings (Eds.). Foundations of critical race theory in education, (pp.163-189). New York, NY: Routledge.

Stepler, R. (2016, February 26). Hispanic, black parents see college education as key to children's success. Pew Research Center. Retrieved from http://www.pewresearch.org /fact-tank/ 2016/02/24/hispanic-black-parents-seecollege-degree-as-key-for-childrens-success/

Sullivan, A. L. \& A'Vant, E. (2009). On the need for cultural responsiveness. NASP Communiquè, $38(3)$, n. p.

Takaki, R., (1993). A different mirror: A history of multicultural America. New York, NY: East Bay Books/Little, Brown and Company.

Tashikkori, A. \& Teddlie, C. (1998). Mixed methodology: Combining qualitative and quantitative approaches. (pp. 1-111). Thousand Oaks, CA: Sage.

Tashakkori, A. \& Teddlie C. (2003). Sage handbook of mixed methods in social and behavioral research. Thousand Oaks, CA: Sage.

Tashakkori, A. \& Teddlie C. (2010). Sage handbook of mixed methods in social and behavioral research. (2nd ed.). Thousand Oaks, CA: Sage. 
Tate, W. (1997). Critical race theory and education: History, theory and implications. Review of Research in Education, 51, 195-247.

Tatum, B. (2000). The complexity of identity: Who am I? In M. Adams, W. Blumenfeld, R. Castaneda, et al (Eds.), Readings for diversity and social justice: An anthology on racism, sexism, heterosexism, ableism, and classism (pp. 9-14). New York, NY: Routledge.

Taylor, E. (2009). Foundations of critical race theory in education: An introduction. In Edward Taylor, David Gillborn \& Gloria Ladson-Billings (Eds.). Foundations of critical race theory in education, (pp.1-13). New York, NY: Routledge.

Taylor, P. \& Cohn, D. (2012, November 7). Election 2012: A milestone en route to becoming a majority minority nation. Pew Research Center. Retrieved from http://www.pewsocialtrends.org

Taylor, R. W. (2010). The role of teacher education programs in creating culturally competent teachers. Multicultural Education, 17(3), 24-28.

Taylor, S. V. \& Sobel, D. M. (2001) Addressing the discontinuity of students' and teachers' Diversity: A preliminary study of pre-service teachers' beliefs and perceived skills. Teaching and Teacher Education, 17, 487-503.

Tervalon, M \& Murray-Garcia, J. (1998). Cultural humility versus cultural competence: A critical distinction in defining training outcomes in multicultural education. Journal of Health Care, 9(2), 117-125.

Thao, Y. (2011). [Class Lecture]. Issues in education.

Tough, P. (2008). Whatever it takes: Geoffrey Canada's quest to change Harlem. New York, NY: Houghton Mifflin.

Tyack, D. (2004). Seeking common ground: Public schools in a diverse society. Cambridge, MA: Harvard University Press.

Ullucci, K. \& Battey, D. (2011). Exposing color blindness/grounding color consciousness: Challenges for teacher education. Urban Education, 46(6), $1195-$ 1225. doi:10.1177/0042085911413150

United States. National Center for Educational Statistics. (2011). National assessment of educational progress. Washington, DC: Department of Education United States.

United States. Department of Education. (2002). No child left behind act of $200 l$. Washington, DC: Author. 
United States. Department of Education. (2014). Every child succeeds act of 2015. Washington, DC: Author.

Urban Teacher Education Program. (2016). Class syllabi. Portland, OR.

Villegas, A. M. \& Lucas, T. (2002a). Educating culturally responsive teachers: A coherent approach. Albany, NY: State University of New York Press.

Villegas, A. M. \& Lucas, T. (2002b). Preparing culturally responsive teachers: Rethinking the curriculum. Journal of Teacher Education, 53(1), 20-32. doi:10.1177/0022487102053001003

West. C. (2013). Courage. In Maurianne Adams, Warren Blumenfeld, Carmelita Castanenda, Heather W. Hackman, Madeline L. Peters and Ximena Zuniga (Eds.), Readings in diversity and social justice (3rd ed.), (pp. 625-627). New York, NY: Routledge.

West, C. (1993). Race matters. Boston, MA: Beacon Press.

Wise, T. (2007). White like me: Reflections on race from a privileged son. Brooklyn, NY: Soft Skull Press.

Wise, T. (2013, April). [Lecture]. Portland State University, Portland, OR.

Wlodkowski, R. J. \& Ginsberg, M. B. (1995). A framework for culturally responsive teaching. Educational Leadership, 53(1), 17-21.

Yin, R. (2009). Case study research. (4th ed.). Thousand Oaks, CA: Sage.

Young, E. (2010). Challenges to conceptualizing and actualizing culturally relevant pedagogy: How viable is the theory in classroom practice? Journal of Teacher Education, 61(3), 248-260. doi:10.1177/0022487109359775

Zeichner, K. (2009). Teacher education and the struggle for social justice. New York, NY: Routledge, Taylor \& Francis Group.

Zeichner, K. \& Liston, D. (1996). Reflective teaching: An introduction. Mahwah, NJ: Lawrence Erlbaum Associates Incorporated Publishers.

Zeichner, K. \& Gore, J. (1990). Teacher socialization. In W. R. Houston (Ed.), Handbook of research on teacher education, (pp. 275-286). New York, NY: Macmillian.

Zinn, H. (2003). A people's history of the United States. New York, NY: HarperCollins Publishers. 


\section{Appendices}

Appendix A

20 Facts about U.S. Inequality
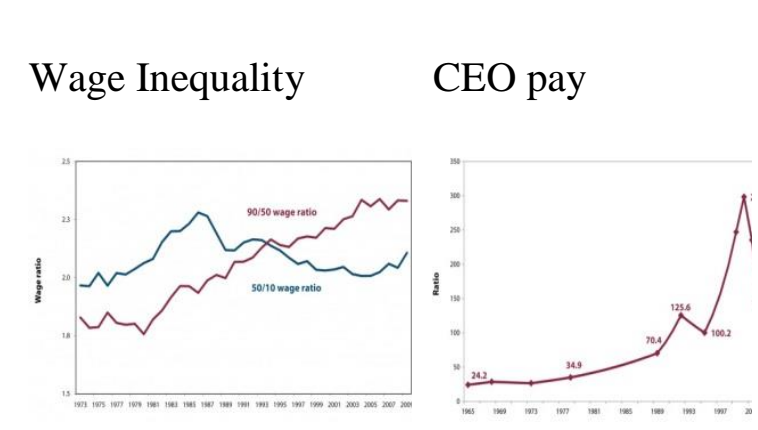

Homelessness

Education Wage

Premium

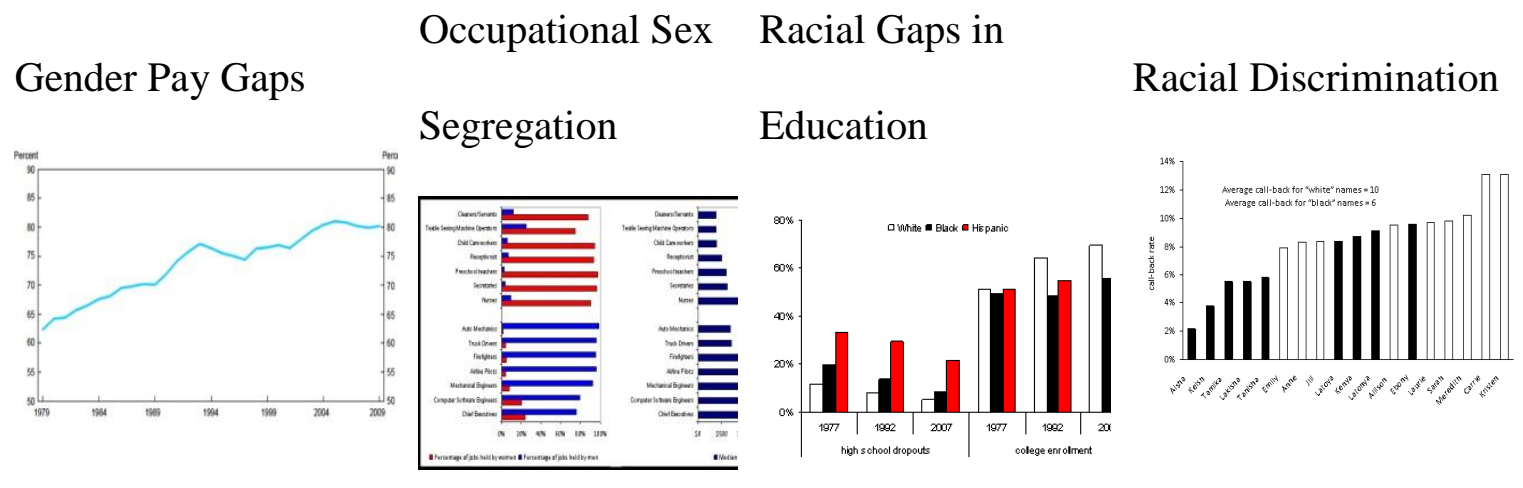

Intragenerational

Child Poverty

Housing

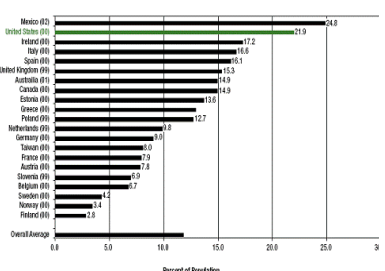

Segregation

Health Insurance Income

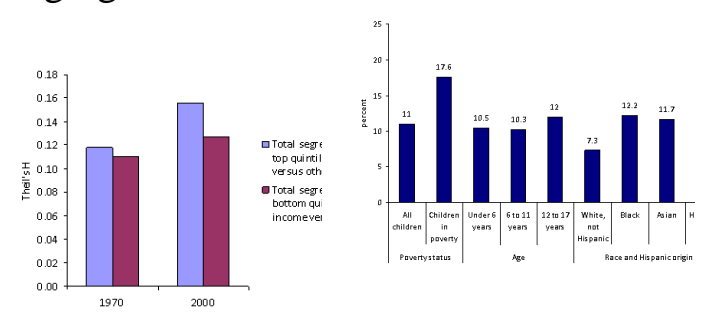

Mobility

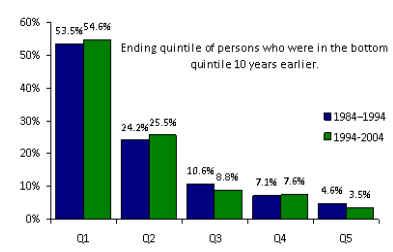


Intergenerational

\section{Discouraged}

Bad Jobs

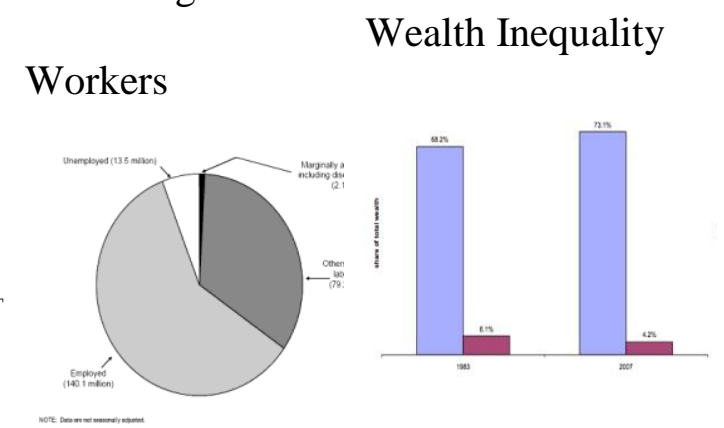

Income

Mobility
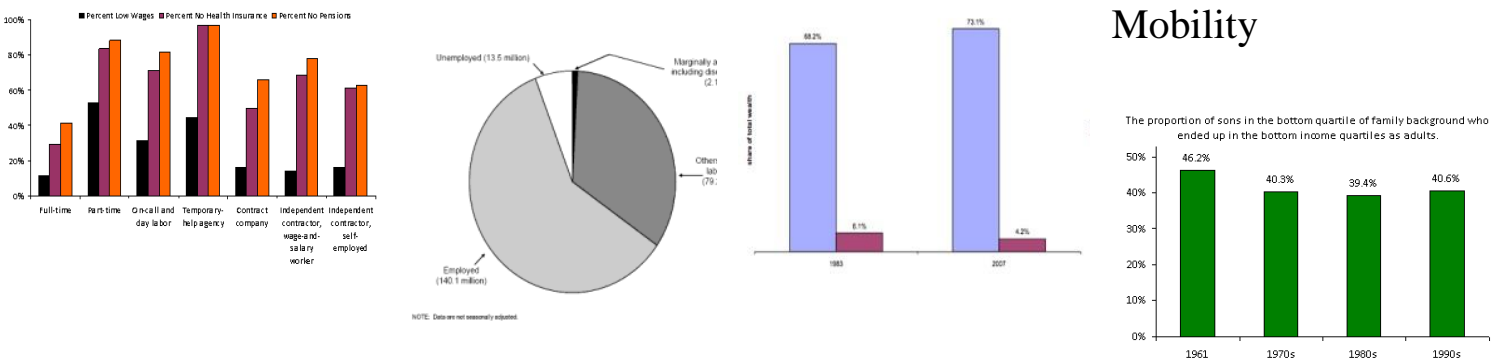

Deregulation of the Job Losses

Labor Market
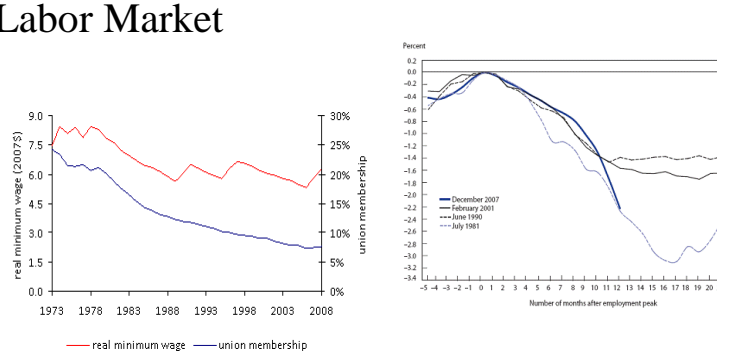

Immigrants and

Productivity and Real

Inequality

Income
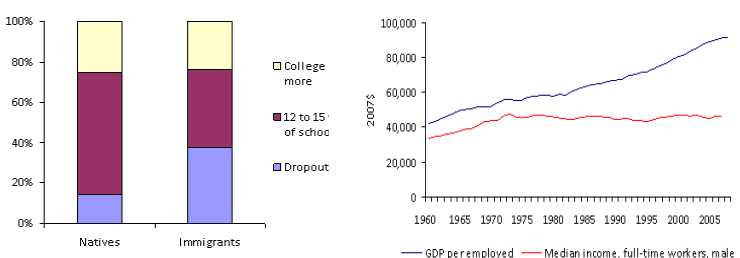

Source: The Stanford Center for the Study of Poverty at http://www.inequality.com 


\section{Appendix B}

\section{Oregon Census Data}

\begin{tabular}{|c|c|c|c|c|c|c|}
\hline \multirow[b]{2}{*}{ Subject } & \multicolumn{2}{|c|}{ Total } & \multicolumn{2}{|c|}{ Below poverty level } & \multicolumn{2}{|c|}{$\begin{array}{c}\text { Percent below } \\
\text { poverty level }\end{array}$} \\
\hline & Estimate & $\begin{array}{l}\text { Margin of } \\
\text { Error }\end{array}$ & Estimate & $\begin{array}{l}\text { Margin of } \\
\text { Error }\end{array}$ & Estimate & $\begin{array}{l}\text { Margin of } \\
\text { Error }\end{array}$ \\
\hline $\begin{array}{l}\text { Population for whom poverty status is } \\
\text { determined }\end{array}$ & 619,556 & $+/-2,659$ & 97,777 & $+/-7,490$ & $15.8 \%$ & $+/-1.2$ \\
\hline \multicolumn{7}{|l|}{ AGE } \\
\hline Under 18 years & 113,777 & $+/-3,085$ & 18,898 & $+/-3,377$ & $16.6 \%$ & $+/-3.0$ \\
\hline Under 5 years & 35,675 & $+/-1,831$ & 5,185 & $+/-1,135$ & $14.5 \%$ & $+/-3.2$ \\
\hline 5 to 17 years & 78,102 & $+/-2,795$ & 13,713 & $+/-2,897$ & $17.6 \%$ & $+/-3.7$ \\
\hline $\begin{array}{l}\text { Related children of householder under } 18 \\
\text { years }\end{array}$ & 112,958 & $+/-3,168$ & 18,079 & $+/-3,335$ & $16.0 \%$ & $+/-3.0$ \\
\hline 18 to 64 years & 432,700 & $+/-3,076$ & 71,689 & $+/-5,033$ & $16.6 \%$ & $+/-1.2$ \\
\hline 18 to 34 years & 171,240 & $+/-2,893$ & 37,524 & $+/-3,285$ & $21.9 \%$ & $+/-1.8$ \\
\hline 35 to 64 years & 261,460 & $+/-3,575$ & 34,165 & $+/-3,518$ & $13.1 \%$ & $+/-1.4$ \\
\hline 60 years and over & 112,438 & $+/-3,567$ & 13,393 & $+/-1,878$ & $11.9 \%$ & $+/-1.6$ \\
\hline 65 years and over & 73,079 & $+/-2,279$ & 7,190 & $+/-1,054$ & $9.8 \%$ & $+/-1.5$ \\
\hline \multicolumn{7}{|l|}{ SEX } \\
\hline Male & 306,524 & $+/-3,425$ & 46,244 & $+/-3,913$ & $15.1 \%$ & $+/-1.3$ \\
\hline Female & 313,032 & $+/-2,838$ & 51,533 & $+/-4,510$ & $16.5 \%$ & $+/-1.4$ \\
\hline \multicolumn{7}{|l|}{$\begin{array}{l}\text { RACE AND HISPANIC OR LATINO } \\
\text { ORIGIN }\end{array}$} \\
\hline White alone & 481,904 & $+/-5,237$ & 63,042 & $+/-5,469$ & $13.1 \%$ & $+/-1.1$ \\
\hline Black or African American alone & 35,540 & $+/-2,899$ & 13,540 & $+/-2,881$ & $38.1 \%$ & $+/-8.2$ \\
\hline American Indian and Alaska Native alone & $\mathrm{N}$ & $\mathrm{N}$ & $\mathrm{N}$ & $\mathrm{N}$ & $\mathrm{N}$ & $\mathrm{N}$ \\
\hline Asian alone & 49,632 & $+/-3,157$ & 10,983 & $+/-2,498$ & $22.1 \%$ & $+/-4.9$ \\
\hline $\begin{array}{l}\text { Native Hawaiian and Other Pacific Islander } \\
\text { alone }\end{array}$ & $\mathrm{N}$ & $\mathrm{N}$ & $\mathrm{N}$ & $\mathrm{N}$ & $\mathrm{N}$ & $\mathrm{N}$ \\
\hline Some other race alone & 11,034 & $+/-2,466$ & 2,263 & $+/-1,091$ & $20.5 \%$ & $+/-9.1$ \\
\hline Two or more races & 33,773 & $+/-4,109$ & 5,869 & $+/-1,657$ & $17.4 \%$ & $+/-4.3$ \\
\hline Hispanic or Latino origin (of any race) & 59,613 & $+/-4,475$ & 12,654 & $+/-3,098$ & $21.2 \%$ & $+/-5.0$ \\
\hline White alone, not Hispanic or Latino & 440,685 & $+/-5,946$ & 54,703 & $+/-4,432$ & $12.4 \%$ & $+/-1.0$ \\
\hline \multicolumn{7}{|l|}{ EDUCATIONAL ATTAINMENT } \\
\hline Population 25 years and over & 458,519 & $+/-3,480$ & 60,690 & $+/-4,483$ & $13.2 \%$ & $+/-1.0$ \\
\hline Less than high school graduate & 39,786 & $+/-3,901$ & 11,381 & $+/-2,339$ & $28.6 \%$ & $+/-5.2$ \\
\hline $\begin{array}{l}\text { High school graduate (includes } \\
\text { equivalency) }\end{array}$ & 68,549 & $+/-4,046$ & 14,518 & $+/-2,187$ & $21.2 \%$ & $+/-2.9$ \\
\hline Some college, associate's degree & 126,025 & $+/-5,172$ & 20,130 & $+/-2,425$ & $16.0 \%$ & $+/-1.8$ \\
\hline Bachelor's degree or higher & 224,159 & $+/-5,774$ & 14,661 & $+/-2,032$ & $6.5 \%$ & $+/-0.9$ \\
\hline EMPLOYMENT STATUS & & & & & & \\
\hline
\end{tabular}




\begin{tabular}{|c|c|c|c|c|c|c|}
\hline \multirow[b]{2}{*}{ Subject } & \multicolumn{2}{|c|}{ Total } & \multicolumn{2}{|c|}{ Below poverty level } & \multicolumn{2}{|c|}{$\begin{array}{c}\text { Percent below } \\
\text { poverty level }\end{array}$} \\
\hline & Estimate & $\begin{array}{l}\text { Margin of } \\
\text { Error }\end{array}$ & Estimate & $\begin{array}{l}\text { Margin of } \\
\text { Error }\end{array}$ & Estimate & $\begin{array}{l}\text { Margin of } \\
\text { Error }\end{array}$ \\
\hline Civilian labor force 16 years and over & 363,399 & $+/-5,531$ & 40,905 & $+/-3,631$ & $11.3 \%$ & $+/-1.0$ \\
\hline Employed & 340,597 & $+/-5,723$ & 30,788 & $+/-3,215$ & $9.0 \%$ & $+/-0.9$ \\
\hline Male & 176,446 & $+/-4,061$ & 13,694 & $+/-2,005$ & $7.8 \%$ & $+/-1.1$ \\
\hline Female & 164,151 & $+/-4,106$ & 17,094 & $+/-1,995$ & $10.4 \%$ & $+/-1.2$ \\
\hline Unemployed & 22,802 & $+/-2,585$ & 10,117 & $+/-1,828$ & $44.4 \%$ & $+/-5.5$ \\
\hline Male & 12,569 & $+/-1,773$ & 5,697 & $+/-1,359$ & $45.3 \%$ & $+/-8.0$ \\
\hline Female & 10,233 & $+/-2,036$ & 4,420 & $+/-1,493$ & $43.2 \%$ & $+/-9.2$ \\
\hline \multicolumn{7}{|l|}{ WORK EXPERIENCE } \\
\hline Population 16 years and over & 516,154 & $+/-3,847$ & 80,548 & $+/-5,313$ & $15.6 \%$ & $+/-1.0$ \\
\hline $\begin{array}{l}\text { Worked full-time, year-round in the past } \\
12 \text { months }\end{array}$ & 223,923 & $+/-5,991$ & 4,878 & $+/-1,112$ & $2.2 \%$ & $+/-0.5$ \\
\hline $\begin{array}{l}\text { Worked part-time or part-year in the past } \\
12 \text { months }\end{array}$ & 151,754 & $+/-5,106$ & 37,044 & $+/-3,260$ & $24.4 \%$ & $+/-2.0$ \\
\hline Did not work & 140,477 & $+/-5,836$ & 38,626 & $+/-3,459$ & $27.5 \%$ & $+/-2.2$ \\
\hline \multicolumn{7}{|l|}{$\begin{array}{l}\text { ALL INDIVIDUALS WITH INCOME } \\
\text { BELOW THE FOLLOWING POVERTY } \\
\text { RATIOS }\end{array}$} \\
\hline 50 percent of poverty level & 48,064 & $+/-4,440$ & $(\mathrm{X})$ & $(\mathrm{X})$ & $(\mathrm{X})$ & $(\mathrm{X})$ \\
\hline 125 percent of poverty level & 129,082 & $+/-8,934$ & $(\mathrm{X})$ & $(\mathrm{X})$ & $(\mathrm{X})$ & $(\mathrm{X})$ \\
\hline 150 percent of poverty level & 152,304 & $+/-8,963$ & $(\mathrm{X})$ & $(\mathrm{X})$ & $(\mathrm{X})$ & $(\mathrm{X})$ \\
\hline 185 percent of poverty level & 189,583 & $+/-9,223$ & $(\mathrm{X})$ & $(\mathrm{X})$ & $(\mathrm{X})$ & $(\mathrm{X})$ \\
\hline 200 percent of poverty level & 203,297 & $+/-9,330$ & $(\mathrm{X})$ & $(\mathrm{X})$ & $(\mathrm{X})$ & $(\mathrm{X})$ \\
\hline 300 percent of poverty level & 298,132 & $+/-8,696$ & $(\mathrm{X})$ & $(\mathrm{X})$ & $(\mathrm{X})$ & $(\mathrm{X})$ \\
\hline 400 percent of poverty level & 374,238 & $+/-9,220$ & $(\mathrm{X})$ & $(\mathrm{X})$ & $(\mathrm{X})$ & $(\mathrm{X})$ \\
\hline 500 percent of poverty level & 435,477 & $+/-8,370$ & $(\mathrm{X})$ & $(\mathrm{X})$ & $(\mathrm{X})$ & $(\mathrm{X})$ \\
\hline $\begin{array}{l}\text { UNRELATED INDIVIDUALS FOR WHOM } \\
\text { POVERTY STATUS IS DETERMINED }\end{array}$ & 212,427 & $+/-7,419$ & 57,005 & $+/-3,838$ & $26.8 \%$ & $+/-1.5$ \\
\hline Male & 108,978 & $+/-5,161$ & 27,749 & $+/-2,498$ & $25.5 \%$ & $+/-1.8$ \\
\hline Female & 103,449 & $+/-4,455$ & 29,256 & $+/-2,532$ & $28.3 \%$ & $+/-2.1$ \\
\hline 15 years & 171 & $+/-200$ & 171 & $+/-200$ & $100.0 \%$ & $+/-50.3$ \\
\hline 16 to 17 years & 648 & $+/-448$ & 648 & $+/-448$ & $100.0 \%$ & $+/-21.7$ \\
\hline 18 to 24 years & 23,473 & $+/-2,590$ & 13,912 & $+/-2,161$ & $59.3 \%$ & $+/-6.0$ \\
\hline 25 to 34 years & 68,625 & $+/-3,863$ & 14,056 & $+/-2,084$ & $20.5 \%$ & $+/-2.7$ \\
\hline 35 to 44 years & 33,595 & $+/-3,177$ & 7,239 & $+/-1,660$ & $21.5 \%$ & $+/-4.7$ \\
\hline 45 to 54 years & 26,648 & $+/-2,577$ & 6,443 & $+/-1,262$ & $24.2 \%$ & $+/-4.3$ \\
\hline 55 to 64 years & 27,456 & $+/-2,491$ & 9,068 & $+/-1,531$ & $33.0 \%$ & $+/-4.6$ \\
\hline 65 to 74 years & 17,815 & $+/-1,608$ & 3,273 & $+/-739$ & $18.4 \%$ & $+/-4.0$ \\
\hline 75 years and over & 13,996 & $+/-1,445$ & 2,195 & $+/-645$ & $15.7 \%$ & $+/-4.3$ \\
\hline $\begin{array}{l}\text { Mean income deficit for unrelated individuals } \\
\text { (dollars) }\end{array}$ & 6,676 & $+/-268$ & $(\mathrm{X})$ & $(\mathrm{X})$ & $(\mathrm{X})$ & $(\mathrm{X})$ \\
\hline $\begin{array}{l}\text { Worked full-time, year-round in the past } 12 \\
\text { months }\end{array}$ & 94,633 & $+/-5,530$ & 2,418 & $+/-702$ & $2.6 \%$ & $+/-0.7$ \\
\hline
\end{tabular}




\begin{tabular}{|c|c|c|c|c|c|c|}
\hline \multirow[b]{2}{*}{ Subject } & \multicolumn{2}{|c|}{ Total } & \multicolumn{2}{|c|}{ Below poverty level } & \multicolumn{2}{|c|}{$\begin{array}{l}\text { Percent below } \\
\text { poverty level }\end{array}$} \\
\hline & Estimate & $\begin{array}{l}\text { Margin of } \\
\text { Error }\end{array}$ & Estimate & $\begin{array}{l}\text { Margin of } \\
\text { Error }\end{array}$ & Estimate & $\begin{array}{l}\text { Margin of } \\
\text { Error }\end{array}$ \\
\hline $\begin{array}{l}\text { Worked less than full-time, year-round in the } \\
\text { past } 12 \text { months }\end{array}$ & 64,129 & $+/-3,929$ & 27,852 & $+/-2,869$ & $43.4 \%$ & $+/-2.9$ \\
\hline Did not work & 53,665 & $+/-3,597$ & 26,735 & $+/-2,679$ & $49.8 \%$ & $+/-3.3$ \\
\hline
\end{tabular}

Source: U.S. Census Bureau, 2015 American Community Survey 1-Year Estimates

Explanation of Symbols:

1. An ${ }^{* * *}$ entry in the margin of error column indicates that either no sample observations or too few sample observations were available to compute a standard error and thus the margin of error. A statistical test is not appropriate.

2. An '-' entry in the estimate column indicates that either no sample observations or too few sample observations were available to compute an estimate, or a ratio of medians cannot be calculated because one or both of the median estimates falls in the lowest interval or upper interval of an open-ended distribution.

3. An '-' following a median estimate means the median falls in the lowest interval of an open-ended distribution.

4. An ' + ' following a median estimate means the median falls in the upper interval of an open-ended distribution.

5. An ${ }^{* * * *}$ entry in the margin of error column indicates that the median falls in the lowest interval or upper interval of an open-ended distribution. A statistical test is not appropriate.

6. An ${ }^{* \star * \star *+}$ entry in the margin of error column indicates that the estimate is controlled. A statistical test for sampling variability is not appropriate.

7. An ' $\mathrm{N}$ ' entry in the estimate and margin of error columns indicates that data for this geographic area cannot be displayed because the number of sample cases is too small.

8. An ' $(X)$ ' means that the estimate is not applicable or not available. 


\section{Appendix C}

Learning to Teach for Social Justice-Beliefs scales and Secondary Teacher Candidates' Final Comments

Learning to Teach for Social Justice-Beliefs scale (Pre-Survey)

Adapted from: Ludlow, Enterline \& Cochran-Smith (2008) Learning to Teach for Social Justice-Beliefs scale.

Please rate the following statements and write your response to the question associated with each belief statement.

\begin{tabular}{|c|c|c|c|c|}
\hline 1 & 2 & 3 & 4 & 5 \\
\hline $\begin{array}{l}\text { I Strongly } \\
\text { Disagree }\end{array}$ & I Disagree & Uncertain & I Agree & $\begin{array}{l}\text { I Strongly } \\
\text { Agree }\end{array}$ \\
\hline
\end{tabular}

1a. In what ways has your teacher education program influence your beliefs about learning to be a teacher? Please explain.

\begin{tabular}{|c|c|c|c|c|}
\hline 1 & 2 & 3 & 4 & 5 \\
\hline $\begin{array}{l}\text { I Strongly } \\
\text { Disagree }\end{array}$ & I Disagree & Uncertain & I Agree & $\begin{array}{l}\text { I Strongly } \\
\text { Agree }\end{array}$ \\
\hline
\end{tabular}

2a. In what ways has your teacher education program prepared you to address these issues in the classroom? Please explain.

3) For the most part, covering multicultural topics is only relevant to certain subject areas, such as social studies and literature.

\begin{tabular}{|l|l|l|l|l|}
\hline 1 & 2 & 3 & 4 & 5 \\
\hline $\begin{array}{l}\text { I Strongly } \\
\text { Disagree }\end{array}$ & I Disagree & Uncertain & I Agree & $\begin{array}{l}\text { I Strongly } \\
\text { Agree }\end{array}$ \\
\hline
\end{tabular}

3a. In what ways has your teacher education program influenced your thoughts about how multicultural topics can be used in other subject areas? Please explain. 
4) Good teaching incorporates diverse cultures and experiences into classroom lessons and discussions.

\begin{tabular}{|l|l|l|l|l|}
\hline 1 & 2 & 3 & 4 & 5 \\
\hline $\begin{array}{l}\text { I Strongly } \\
\text { Disagree }\end{array}$ & I Disagree & Uncertain & I Agree & $\begin{array}{l}\text { I Strongly } \\
\text { Agree }\end{array}$ \\
\hline
\end{tabular}

4a. In what ways has your teacher education program influenced your thoughts about incorporating diverse cultures and experiences in your teaching? Please explain.

5) The most important goal in working with immigrant children and English language learners is that they assimilate into American society.

\begin{tabular}{|l|l|l|l|l|}
\hline 1 & 2 & 3 & 4 & 5 \\
\hline $\begin{array}{l}\text { I Strongly } \\
\text { Disagree }\end{array}$ & I Disagree & Uncertain & I Agree & $\begin{array}{l}\text { I Strongly } \\
\text { Agree }\end{array}$ \\
\hline
\end{tabular}

5a. In what ways has your teacher education program influenced your approach to working with culturally and linguistically diverse learners? Please explain.

6) It's reasonable for teachers to have lower classroom expectations for students who don't speak English as their first language.

\begin{tabular}{|l|l|l|l|l|}
\hline 1 & 2 & 3 & 4 & 5 \\
\hline $\begin{array}{l}\text { I Strongly } \\
\text { Disagree }\end{array}$ & I Disagree & Uncertain & I Agree & $\begin{array}{l}\text { I Strongly } \\
\text { Agree }\end{array}$ \\
\hline
\end{tabular}

6a. In what ways has your teacher education program influenced your approach to working with students who are English language learners and determining what these learners are capable of? Please explain.

7) Part of the responsibilities of the teacher is to challenge school arrangements that maintain societal inequities.

\begin{tabular}{|l|l|l|l|l|}
\hline 1 & 2 & 3 & 4 & 5 \\
\hline $\begin{array}{l}\text { I Strongly } \\
\text { Disagree }\end{array}$ & I Disagree & Uncertain & I Agree & $\begin{array}{l}\text { I Strongly } \\
\text { Agree }\end{array}$ \\
\hline
\end{tabular}

7a. In what ways has your teacher education program influenced your thoughts about inequities that exist in schools? Please explain.

8) Teachers should teach students to think critically about government positions and actions.

\begin{tabular}{|l|l|l|l|l|}
\hline 1 & 2 & 3 & 4 & 5 \\
\hline $\begin{array}{l}\text { I Strongly } \\
\text { Disagree }\end{array}$ & I Disagree & Uncertain & I Agree & $\begin{array}{l}\text { I Strongly } \\
\text { Agree }\end{array}$ \\
\hline
\end{tabular}

8a. In what ways has your teacher education program influenced your beliefs about the government's role in education? Please explain. 
9) Economically disadvantaged students have more to gain in schools because they bring less into the classroom.

\begin{tabular}{|l|l|l|l|l|}
\hline 1 & 2 & 3 & 4 & 5 \\
\hline $\begin{array}{l}\text { I Strongly } \\
\text { Disagree }\end{array}$ & I Disagree & Uncertain & I Agree & $\begin{array}{l}\text { I Strongly } \\
\text { Agree }\end{array}$ \\
\hline
\end{tabular}

9a. In what ways has your teacher education program influenced your approach to working with economically disadvantaged students? Please explain.

\begin{tabular}{|c|c|c|c|c|}
\hline 1 & 2 & 3 & 4 & 5 \\
\hline $\begin{array}{l}\text { I Strongly } \\
\text { Disagree }\end{array}$ & I Disagree & Uncertain & I Agree & $\begin{array}{l}\text { I Strongly } \\
\text { Agree }\end{array}$ \\
\hline
\end{tabular}

10a. In what ways has your teacher education program influenced your thoughts about the teacher's role in changing society? Please explain.

\begin{tabular}{|c|c|c|c|c|}
\hline 1 & 2 & 3 & 4 & 5 \\
\hline $\begin{array}{l}\text { I Strongly } \\
\text { Disagree }\end{array}$ & I Disagree & Uncertain & I Agree & $\begin{array}{l}\text { I Strongly } \\
\text { Agree }\end{array}$ \\
\hline
\end{tabular}

11a. In what ways has your teacher education program influenced your beliefs about the relationship between success and working hard? Please explain.

12) Realistically, the job of a teacher is to prepare students for the lives they are likely to lead.

\begin{tabular}{|l|l|l|l|l|}
\hline 1 & 2 & 3 & 4 & 5 \\
\hline $\begin{array}{l}\text { I Strongly } \\
\text { Disagree }\end{array}$ & I Disagree & Uncertain & I Agree & $\begin{array}{l}\text { I Strongly } \\
\text { Agree }\end{array}$ \\
\hline
\end{tabular}

12a. In what ways has your teacher education program influenced your thoughts about what your job as a teacher is? Please explains. 
Learning to Teach for Social Justice-Beliefs scale (Post-Survey)

Adapted from: Ludlow, Enterline \& Cochran-Smith (2008) Learning to Teach for Social Justice-Beliefs scale.

Please rate the following statements and write your response to the question associated with each belief statement.

\begin{tabular}{|c|c|c|c|c|}
\hline 1 & 2 & 3 & 4 & 5 \\
\hline $\begin{array}{l}\text { I Strongly } \\
\text { Disagree }\end{array}$ & I Disagree & Uncertain & I Agree & $\begin{array}{l}\text { I Strongly } \\
\text { Agree }\end{array}$ \\
\hline
\end{tabular}

1a. In what ways did your teacher education program influence your beliefs about learning to be a teacher?

2) Issues related to racism and inequity should be openly discussed in the classroom.

\begin{tabular}{|l|l|l|l|l|}
\hline 1 & 2 & 3 & 4 & 5 \\
\hline $\begin{array}{l}\text { I Strongly } \\
\text { Disagree }\end{array}$ & I Disagree & Uncertain & I Agree & $\begin{array}{l}\text { I Strongly } \\
\text { Agree }\end{array}$ \\
\hline
\end{tabular}

2a. How did your teacher education program prepare you to address these issues in the classroom? Please explain and provide examples.

3) For the most part, covering multicultural topics is only relevant to certain subject areas, such as social studies and literature.

\begin{tabular}{|l|l|l|l|l|}
\hline 1 & 2 & 3 & 4 & 5 \\
\hline $\begin{array}{l}\text { I Strongly } \\
\text { Disagree }\end{array}$ & I Disagree & Uncertain & I Agree & $\begin{array}{l}\text { I Strongly } \\
\text { Agree }\end{array}$ \\
\hline
\end{tabular}

3a. How did your teacher education program influence your beliefs and prepare you to incorporate multicultural topics in other subject areas? Please explain and provide examples.

4) Good teaching incorporates diverse cultures and experiences into classroom lessons and discussions.

\begin{tabular}{|l|l|l|l|l|}
\hline 1 & 2 & 3 & 4 & 5 \\
\hline $\begin{array}{l}\text { I Strongly } \\
\text { Disagree }\end{array}$ & I Disagree & Uncertain & I Agree & $\begin{array}{l}\text { I Strongly } \\
\text { Agree }\end{array}$ \\
\hline
\end{tabular}

4a. What did your teacher education program do to prepare you to incorporate diverse cultures and experiences in your teaching? Please explain and provide examples. 
5) The most important goal in working with immigrant children and English language learners is that they assimilate into American society.

\begin{tabular}{|l|l|l|l|l|}
\hline 1 & 2 & 3 & 4 & 5 \\
\hline $\begin{array}{l}\text { I Strongly } \\
\text { Disagree }\end{array}$ & I Disagree & Uncertain & I Agree & $\begin{array}{l}\text { I Strongly } \\
\text { Agree }\end{array}$ \\
\hline
\end{tabular}

5a. What did you learn from your teacher education program about how to approach working with culturally and linguistically diverse learners? Please explain and provide examples.

6) It's reasonable for teachers to have lower classroom expectations for students who don't speak English as their first language.

\begin{tabular}{|l|l|l|l|l|}
\hline 1 & 2 & 3 & 4 & 5 \\
\hline $\begin{array}{l}\text { I Strongly } \\
\text { Disagree }\end{array}$ & I Disagree & Uncertain & I Agree & $\begin{array}{l}\text { I Strongly } \\
\text { Agree }\end{array}$ \\
\hline
\end{tabular}

6a. In what ways did your teacher education program educate and prepare you to work with students who are English language learners and use what these learners know to determine what they are capable of? Please explain and provide examples.

7) Part of the responsibilities of the teacher is to challenge school arrangements that maintain societal inequities.

\begin{tabular}{|l|l|l|l|l|}
\hline 1 & 2 & 3 & 4 & 5 \\
\hline $\begin{array}{l}\text { I Strongly } \\
\text { Disagree }\end{array}$ & I Disagree & Uncertain & I Agree & $\begin{array}{l}\text { I Strongly } \\
\text { Agree }\end{array}$ \\
\hline
\end{tabular}

7a. What strategies did learn in your teacher education program that prepared you to address inequities that exist in schools? Please explain and provide examples.

\begin{tabular}{|c|c|c|c|c|}
\hline 1 & 2 & 3 & 4 & 5 \\
\hline $\begin{array}{l}\text { I Strongly } \\
\text { Disagree }\end{array}$ & I Disagree & Uncertain & I Agree & $\begin{array}{l}\text { I Strongly } \\
\text { Agree }\end{array}$ \\
\hline
\end{tabular}

8a. How did your teacher education program prepare you to act and influence the government's role in education? Please explain and provide examples.

9) Economically disadvantaged students have more to gain in schools because they bring less into the classroom.

\begin{tabular}{|l|l|l|l|l|}
\hline 1 & 2 & 3 & 4 & 5 \\
\hline $\begin{array}{l}\text { I Strongly } \\
\text { Disagree }\end{array}$ & I Disagree & Uncertain & I Agree & $\begin{array}{l}\text { I Strongly } \\
\text { Agree }\end{array}$ \\
\hline
\end{tabular}

9a. How did your teacher education program prepare you to combat deficit thinking with regard to working with economically disadvantaged students? Please explain and provide examples. 
10) Although teachers have to appreciate diversity, it's not their job to change society.

\begin{tabular}{|l|l|l|l|l|}
\hline 1 & 2 & 3 & 4 & 5 \\
\hline $\begin{array}{l}\text { I Strongly } \\
\text { Disagree }\end{array}$ & I Disagree & Uncertain & I Agree & $\begin{array}{l}\text { I Strongly } \\
\text { Agree }\end{array}$ \\
\hline
\end{tabular}

10a. How did your teacher education program influence your beliefs about your role as a teacher and your attitude about your role in changing society? Please explain and provide examples.

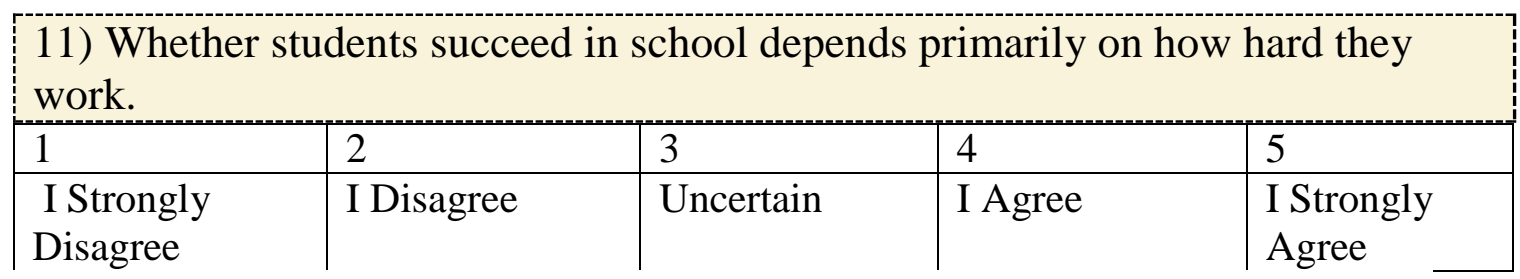

11a. What practices/strategies did your teacher education program impart that inform your beliefs about the relationship between success and working hard? Please explain and provide examples.

12) Realistically, the job of a teacher is to prepare students for the lives they are likely to lead.

\begin{tabular}{|l|l|l|l|l|}
\hline 1 & 2 & 3 & 4 & 5 \\
\hline $\begin{array}{l}\text { I Strongly } \\
\text { Disagree }\end{array}$ & I Disagree & Uncertain & I Agree & $\begin{array}{l}\text { I Strongly } \\
\text { Agree }\end{array}$ \\
\hline
\end{tabular}

12a. How did your teacher education program prepare you to counter status quo thinking as it relates to what your job is as a teacher? Please explain and provide examples. 


\section{Secondary Teacher Candidates' Final Thoughts}

Please feel free to share any final thoughts you have about your teacher education experience and your readiness to work with diverse learners. 
Appendix D

Letter to Portland Metro-Area Deans of Education

\section{To Whom It May Concern:}

Please let me introduce myself. My name is Rosalyn Taylor, and I am doctoral student at Portland State University (PSU) in the Educational Leadership Program with a Specialization in Curriculum and Instruction. The Chair of my dissertation committee is Dr. Esperanza De La Vega. I write to you to request a meeting to speak with you about my proposed research study titled, The Role of Culturally Responsive Pedagogy in Urban Teacher Education Programs.

I recently received approval from the Human Subjects Research Review Committee (HSRRC) to conduct my study which investigates the use of culturally responsive pedagogy in urban teacher education programs that prepare secondary teacher candidates. My proposal was approved on December 23, 2014 and can be referenced using HSRRC Proposal \# 143251.

Your program's reputation and commitment to educational equity and social justice distinguishes it as an ideal site to conduct my research study. It would be an honor to meet with you to discuss the possibility of conducting my study at your site with the hopes of collaborating with you to improve the educational outcomes of urban secondary learners in the Pacific Northwest.

I am available to speak with you by phone or in person at your earliest convenience. I can be reached by phone at 503.522 .7603 (cell) or by email at taylorr778@ gmail.com.

Additionally, below is where I can be reached at PSU along with contact information for my faculty advisor and the PSU Institutional Review Board should you need them.

Thank you in advance for considering my request. I look forward to hearing from you soon.

Sincerely,

Rosalyn Taylor, MEd

Portland State University

503.725 .3817

taylorr@pdx.edu 
Faculty Advisor, Dr. Esperanza De La Vega

Portland State University

503.725.9902

delavega@pdx.edu

PSU Institutional Review Board

Office of Research Integrity

1600 SW 4th Ave., Market Center Building, Ste. 620

Portland, OR 97201

(503) 725-2227 or 1 (877) 480-4400 


\section{Appendix E}

\section{Email to Recruit Secondary Teacher Educators}

Good morning UTEP Faculty,

I hope this email message finds you doing well. My name is Rosalyn Taylor, and I'm a doctoral student at Portland State University (PSU) with a specialization in Curriculum and Instruction; my dissertation chair is Dr. Esperanza De La Vega. Recently, I received permission from the Graduate School of Education at Urban Teacher's University (pseudonym) to conduct my research study within the Urban Teacher Education Program (UTEP).

The purpose of this study is to investigate how an urban teacher education program (UTEP) with an educational equity and social justice mission prepares its secondary teacher candidates to work successfully with culturally diverse learners and to determine to what extent, if any, culturally responsive pedagogy plays a role.

I would like to meet with you to discuss your participation in this important study. This case study involves 2 interviews (60-90 minutes) with secondary teacher educators. If you agree to participate, these interviews will be scheduled 3-4 weeks apart at a time that works best for you. I am happy to email you additional information if needed.

Thank you in advance for considering my request. I look forward to hearing from you soon.

Stay well,

Rosalyn Taylor 
Appendix F

Script for Classroom Visits

Good morning/Good afternoon,

Thank you very much for allowing to visit your class today. My name is Rosalyn Taylor, and I am a doctoral student at Portland State University with a Specialization in Curriculum and Instruction.

I recently received permission to conduct my research at your institution. My research investigates how an urban teacher education program - like yours-with an educational equity and social justice mission prepares its secondary teacher candidates to work successfully with culturally diverse learners and to determine if culturally responsive pedagogy plays a role.

I have come to you today to invite you to participate in my study. Participation will involve completing pre-and-post administration of The Learning to Teach for Social Justice-Beliefs scale and open-ended responses to 12 Likert scale items.

If you decide to participate you will receive and $\$ 10.00$ gift card for completing each administration of the survey. Your participation is voluntary, and you can withdraw from the study at any time.

If you are interested, I'd like you to provide me with your name and email address so that I may send you the Letter of Informed Consent. This letter explains the purpose of the research as well provisions for protecting participant privacy and the benefits of your participation.

Upon receiving your signed Letter of Informed Consent electronically, you will receive an email with a link to the survey. At which time you will have 4 weeks to complete the first administration.

Are there any question?

Please take a moment to consider my request and if interested, please provide me with your email so that I can send you a Letter of Informed Consent and the link to The Learning to Teach for Social Justice-Beliefs scale.

Thank you very much for your time and good luck with your programs of study. 
Appendix G

Informed Consent Forms for Secondary Teacher Candidates and Secondary Teacher
Educators
Informed Consent Form for Secondary Teacher Candidates

Title of research: The Role of Culturally Responsive Pedagogy in Teacher Education and Preparation Programs: Dissertation

Principal Investigators: Dr. Esperanza De La Vega and Rosalyn Taylor, M. Ed. Before agreeing to participate in this research study, it is important that you read the following explanation of the study. This statement describes the purpose, procedures, benefits, risks, discomforts, and precautions of the program. Also described are the alternative procedures available to you, as well as your right to withdraw from the study at any time. No guarantees or assurances can be made as to the results of the study.

Explanation of Procedures: This study is designed to examine the role of teacher education and preparation programs in improving achievement for diverse learners. Dr. De La Vega and Rosalyn Taylor, a graduate student in the Graduate School of Education at Portland State University, are conducting this study to understand more about teacher education programming and its relationship to achievement. Participation in the study requires responses to two surveys administered before and after the student teaching or field experience. The data collected from the surveys will be analyzed and correlated with data collected from interviews with administrators and faculty that speak to the program's missions, curriculum goals, instructional practices, and extra-curricular activities. The surveys will be administered online so that you can complete them at your leisure but also in a timely manner.

Risks and Discomforts: There are minimal risks and few discomforts that are anticipated from your participation in this research study. Potential risks may include inconvenience of time, sensitivity/discomfort with questions related to social justice and educational equity. You may decline to answer any uncomfortable questions at any. For your time, you will receive a gift card for your time.

Benefits: The possible benefits from participation in this research study will be the opportunity to share your thoughts, ideas, concerns, and experiences related to your experience as a secondary teacher candidate whose role is to learn, apply, manage a classroom, plan lessons, make decisions about curriculum, assessment and instruction that impact your professional development and educational experience and that of your students.

Alternative Treatment: Because this study does not involve specific treatment or procedures, there are no known alternative treatments to participating in this study. 
Confidentiality: The information gathered during this study will remain confidential in locked drawer. Only the researchers will have access to the study data and information. There will not be any identifying names on the surveys, and participants' names will not be made available to anyone other than the investigator. The surveys will remain in the possession of the researcher for three years after the completion of the study. The results of the study will be published in a dissertation.

Your signature indicates that you have read the above information and agree to take part in this research study. Please understand that you may withdraw from the research study at any time, and that, by signing, you are waiving your legal claims, rights, or remedies. The researchers will provide you a copy of this form for your own records.

Signature

Date

Please note: Should you have questions regarding being a research participant please contact:

Faculty Advisor: Dr. Esperanza De La Vega, delavega@pdx.edu 503-725-9902

and/or Rosalyn Taylor, Researcher

taylorr@pdx.edu, or

PSU Institutional Review Board

Office of Research Integrity

1600 SW 4th Ave., Market Center Building, Ste. 620

Portland, OR 97201

(503) 725-2227 or 1 (877) 480-4400 


\section{Informed Consent Form for Secondary Teacher Educators}

Title of research: The Role of Culturally Responsive Pedagogy in Teacher Education Programs: Dissertation

Principal Investigators: Dr. Esperanza De La Vega and Rosalyn Taylor, M. Ed. Before agreeing to participate in this research study, it is important that you read the following explanation of the study. This explanation describes the purpose, procedures, benefits, risks, discomforts, and precautions of the program. Also described are the alternative procedures available to you, as well as your right to withdraw from the study at any time. No guarantees or assurances can be made as to the results of the study.

Explanation of Procedures: This study is designed to examine the role of urban teacher education programs in improving achievement for diverse learners. Rosalyn Taylor, a graduate student in the Graduate School of Education at Portland State University, is conducting this study to understand more about how an urban teacher education program prepares secondary teacher candidates how to work with diverse learners. Participation in the study requires two 60-90 minute interviews and a member check meeting/conversation of about 60 minutes to ensure transcription accuracy. The interview will be audio-taped and transcribed by the researchers. The interviews will be conducted in a mutually agreed upon location.

Risks and Discomforts: There are minimal risks and few discomforts that are anticipated from your participation in this research study. Potential risks may include inconvenience of time, sensitivity/discomfort with questions related to social justice and educational equity. You may decline to answer any uncomfortable questions at any. For your time, you will receive a gift card for each interview and member check in which you participate.

Benefits: The possible benefits from participation in this research study will be the opportunity to share your thoughts, ideas, concerns, and experiences related to your work as an administrator or faculty member whose role is to manage personnel, make decisions about policies and curriculum, and implement rules and regulations governing the education and preparation of secondary teacher candidates.

Alternative Treatment: Because this study does not involve specific treatment or procedures, there are no known alternative treatments to participating in this study.

Confidentiality: The information gathered during this study will remain confidential and kept in a locked drawer. Only the researchers will have access to the study data and information. There will not be any identifying names on the tapes, and participants' names will not be made available to anyone other than the investigator. The tapes will remain in the possession of the researcher for three years after the completion of the study. The results of the study will be published in a dissertation. 
Your signature indicates that you have read the above information and agree to take part in this research study. Please understand that you may withdraw from the research study at any time, and that, by signing, you are waiving your legal claims, rights, or remedies. The researchers will provide you a copy of this form for your own records.

Signature

Date

Please note: Should you have questions regarding being a research participant please contact:

Faculty Advisor: Dr. Esperanza De La Vega,

delavega@pdx.edu 503-725-9902

and/or

PSU Institutional Review Board

Office of Research Integrity

1600 SW 4th Ave., Market Center Building, Ste. 620

Portland, OR 97201

(503) 725-2227 or 1 (877) 480-4400 


\section{Appendix $\mathrm{H}$}

Demographic Information from Secondary Teacher Educators

Demographic information:

- Name

- Gender

- Ethnicity

- Educational degrees

- Granting institution

- Years of service with their institution

- Capacities served at the institution 


\section{Appendix I}

Demographic Information from Secondary Teacher Candidates Collected Electronically Demographic Information:

- Name

- Gender

- Age Range

- Ethnicity

- Educational degrees

- Granting institution

- Years of teaching experience

- At what level is your teaching experience

- In what capacities have you served at these educational agencies

- Family of origin's socio-economic status

- Area of focus in teacher education program

- Upon graduation where do you hope to teach rural suburban or urban school district 
Appendix $\mathbf{J}$

Semi-structured Interview Questions for Secondary Teacher Educators

Interview 1

1. What makes your teacher education program an exemplary one in terms of its preparation of teacher candidates to work well with our ever-growing population of diverse learners?

2. As a secondary level administrator, what are your duties and responsibilities?

3. How would you characterize your teacher education program's philosophical stance or orientation?

4. In what ways do you feel your TEP meets NCATE/CAEP's mission to prepare teacher candidates to work successfully with diverse learners?

5. What do the terms educational equity and social justice mean to you? How do you see the program's mission of educational equity and social justice being operationalized?

6. In what ways do you feel your teacher education program can do more to improve the educational experience teacher candidates receive at your institution? 


\section{Appendix K}

\section{Semi-structured Interview Questions for Secondary Teacher Educators}

Interview 2

1. What specifics are involved in helping students understand what it means to work with diverse learners?

2. What specifics are involved in helping students understand how their diversity impacts how they teach?

3. How do you use s reflective assignment to aid students in being able to craft lesson plans that take into account diversity in their classroom?

4. How does reflection correlate into strategies or techniques for learning in the classroom?

5. What classes do you teach?

6. Is there something you think your program could be doing more of to shore up its work on instructional engagement?

7. How is the UTEP evaluated? 
Appendix L

Thank you Note to Participants

Dear Participant,

I hope this card finds you well. Thank you very much for your participation in my research study. Your voice adds to our understanding of your experience and efforts to become an educator.

Enclosed is a small token of my appreciation. Thank you again for your help and good luck with your studies.

Sincerely, Rosalyn 